\title{
Notas taxonômicas em Hesperiidae neotropicais, com descrições de novos taxa (Lepidoptera) ${ }^{1}$
}

\author{
Olaf H.H. Mielke ${ }^{2}$ \\ Mirna M. Casagrande ${ }^{2}$
}

\begin{abstract}
Taxonomic notes on neotropical Hesperiidae (Lepidoptera), with descriptions of new taxa. The following species is excluded from the neotropical fauna: Hesperia yva Plötz, 1886, mentioned by Evans (1955) as Mucia yva, is an Asian species, probably a synonym of Suastus gremius (Fabricius, 1798).

The following species are transferred to the neotropical region: Aurina dida Evans, 1939, described from Sierra Leoa, Africa, and Hesperia subviridis Plötz, 1886, a species of Penicula Evans, 1955, described from São Paulo, Brazil, was erroneously transferred by Evans (1957) to Ceylon (= Sri Lanka).

The types species of two genera are changed: Hydraenomia aberrans Draudt, 1924 is the new type of Clito Evans, 1953, and Cantha calva Evans, 1955 is the new type of Cantha Evans, 1955 (ICZN, Art. 70.3.2.). Papilio clito Fabricius, 1787, designated by Evans (1953) as the type species of Clito, is a species of Milanion Godman \& Salvin, 1895. Cyclopides celeus Mabille, 1891, designated by Evans (1955) as the type species of Cantha, is a species of Vehilius Scudder, 1872.

The following taxa are nom. nov.: Enosis schausi for Hesperia misera Schaus, 1902, praeocc. (Lucas, 1856); Jongiana for Surina de Jong, 1983, praeocc. (Walker, 1869 [Lepidoptera]).

The following taxa is a nom. nud.: Polygonus mimeticus J. Zikán \& W. Zikán, 1968. The following taxa are sp. rev.: Aethilla haber (Mabille, 1891); Clito aberrans (Draudt, 1924); Mylon maimon (Fabricius, 1775); Atalopedes flaveola (Mabille, 1891); Carystoides alda (Plötz, 1882); Chalcone briquenydan briquenydan (Weeks, 1901); Cobalopsis hazarma (Hewitson, 1877); Corticea rivula (Mabille, 1891); Enosis uza uza (Hewitson, 1877); Eutocus vetulus vetulus (Mabille, 1883); Eutychide rastaca (Schaus, 1902); Lerodea petrovna (Schaus, 1902); Paratrytrone gala (Godman, 1900); Poanes zachaeus (Plötz, 1883); Saturnus reticulata reticulata (Plötz, 1883); Virga silvanus (Hayward, 1947).

The following taxa is a ssp. rev.: Polygonus leo pallida Röber, 1925.

The following taxa are stat. rev.: Chioides cinereus (Mabille \& Vuillot, 1891); Potamanaxas paralus (Godman \& Salvin, 1895).

The following taxa are stat. nov.: Sarbia soza Evans, 1951; Polygonus savigny savigny (Latreille, [1824]); Anastrus chaqua Evans, 1953; Chalcone briquenydan chalcone (Schaus, 1902); Cynea anthracinus holomelas (Mabille, 1891); Moeris striga menopis (Schaus, 1902); Monca telata crsipinus (Plötz, 1882).

The following taxa are spp. nov.: Sarbia curitiba from Brazil (Minas Gerais, São Paulo, Paraná, Santa Catarina, Rio Grande do Sul); Pythonides nides from Brazil (Espírito Santo); Carystus ploetzi from Brazil (Pará, Amazonas) and Peru (Huánuco, Loreto).

The following is a ssp. nov.: Zenis jebus beckeri from Brazil (Bahia, Distrito Federal,
\end{abstract}

1) Contribuição número 1187 do Departamento de Zoologia, Universidade Federal do Paraná.

2) Departamento de Zoologia, Universidade Federal do Paraná. Caixa Postal 19020, 81531-980 Curitiba, Paraná, Brasil. E-mail: omhesp@bio.ufpr.br; mibras@bio.ufpr.br 
Espírito Santo, Goiás, Maranhão, Mato Grosso, Rondônia, São Paulo).

The following taxa are syn. nov.: Aspitha teffa Evans, 1951 of Aspitha aspitha aspitha (Hewitson, 1866); Thymele grullus Mabille, 1888 of Astraptes latimargo latimargo (Herrich-Schäffer, 1869); Erycides imbreus Plötz, 1879, and Erycides spurius Mabille, 1880 of Phocides polybius lilea (Reakirt, 1867); Polygonus leo ishmael Evans, 1952 of Polygonus leo leo (Gmelin, 1790); Polygonus manueli manueli Bell \& W. Ph. Comstock, 1948 of Polygonus savigny savigny (Latreille, [1824]); Goniuris [sic] decussata Ménétriés, 1855 of Polythrix octomaculata (Sepp, [1844]); Milanion plumnus var. hemestinus Mabille \& Boullet, 1917 of Milanion leucaspis (Mabille, 1878); Papilio menippus Fabricius, 1776 of Mylon maimon (Fabricius, 1775); Tagiades chacona Plötz, 1886 of Ouleus fridericus fridericus (Geyer, 1832); Ouleus matria matria Evans, 1953 of Ouleus juxta juxta (Bell, 1934); Pythonides vecina Mabille \& Boullet, 1917 of Pythonides herennius herennius Geyer, [1838]; Quadrus zolus Mielke, 1968 of Quadrus jacobus (Plötz, 1884); Cobalus nigritulus Mabille, 1883 of Anthoptus epictetus (Fabricius, 1793); Pamphila cerymicoides Burmeister, 1878, and Carystus argus Möschler, 1879 of Argon lota (Hewitson, 1877); Tigasis akuris Bell, 1942 of Arita arita (Schaus, 1902); Lerodea remea Bell, 1941 of Arita polistion (Schaus, 1902); Mnasitheus similis de Jong, 1983 of Arotis pandora (Lindsey, 1925); Atalopedes clarkei Burns, 1989 of Atalopedes flaveola (Mabille, 1891); Hesperia beda Plötz, 1886 of Callimormus rivera (Plötz, 1882); Chalcone chalcone corta Evans, 1955 of Chalcone briquenydan briquenydan (Weeks, 1901); Augiades anita Schaus, 1902 of Chalcone tania (Schaus, 1902); Cobalus zetus Bell, 1942 of Cobalopsis nero (Herrich-Schäffer, 1869); Megistias sancoya Schaus, 1902 of Cobalopsis hazarma

(Hewitson, 1877); Megistias vegrandis Hayward, 1934 of Cobalopsis miaba (Schaus, 1902); Ancyloxypha melanoneura orientalis Hayward, 1967 of Copaeodes jean favor Evans, 1955; Lento muska Evans, 1955 of Corticea mendica schwarzi (Bell, 1941); Megistias vanilia Schaus, 1902 of Cymaenes perloides (Plötz, 1882); Eutychide astiga Schaus, 1902 of Cymaenes tripunctata tripunctata (Latreille, [1824]); Rhinthon luctatius Schaus, 1913 of Cynea anthracinus holomelas (Mabille, 1891); Rhinthon bomax Schaus, 1902 of Cynea bistrigula (Herrich-Schäffer, 1869); Cynea conta Mielke, 1968 of Cynea robba nippa Evans, 1955; Pamphila agassus Mabille, 1891 of Enosis uza uza (Hewitson, 1877); Amblyscirtes insulae-pinorum [sic] Holland, 1916 of Euphyes cornelius cornelius (Latreille, [1824]); Eutocus matildae vinda Evans, 1955, and Vehilius vetustus Mielke, 1968 of Eutocus vetulus vetulus (Mabille, 1883); Eutychide angus Evans, 1955 of Eutychide rastaca (Schaus, 1902); Stomyles gallio Mabille, 1904 of Gallio carasta (Schaus, 1902); Eutychide candallariae Strand, 1921 of Halotus angellus (Plötz, 1886); Lerodea tesera Schaus, 1902 of Lerodea erythrostictus (Prittwitz, 1868); Pamphila fasciata Möschler, ?-1877 of Metron zimra (Hewitson, I-1877); Perimeles stollmeyeri Bell, 1932 of Mnasicles hicetaon Godman, 1901; Vehilius norma Dyar, 1917 of Mnasilus allubita (Butler, 1877); Phlebodes silvicultrix Hayward, 1934 of Moeris striga menopis (Schaus, 1902); Molo menta menta Evans,

1955 of Molo calcarea calcarea (Schaus, 1902); Molo petra Evans, 1955 of Molo visendus (Bell, 1942); Cyclopides metius Mabille, 1891 of Monca telata telata (HerrichSchäffer, 1869); Hesperia tyrtaeus Plötz, XI-1882 of Monca telata crispinus (Plötz, V-1882); Hesperia leucopogon Plötz, 1882 of Morys compta compta (Butler, 1877); Hesperia yva Plötz, 1886 of Suastus gremius (Fabricius, 1798); Cymaenes geijskesi de Jong, 1983 of Nastra chao (Mabille, 1898); Lerodea unipunctata Hayward, 1934, and Lerodea uniformis Hayward, 1939 of Nastra incomptus (Hayward, 1934); Lerodea hoffmanni Bell, 1947 of Nastra julia (Freeman, 1945); Rhinthon cubana australis Mielke, 1970 of Neoxeniades braesia andricus (Mabille, 1895); Hesperia ulrica Plötz, 1882 of Niconiades merenda (Mabille, 1878); Hesperia senex Plötz, 1882 of Panoquina peraea (Hewitson, 1866); Lerodea unicolor Hayward, 1938, and Lerodea modesta 
Hayward, 1939 of Papias phainis Godman, 1900; Hesperia infuscata Plötz, 1882, and Pamphila integra Mabille, 1891 of Papias subcostulata (Herrich-Schäffer, 1870); Paratrytone miahua Steinhauser, 1996 of Librita raspa Evans, 1955; Parphorus nemorus Bell, 1941, and Tigasis altona Evans, 1955 of Parphorus fartuga (Schaus, 1902); Peba striata Mielke, 1968 of Peba verames (Schaus, 1902); Pheraeus manes Steinhauser, 1991 of Pheraeus unia (Butler, 1870); Euroto schmithi Bell, 1940 of Phlebodes sameda (Herrich-Schäffer, 1869); Pamphila rolla Mabille, 1883, and Pamphila lagon Mabille, 1891 of Poanes zachaeus (Plötz, 1883); Pamphila crassinota Mabille, 1898 of Pamphila amblyspila (Mabille, 1898); Rhinthon proximus Bell, 1934, and Synapte infusco Nicolay, 1980 of Propapias sipariana (Kaye, 1925); Psoralis ravus Evans, 1955 of Psoralis coyana (Schaus, 1902); Mellana myron verba Evans, 1955 of Quasimellana servilius (Möschler, 1883); Papilio atiopides Larrañaga, 1923 of Quinta cannae (Herrich-Schäffer, 1869); Proteides chiriquensis Mabille, 1889, p. 239 (nec p. 157) of Rhinthon cubana osca (Plötz, 1882); Styrioides [sic] quaka Evans, 1955 of Styriodes dedecora (Plötz, 1882); Enosis inframaculata Strand, 1921 of Styriodes quadrinotata (Mabille, 1889); Thespieus cacajo Dyar, 1913 of Thespieus macareus (HerrichSchäffer, 1869); Thespieus paula Evans, 1955 of Thespieus tapayuna Evans, 1955; Molo stygia Evans, 1955 of Turesis complanula (Herrich-Schäffer, 1869); Pyrrhopyge maravilha Foetterle, 1902 of Turmada camposa (Plötz, 1886); Vehilius almoneus Schaus, 1902, and Vehilius vetus oiticicai Mielke, 1973 of Vehilius celeus celeus (Mabille, 1883); Lerodea chinta Schaus, 1902, and Lerodea mocoreta Hayward, 1939 of Vehilius inca (Scudder, 1872); Virga phola Evans, 1955, and Virga eliasi Mielke, 1968 of Virga silvanus (Hayward, 1947); Pamphila helva Möschler, 1877 of Wallengrenia otho clavus (Erichson, [1849]); Atrytone chingachgook Weeks, 1909 of Wallengrenia premnas (Wallengren, 1860); Copaeodes chromis Skinner, 1919 of Zariaspes mythecus Godman, 1900; Hesperia melaleuca Plötz, 1882 of Zenis minos (Latreille, [1824]).

The following taxa are comb. nov.: Jemadia gnetus brevipennis Schaus, 1902; Polygonus savigny punctus Bell \& W. Ph. Comstock, 1948; Heliopyrgus domicella margarita (Bell, 1937); Milanion clito (Fabricius, 1787); Quadrus jacobus (Plötz, 1884); Argon lota (Hewitson, 1877); Callimormus rivera (Plötz, 1882); Chalcone briquenydan briquenydan (Weeks, 1901); Chalcone briquenydan chalcone (Schaus, 1902); Chalcone briquenydan australis Mielke, 1980; Cobalopsis hazarma (Hewitson, 1877); Corticea rivula (Mabille, 1891); Cynea anthracinus holomelas (Mabille, 1891); Damas horridus (Bell, 1940); Enosis uza uza (Hewitson, 1877); Enosis uza pruinosa (Plötz, 1882); Eutocus vetulus vetulus (Mabille, 1883); Eutocus vetulus matildae (Hayward, 1941); Gallio carasta (Schaus, 1902); Jongiana unica (de Jong, 1983); Moeris striga menopis (Schaus, 1902); Molo calcarea calcarea (Schaus, 1902); Molo calcarea penda Evans, 1955; Molo visendus (Bell, 1942); Monca telata crispinus (Plötz, 1882); Nastra incomptus (Hayward, 1934); Paratrytone gala (Godman, 1900); Penicula subviridis (Plötz, 1886); Psoralis coyana (Schaus, 1902); Quasimellana servilius (Möschler, 1883); Saturnus reticulata conspicuus (Bell, 1941); Saturnus reticulata obscurus (Bell, 1941); Saturnus reticulata suffusus (Hayward, 1940); Saturnus reticulata tiberius (Möschler, 1883); Styriodes dedecora (Plötz, 1882); Vehilius celeus celeus (Mabille, 1891); Vehilius celeus ochraceus Biezanko \& Mielke, 1983; Vehilius celeus vetus Mielke, 1969.

The following taxa is a comb. rev.: Mimoniades baroni (Godman \& Salvin, 1893).

Lectotypes for the following taxa are designated: Pyrrhopyga [sic] oneka Hewitson, 1866; Eudamus latimargo Herrich-Schäffer, 1869; Erycides imbreus Plötz, 1879; Papilio amyntas Fabricius, 1775; Hesperia savigny Latreille, [1824]); Papilio clito Fabricius, 1787; Pythonides leucaspis Mabille, 1878; Milanion pilumnus var. hemestinus Mabille \& Boullet, 1917; Papilio maimon Fabricius, 1775; Tagiades chacona Plötz, 1886; Tagiades jacobus Plötz, 1884; Hesperia epictetus Fabricius, 1793; Cobalus nigritulus Mabille, 1883; Hesperia lota Hewitson, 1877; Pamphila cerymicoides

Revta bras. Zool. 19 (Supl. 1): 27 - 76, 2002 


\begin{abstract}
Burmeister, 1878; Pamphila flaveola Mabille, 1891; Hesperia beda Plötz, 1886; Pamphila briquenydan Weeks, 1901; Hesperia hazarma Hewitson, 1877; Pamphila rivula Mabille, 1891; Hesperia tripunctata Latreille, [1824]; Pamphila holomelas Mabille, 1891; Rhinthon luctatius Schaus, 1913; Hesperia uza Hewitson, 1877; Pamphila agassus Mabille, 1891; Amblyscirtes insulae- pinorum [sic] Holland, 1916; Cobalus vetulus Mabille, 1883; Hesperia angellus Plötz, 1886; Mnasicles hicetaon Godman, 1901; Pamphila allubita Butler, 1877; Padraona calcarea Schaus, 1902; Cyclopides metius Mabille, 1891; Hesperia tyrtaeus Plötz, 1882; Pamphila morys Butler, 1877; Hesperia leucopogon Plötz, 1882; Pamphila chao Mabille, 1898; Proteides andricus Mabille, 1895; Proteides merenda Mabille, 1878; Hesperia peraea Hewitson, 1866; Hesperia lucas Fabricius, 1793; Goniloba sylvicola Herrich-Schäffer, 1865; Papias phainis Godman, 1900; Hesperia infuscata Plötz, 1882; Pamphila integra Mabille, 1891; Hesperia subviridis Plötz, 1886; Phlebodes unia Butler, 1870; Cobalus sameda Herrich-Schäffer, 1869; Pamphila lagon Mabille, 1891; Pamphila crassinota Mabille, 1898; Cymaenes sipariana Kaye, 1925; Cobalus cannae HerrichSchäffer, 1869; Hesperia dedecora Plötz, 1882; Goniloba macareus Herrich-Schäffer, 1869; Thespieus cacajo Dyar, 1913; Hesperia camposa Plötz, 1886; Pyrrhopyge maravilha Foetterle, 1902; Cyclopides celeus Mabille, 1891; Lerodea inca Scudder, 1872; Hesperia clavus Erichson, [1849]; Pamphila helva Möschler, 1877; Hesperia premnas Wallengren, 1860; Atrytone chingachgook Weeks, 1909; Zariaspes mythecus Godman, 1900; Hesperia minos Latreille, [1824]; Hesperia melaleuca Plötz, 1882. Neotypes for the following taxa are designated: Polygonus lividus Hübner, [1825], and Papilio atiopides Larrañaga, 1923.

The designated Lectotype of Aguna albistria leucogramma (Mabille, 1888) by AusTIN \& MIELKE (1998) is invalid.
\end{abstract}

KEY WORDS. Lepidoptera, Hesperiidae, taxonomic notes, Neotropical region

O estudo sistemático dos Hesperiidae americanos ocupou um dos autores durante muitos anos e agora será publicado um "check-list" de todas as espécies neotropicais dentro do projeto "Atlas of Neotropical Lepidoptera", da Association for Tropical Lepidoptera, coordenado e editado pelo Dr. John B. Heppner. Nesta "check list", devido ao estilo adotado pelo editor, não é possível incluir as mudanças taxonômicas a seguir apresentadas, razão desta contribuição.

\title{
MATERIAL E MÉTODOS
}

O presente estudo é resultante da visita à maioria dos museus em que os tipos de Hesperiidae estão depositados e mencionados em cada espécie estudada. Os museus em que foram encontrados os tipos têm os seguintes acrônimos, de acordo com HEPPNER \& LAMAS (1982) - entre parênteses estão mencionados os curadores presentes quando da visita.

AME - Allyn Museum of Entomology, Sarasota, Florida, USA (Drs Lee D. Miller, Jacqueline Y. Miller, Stephen R. Steinhauser); AMNH - American Museum of Natural History, Nova York, USA (Drs Frederick Rindge, James Miller); BM (NH) - The Natural History Museum, Londres, Inglaterra (Drs Phillip R. Ackery e Richard Vane-Wright); CMP - Carnegie Museum, Pennsylvania, USA (Dr. Chen W. Young, John Rawlins); CU - Cornell University, Ithaca, New York, USA (Dr. John G. Franclemont); DEI - Institut für Pflanzenschutzforschung (antigo Deutsches Entomologisches Institut), Kleinmachnov, Eberswalde, Alemanha (Dr. 
Reinhard Gaedike); EMAU - Zoologie, Sektion Biologie, Ernst Moritz-Arndt-Universität, Greifswald, Alemanha (Dr. G. Müller-M.); IML - Instituto Miguel Lillo, Tucumán, Argentina (Dr. Kenneth J. Hayward-falecido); MBR - Museo Argentino de Ciencias Naturales "Bernadino Rivadavia", Buenos Aires, Argentina (Dr. Manuel Vianna - falecido); MCZ - Museum of Comparative Zoology, Harvard University, Cambridge, USA (Dra M. Deane Bowers); MLP - Facultad de Ciencias Naturales y Museo, La Plata, Argentina (Dr. Luiz de Santis - falecido); NHMW Naturhistorisches Museum, Viena, Austria (Dr. Fritz Kasy - falecido); MNHN Muséum national d'Histoire naturelle, Paris, França (Drs Pierre Viette, G. Bernardi - falecido, Jacques Pierre); MNRJ - Museu Nacional, Universidade Federal do Rio de Janeiro (Dr. Luiz S. Otero); NRS - Naturhistorika Riksmuseet, Estocolmo, Suécia (Dr. Bert Gustafsson); SMF - Senckenberg Museum, Frankfurt am Main, Alemanha (Dr. Heinz Schröder); SMTD - Staatliches Museum für Tierkunde, Dresden, Alemanha (Dr. R. Krause); UFPC - Departamento de Zoologia, Universidade Federal do Paraná, Curitiba, Paraná, Brasil (OM - coleção Mielke); USNM - National Museum of Natural History, Washington, DC, USA (Drs John Burns, Robert K. Robbins); ZISP - Instituto de Zoologia, Academia de Ciências, São Petersburgo, Rússia (Drs Vladimir Kuznetzov, Aleksandr Lvovski); ZMHU Museum für Naturkunde der Humboldt Universität, Berlin, Alemanha (Drs HansJoachim Hannemann, Wolfram Mey); ZMUC - Zoologisk Museum, Universitets Copenhague, Dinamarca (Dr. Niels Peder Kristensen); ZSBS - Zoologische Sammlung des bayrischen Staates, Munique, Alemanha (Drs Walter Forster, Wolfgang Dierl - falecidos).

Outras abreviaturas utlizadas: (d) dorsal; (gen. masc.) genitália masculina; (gen. fem.) genitália feminina; (gen. prep.) genitália preparada; (v) ventral.

Em cada espécie são mencionadas as referência da descrição original e a que estabeleceu o status da espécie ou subespécie atualmente aceito.

Sempre que na descrição original o número de exemplares não é mencionado, designa-se um LECTÓTIPO, pois só assim a identificação pode ser garantida. Os lectótipos e neótipos, aqui designados, serão etiquetados convenientemente e as etiquetas enviadas aos respectivos curadores.

Hesperioidea (Latreille, 1809) J.H. Comstock \& A. B. Comstock, 1904 Hesperiidae (Latreille, 1809) Stephens, 1828 Pyrrhopyginae (Mabille, 1877) Watson, 1893

\section{Passovini Mielke, 2001 \\ Aspitha aspitha aspitha (Hewitson, 1866)}

Pyrrhopyga [sic] aspitha Hewitson, 1866. Trans. ent. Soc. London (3) 2: 481; macho e fêmea, Pará e St. Paulo [de Olivença], Amazonas, [Brasil]; coleção Hewitson.

Aspitha teffa Evans, 1951. Cat. Amer. Hesp. 1, p. 83; [holó]tipo fêmea, Teffé (Ega), Amazonas, [Brasil]; $\mathrm{BM}(\mathrm{NH}) ;$ syn. nov.

A. teffa é a fêmea de $A$. aspitha aspitha, razão da nova sinonímia. 


\section{Pyrrhopygini Mabille, 1877}

\section{Jemadia gnetus brevipennis Schaus, 1902, comb. nov.}

Jemadia brevipennis Schaus, 1902. Proc. U.S. Nat. Mus. 24: 425; [holó]tipo n 5.962, São Paulo, Brazil; UNSNM.

Jemadia hewitsonii brevipennis; Evans, 1951. Cat. Amer. Hesp. 1, p. 54.

O exame do holótipo mostrou ser uma uma subespécie de Jemadia gnetus (Fabricius, 1781). Evans (1951) a considerou uma subespécie de Jemadia hewitsonii (Mabille, 1878). Difere de J. gnetus gnetus (Fabricius, 1781) pelo azul menos brilhante, as manchas transparentes da asa anterior bem maiores, sendo as dos espaços M2-M3 e M3-CuA1 quase quadradas, a do espaço CuA1-CuA2 mais longa que alta, na face dorsal da asa posterior a faixa discal azul mais estreita e a faixa central interrompida ou praticamente assim. Esta subespécie ocorre no Brasil - Distrito Federal (Brasília), São Paulo (Casabranca, Campinas), Paraná (Jaguariaiva), e Paraguay - Villarica.

\section{Mimoniades baroni (Godman \& Salvin, 1895), comb. rev.}

Amenis baroni Godman \& Salvin, 1895. Ann. \& Mag. Nat. Hist. (6) 15: 372; macho e fêmea, Cajamarca, N. Peru, 10000 ft., O. T. Baron leg.- Evans, 1951. Cat. Amer. Hesp. 1, p. 62, pl. 7 (gen. masc.)

Esta espécie possue todos os caracteres de Mimoniades Hübner, 1823, razão da nova combinação. EvANS (1951) a menciona no gênero Amenis Watson, 1893.

\section{Sarbia curitiba Mielke \& Casagrande, sp. nov.}

Figs 1-4, 29.

Sarbia sp. C. Mielke, 1995. Revta. bras. Zool. 11: 761.

Comprimento da asa anterior, macho: 23-28 mm; fêmea: 27-30 mm, sendo os machos com $26 \mathrm{~mm}$ e as fêmeas com $29 \mathrm{~mm}$, mais frequentes; machos com menos de 25 mm são raros.

Espécie muito semelhante à S. pertyi (Plötz, 1879) (Figs 13-16), pois as faixas amarelas mediana e apical na face dorsal das asas são semelhantes, mas se destingue pelo maior tamanho em média, em $S$. pertyi o tamanho máximo do comprimento da asa anterior no macho de 23 a $26 \mathrm{~mm}$, e na fêmea de 26 a $28 \mathrm{~mm}$, e pela face ventral da asa posterior onde a faixa proximal possue uma largura aproximadamente uniforme da margem costal até a metade superior do espaço CuA2-2A em $S$. pertyi, enquanto que em $S$. curitiba somente atinge a metade superior da célula, sendo normalmente ausente, ou quando presente muito reduzida, na metade inferior da célula e presente em forma de ponto na metade superior do espaço CuA2-2A, este, raras vêzes totalmente ausente. A valva da genitália masculina (Fig. 29) difere da de $S$. pertyi; compare com a figura de EvANS (1951).

Distribuição geográfica: Ocorre no Brasil, nos campos elevados de Minas Gerais (Poços de Caldas), São Paulo (Campos do Jordão), Paraná (Curitiba, General Carneiro, Guarapuava, Palmas, Prudentópolis e São José dos Pinhais), Santa Catarina (Bom Jardim, Curitibanos, Lages, Santa Cecília, São Bento do Sul, São Joaquim, Urubici), Rio Grande do Sul (Bom Jesus, Cambará, São Francisco de Paula, Vacaria), onde é comum entre fins de janeiro e início de março. 

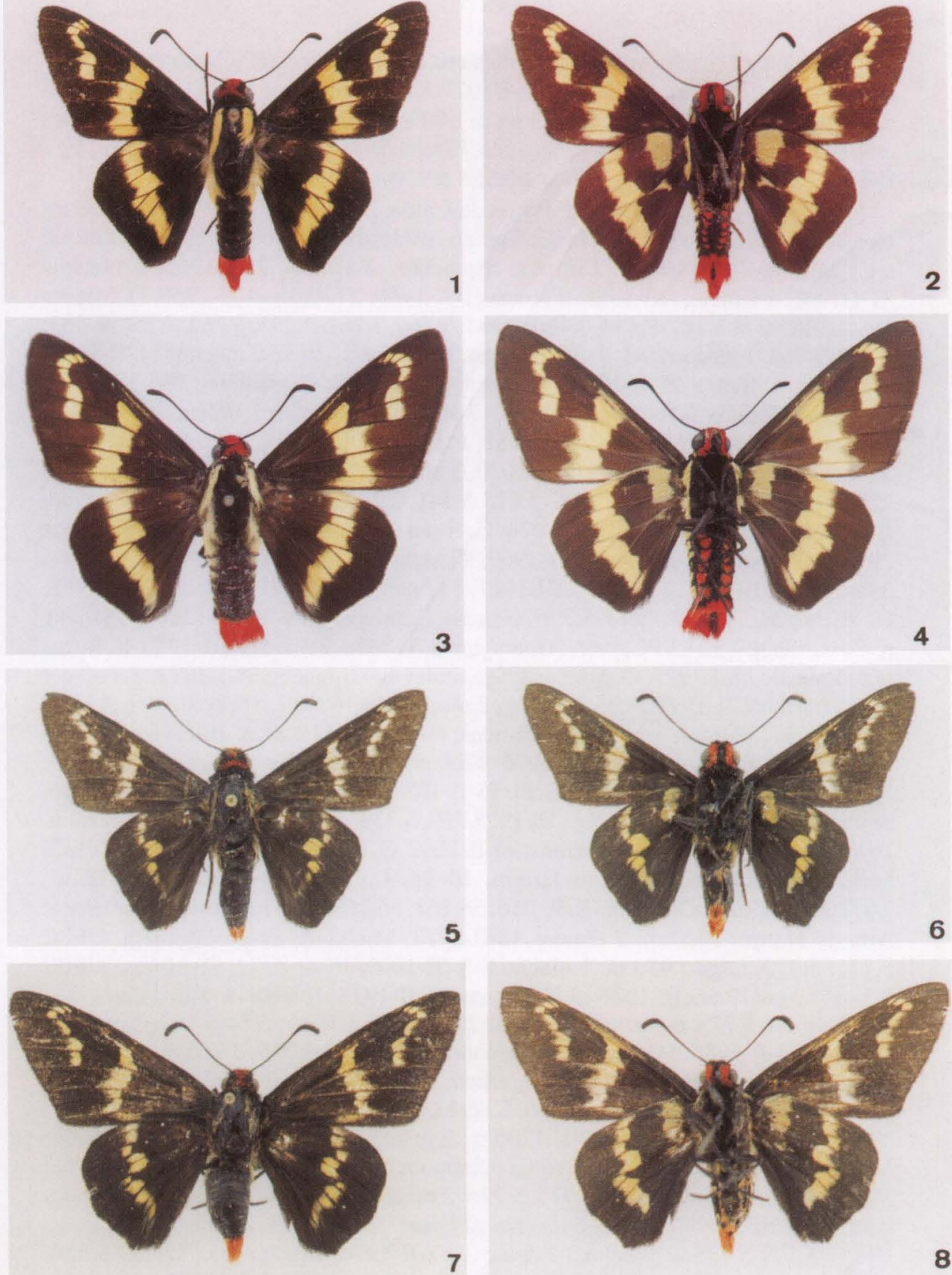

Figs 1-8. (1-4) Sarbia curitiba: (1-2) holótipo macho, faces dorsal e ventral; (3-4) alótipo fêmea, faces dorsal e ventral: (5-8) Sarbia oneka: (5-6) macho, faces dorsal e ventral, Brasil; (7-8) fêmea, faces dorsal e ventral, Brasil. 
Holótipo macho com as seguintes etiquetas: / Holotipo/ [Cascatinha], Curitiba, Paraná, 900 metros, Brasil, 22-I-1977, O. Mielke leg./ DZ 5.055/ Holótipo Sarbia curitiba Mielke \& Casagrande, 2002/; alótipo fêmea com as seguites etiquetas: / Alotipo/ Cascatinha, Curitiba, Paraná, Brasil, 11-II-1967 O. Mielke leg./ DZ 5.022/ Alótipo Sarbia curitiba Mielke \& Casagrande, 2002/; UFPC.

Parátipos: Minas Gerais: Poços de Caldas, 1 fêmea 10-XII-1966, 1250 m, H. Ebert leg., DZ 5.030; São Paulo: Campos do Jordão, 1 fêmea II-1935, C. Guinle leg., MN 34.011; Paraná: Curitiba, 8 machos, 2 fêmeas 25-I-1966, 2 machos 31-I-1966, 2 fêmeas 1-II-1966, 2 fêmeas 1-II-1966, 2 fêmeas, 4-II-1966, O. Mielke leg., UFPC-OM 8.482-8.489, 8.480, 8.481, 7.760, 7.761, 7.755, 7.762, 7.756, 9.363, 7.753, 7.754, 1 macho 29-I-1967, 1 macho, 1 fêmea 8-II-1967, 2 machos 11-II-1967, 1 macho, 1 fêmea 28-II-1967, 1 fêmea 15-III-1967, 2 machos, 29-I-1968, 19 machos, 4 fêmeas 6-II-1968, 1 fêmea 17-II-1968, 1 macho, 1 fêmea 7-II-1968, 2 fêmeas 17-II-1968, 3 macho, 22-II-1968, 1 fêmea 15-III-1968, 2 machos 4-II-1969, 1 fêmea 28-II-1969, 1 fêmea 20-III-1970, 3 machos, 2 fêmeas 13-I-1971, 3 machos 22-I-1977, O. Mielke leg., UFPC 5.615-5.641, 2.462, 2.462, 5642-5673, 1 macho 23-I-1971, H. Ebert leg., UFPC 5.674; Curitiba (Cascatinha), 26 machos, 5 fêmeas 29-I-1967, 1 macho, 1 fêmea 8-II-1967, 9 machos, 1 fêmea 11-II-1967, 2 machos, 3 fêmeas 14-II-1967, 1 fêmea 8-III-1967, 1 fêmea 9-III-1967, 2 machos 26-I-1968, O. Mielke leg., UFPC 5.675-5.726; General Carneiro, 2-IV-1980, 1200 m, Mielke \& Casagrande leg., UFPC 5.727; Guarapuava, $1100 \mathrm{~m}, 2$ machos III-1950, F. Justus leg., 1 macho 28-I-1972, O. Mielke \& Schneider leg., 1 macho 28-I-1972, Schneider leg., 1 macho 2-II-1972, Schneider leg., 2 machos 20-II-1972, Schneider leg., UFPC 5.731-5.737; Palmas, 4 machos, 4 fêmeas, 6-II-1977, Mielke \& Buzzi leg., UFPC 5.738-5.745; Prudentópolis, 2-II-1976, 1200 m, Mielke \& Buzzi leg., UFPC 5.728; São José dos Pinhais, 900 m, 1 macho 13-II-1881, Mielke leg., 1 fêmea 27-II-1986, 900 m, Mielke \& Callaghan leg., UFPC 5.729, 5.730; Santa Catarina: Bom Jardim, 10 km O, 1100 m, 3 machos 1 fêmea, 24-II-2002, O. Mielke leg., UFPC-OM 56.155, 56.176, 56.183, 56.169; Bom Jardim, 10 km L, 1300 m, 4 machos, 1 fêmea 24-II-2002, UFPC-OM 56.043, 56.056, 56.161, 56.162, 56.070; Curitibanos (Ponte Alta do Norte), 1000 m, 2 fêmeas 12-II-1973, Mielke \& Sakakibara leg., UFPC 5.771, 5.772; Lages, 950 m, 1 macho 6-8-III-1973, H. \& K. D. Ebert leg., UFPC 5.746; Lages (Painel), 1000 m, 3 fêmeas 14-II-1973, Mielke \& Sakakibara leg., UFPC 5.751-5.753; 8 machos, 5 fêmeas 23-II-1973, UFPC 5.754-5.765; 3 machos, 1 fêmea 24-II-1983, Mielke \& Casagrande leg., UFPC 6.055, 5.766-5.769; Lages (Parque Pedras Brancas), 920 m, 3 machos, 1 fêmea 13-II-1973, Mielke \& Sakakibara leg., UFPC 5.747-5.750; Monte Castelo, 800 m, 1 macho 24-II-1973, H. Ebert leg., UFPC 5.770; Santa Cecília, 1200 m, 2 machos 26-II-1968, Moure \& Mielke leg., UFPC 5773, 5774; Santa Cecília (Campo Alto), 1200 m, 2 fêmeas 27-II-1968, Moure \& Mielke leg., UFPC 5.775, 5.776; 2 machos 12-II-1973, Mielke \& Sakakibara leg., UFPC 5.777, 5.778; 5 machos, 2 fêmeas 22-II-1973, Mielke \& Buzzi leg., UFPC 5.779-5.785; 7 machos, 3 fêmeas 13-II-1976, Mielke leg., UFPC 5.7865.796; 1 macho 25-II-1983, Mielke \& Casagrande leg., UFPC 5.796; Santa Cecília (Campo Alto), 1100 m, 1 macho, 2 fêmeas 26-II-2002, Mielke \& Casagrande leg., UFPC-OM 55.888, 55.951, 55.958; São Bento do Sul, 1 macho 9-II-1971, Weiss 
leg., UFPC 5.797; São Bento do Sul (Rio Vermelho), 850 m, 1 fêmea 11-III-1977, Rank leg., UFPC 5.798; 1 fêmea 7-III-1987, O. \& C. Mielke leg., UFPC-OM 14.471; São Joaquim, 2 machos 2-4-II-1973, H. \& H. D. Ebert leg., UFPC 6.053, 6.054; 1 macho, 3 fêmeas 24-II-1973, Mielke leg., UFPC 6.049-6.052; São Joaquim (14 Km S), 1400 m, 3 machos 23-II-1983, Mielke \& Casagrande leg., UFPC 5.799-5.801; São Joaquim (13 km L), 1400 m, 1 fêmea 24-II-2002, Mielke \& Casagrande leg., UFPC- OM 56.286; São Joaquim (Mantiqueira), 1400 m, 25-II-1973, Mielke leg., UFPC 5.802, 5.803; São Joaquim (Pericó), 1320 m, 2 macho, 4 fêmeas 25-II-1973, Mielke leg., UFPC 6.048, 5.804-5.808; Urubici, 1500 m, 8 machos, 6 fêmeas 25-II-1973, O. Mielke leg., UFPC 5.809-5.822; Urubici (Morro da Igreja), $1600 \mathrm{~m}$, 12 machos 19-II-1997, O. \& E. Mielke leg., UFPC-OM 45.045, 45.109, 45.156, $45.165,45.173,45.300,45.308,45.324,45.364,45.388,58.277,58.286$; Urubici (Morro da Igreja), 1700-1800 m, 2 machos, 2 fêmeas 19-II-1997, O. - E. Mielke leg., UFPC-OM 45.325, 45.333, 45.341, 45.349; Rio Grande do Sul: Bom Jesus, 1050 m, 3 machos, 6 fêmeas 12-II-1976, Mielke \& Buzzi leg., UFPC 5.823-5.831, 1 fêmea 22-II-1983, Mielke \& Casagrande leg., UFPC 5.832; Bom Jesus (Arroio Tiririca), 1000 m, 3 fêmeas 27-II-1973, Mielke leg., UFPC 5.833-5.835; Cambará, 4 machos, 4 fêmeas 22-II-1983, Mielke \& Casagrande leg., UFPC 5.836-5.843; São Francisco de Paula, 850 m, 1 macho 27-I-1973, H. Ebert leg., UFPC 5.844; Vacaria, 2 machos 22-II-1949, H. Pearson leg., UFPC-OM 11.150, 36.384, 1 fêmea 21-II1983, Mielke \& Casagrande leg., UFPC 5.845.

Etimologia. Nome dado em homenagem à cidade de Curitiba, Paraná, onde a espécie foi descoberta.

\section{Sarbia oneka (Hewitson, 1866)}

Figs $5-8,30$

Pyrrhopyga [sic] oneka Hewitson, 1866. Trans. ent. Soc. London (3) 2: 480; sem dados [Venezuela, no rótulo do tipo]; $\mathrm{BM}(\mathrm{NH})$

Um síntipo fêmea é aqui designado LECTÓTIPO, possuindo as seguintes etiquetas: / Type/ Type H. T./ 44 124/ Venezuela Becker 44-124/ - BM (NH). O lectótipo é designado para garantir a identificação da espécie.

A espécie é aqui ilustrada pela primeira vez, inclusive a valva da genitália masculina, para comparação com $S$. soza e $S$. curitiba. Além do lectótipo só se conhecem mais três exemplares, um macho no BM (NH) do Peru, provavelmente outro erro de procedência, pois todas as espécies de Sarbia Watson, 1893 ocorrem no centro-sul do Brasil, Uruguai e norte da Argentina, e um casal na UFPC do Brasil. Ainda não foi possível descobrir o local de sua ocorrência.

\section{Sarbia soza Evans, 1951, stat. nov.} Figs $9-12,31$

Sarbia oneka soza Evans, 1951. Cat. Amer. Hesp. 1, p. 64; [holó]tipo macho, Castro, Paraná, [Brasil]; $\mathrm{BM}(\mathrm{NH})$.

Tendo em vista as diferenças no aspecto da valva da genitália masculina (comparar com a figura 30), o taxon é considerado uma espécie distinta de $S$. oneka; também o aspecto das faixas amarelas das asas, assim como o formato das mesmas 
corrobora (compare as figuras 5-8 e 9-12). Ocorre em lugares bem localizados nos campos altos do sul do Brasil, em Minas Gerais (Camanducaia - Monteverde, 1650 m), Estado do Rio de Janeiro (Itatiaia) e Santa Catarina (Santa Cecília, 1200 m).

\section{Pyrginae (Burmeister, [XII]-1878) Speyer, 1879 Eudamini Mabille, 1877}

Aguna albistria leucogramma (Mabille, 1888)

Eudamus leucogramma Mabille, 1888. Le Nat. (2) 2 (28): 109, fig. 3 (d, v); Porto-Cabello, [Venezuela]; coleção Staudinger.

Aguna albistria leucogramma; Austin \& Mielke, 1998. Revta bras. Zool. 14: 906, fig. 6 (fêmea d, v); syn.: guatemalaina; LECTÓTIPO de leucogramma: macho, Sant[arém, Pará, Brasil] - ZMHU.

O lectótipo designado por AUSTIN \& MIELKE (1998) foi um lapso, embora o exemplar tivesse rotulado como [sín]tipo, pois certamente não representa a população descrita, além de não ser da Venezuela, localidade típica, e sim de Santarém, Pará, Brasil, área de ocorrência da subespécie típica. Não foram encontrados verdadeiros síntipos no ZMHU. Talvez seja necessário designar um neótipo.

\section{Astraptes latimargo latimargo (Herrich-Schäffer, 1869)}

Eudamus latimargo Herrich-Schäffer, 1869. Corr.-Blatt zool.-min. Ver. Regensburg 23: 185; USA America tropical.

Thymele grullus Mabille, 1888. Le Nat. (2) 2 (31): 147, fig. 7 (d, v); Chiriqui, [Panamá]; coleção Staudinger; syn. nov.

Os exames do síntipo macho de E. latimargo, aqui designado LECTÓTIPO, possuindo as seguintes etiquetas: / Origin./ Coll. H.-Sch./ Eudamus latimargo HS/ latimargo H-Sch./-ZMHU, e do síntipo fêmea de T. grullus, aqui designado LECTÓTIPO, possuindo as seguintes etiquetas: /Origin./ Chiriqui/ Th. grullus Mab./ Telegonus grullus./ Telegonus Grullus Mab./ Grullus Mab./ - ZMHU, mostraram a sinonímia. EvANS (1952) considerou T. grullus um sinônimo de Astraptes alardus alardus (Stoll, 1790). Os lectótipos são designados para garantir a identificação da espécie.

\section{Aurina dida Evans, 1939}

Aurina dida Evans, 1939. Cat. Afric. Hesp., p. 26, pl. 2, figs 10 (macho d, v), 11 (fêmea d, v), pl. 10 (gen. masc.); [hol6]tipo macho, Ivory Coast, [Africa], Dimrock leg., ex coll. V. Dyot; BM (NH).

Um exame da foto do holótipo macho mostrou ser uma espécie neotropical que ocorre na Guiana Francesa e no Brasil (Amapá), razão da sua inclusão na "check list”. A procedência Costa do Marfim, África, é obviamente um lapso.

Figs 9-16. (9-12) Sarbia soza: (9-10) Macho, faces dorsal e ventral, 13-II-1976, Campo Alto, Santa Cecilia, Santa Catarina, Brasil, 1200 m, Mielke \& Buzzi leg.; (11-12) fêmea, faces dorsal e ventral: 27-II-1968, Campo Alto, Santa Cecília, Santa Catarina, Brasil, $1200 \mathrm{~m}$, Moure \& Mielke leg.; (13-16) Sarbia pertyi: (13-14) Macho, faces dorsal e ventral: 13-II-1973, Parque Pedras Brancas, Lages, Santa Catarina, Brasil, 920 m, Mielke \& Sakakibara leg.; (15-16) fêmea, faces dorsal e ventral: 29-II-1973, Painel, Lages, Santa Catarina, Brasil, 1000 m, Mielke leg. 


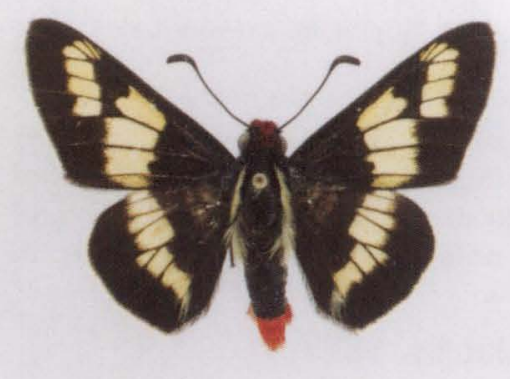

9

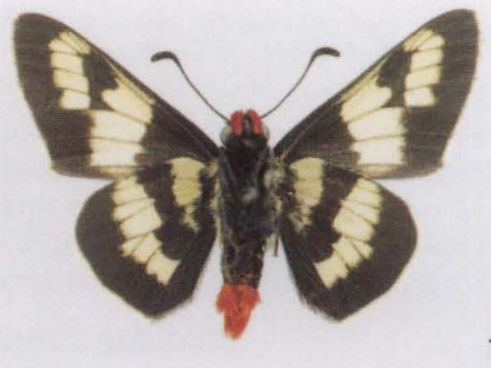

10
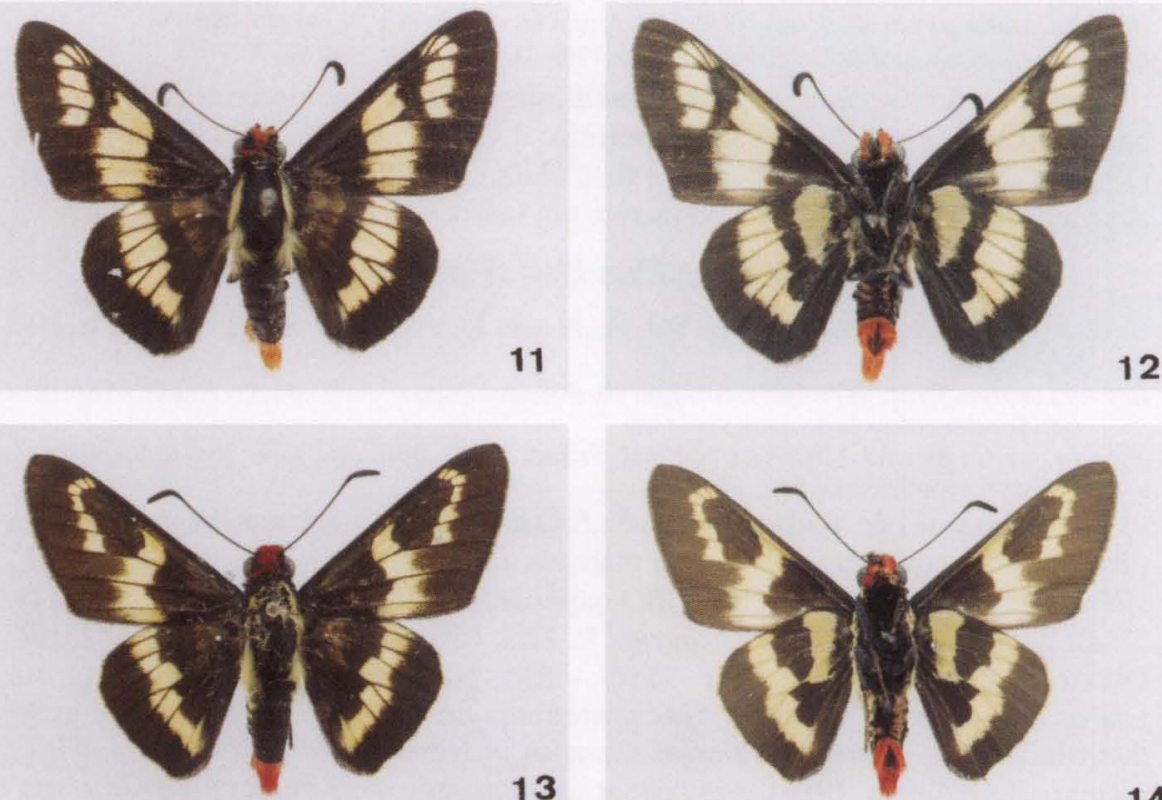

11

12

13
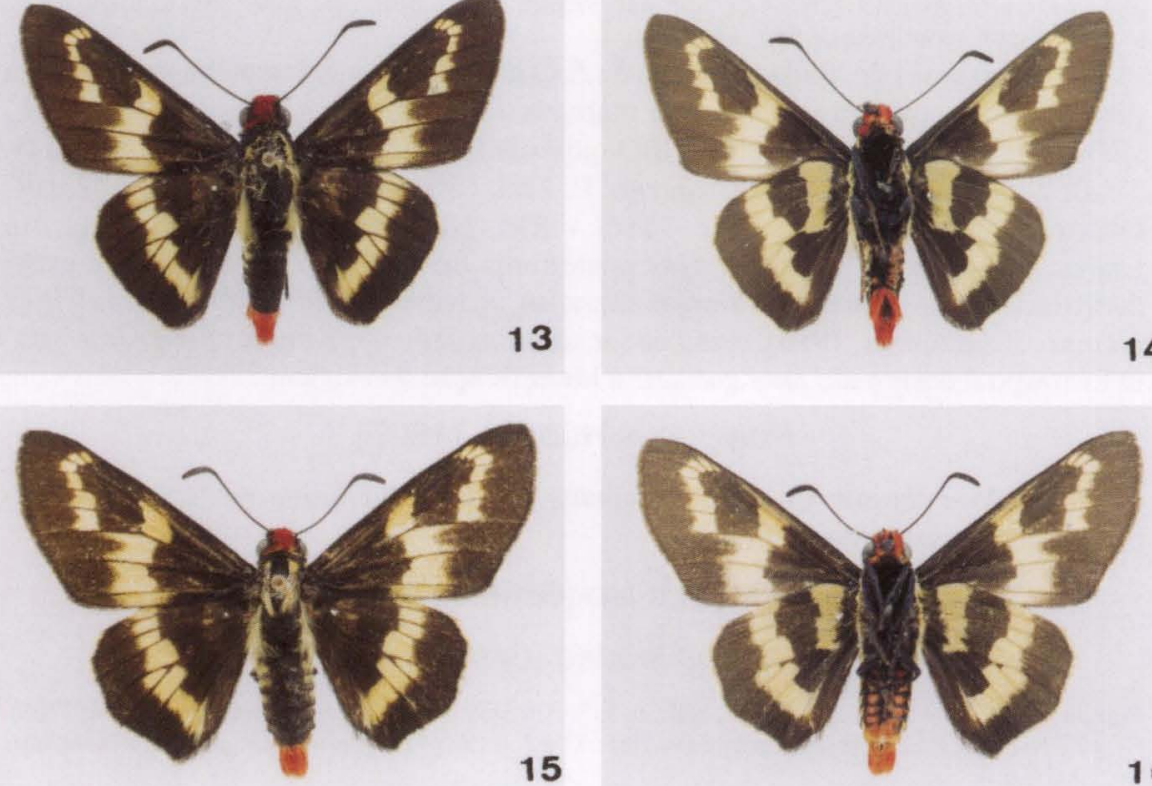


\section{Chioides cinereus (Mabille \& Vuillot, 1891), stat. rev.}

Goniurus cinereus Mabille \& Vuillot, 1891. Novit. Lep. 4, p. 25, 29, pl. 4, fig. 4 (fêmea d, v); 1 fêmea

[holótipo], Brasil; coleção Mabille.

Chioides catillus cinereus; Evans, 1952. Cat. Amer. Hesp. 2, p. 57, pl. 14 (gen. masc.).

Chioides cinereus ocorre de modo simpátrico e sincrônico com $C$. catillus jethira (Butler, 1870) nos andes ocidentais do Peru (La Libertad e Ancash, 1900$2550 \mathrm{~m}$ ) e do Equador, razão da revalidação do status (G. Lamas in litt.). EvANS (1952) a considerou uma subespécie de C. catillus catillus (Cramer, 1779). A procedência do holótipo é obviamente um lapso.

\section{Chioides concinnus (Mabille, 1877)}

Eudamus concinnus Mabille, 1877. Ann. Soc. ent. France (5) 7, Bull. ent., p. 39; Brasil; coleção Mabille. Chioides catillus concinnus; Evans, 1952. Cat. Amer. Hesp. 2, p. 57, pl. 14 (gen. masc.).

Chioides concinnus; Lamas; Grados \& Valencia, 1999. Rev. peruana Ent. 41 : 3.

Chioides concinnus ocorre de modo simpátrico e sincrônico com C. catillus catillus (Cramer, 1779) no Peru (Apurimac e Cuzco, 2000 m e 3000 m). Evans (1952) a considerou uma subespécie de Chioides catillus catillus (Cramer, 1779). A procedência do holótipo é obviamente um lapso.

\section{Phocides polybius lilea (Reakirt, 1867)}

Erycides lilea Reakirt, 1867. Proc. Ac. Nat. Sc. Philad. 18: 339; near Veracruz, Mexico, Wm. H. Edwards leg.

Erycides imbreus Plötz, 1879. Stett. ent. Ztg. 40: 406; [holó]tipo n 4.992, Centr. America [América meridional na etiqueta do tipo]; syn. nov.

Erycides spurius Mabille, 1880. Ann. Soc. ent. France (5) 10, Bull. ent., p. 46; sem dados [Bogotá, Colombia na etiqueta do tipo]; syn. nov.

Os exames do holótipo fêmea de $E$. imbreus, em que a mancha vermelha da face dorsal da asa anterior não está marcada - ZMHU, e do síntipo macho de $E$. spurius, aqui designado LECTÓTIPO, possuindo as seguintes etiquetas: /Type H. T./ Bogota Nolcken/ Erycides spurius P. Mab./ Ex musaeo P. Mabille 1923/ R. Oberthür Coll. Brit. Mus. 1931 - 186/ - BM (NH), mostraram a sinonímia. As franjas nos ângulos anais das asas posteriores do lectótipo de E. spurius estão danificadas e substituidas por franjas amarelas, provavelmente de Phocides polybius phanias (Burmeister, 1880), razão de ser sinonimizado por EVANS (1952) com esta. O lectótipo é designado para garantir a identificação da espécie.

\section{Polygonus Hübner, [1825]}

Após examinar os tipos existentes dos taxa incluidos neste gênero, são necessárias as seguintes alterações:

\section{Polygonus leo (Gmelin, 1790) Polygonus leo leo (Gmelin, 1790)}

Papilio amyntas Fabricius, 1775. Syst. Ent., p. 533; America; Mus. Tottianum; praeocc. (Poda, 1761). Papilio leo Gmelin, 1790, in: Linnaeus. Syst. Nat., $13^{\mathrm{a}}$ ed., 1 (5), p. 2363; nom. nov. pro Papilio amyntas Fabricius.

Astraptes lividus Hübner, [1819]. Verz. bek. Schmett., p. 103; nom. nud. (ICZN, Art. 12.1. - sem descrição) 
Polygonus lividus Hübner, [1825]. Samml. exot. Schmett. 2, pl. [144], figs 1-4 (macho, fêmea d, v); sem dados. - W. Ph. Comstock, 1944. Sc. Surv. P. Rico \& Virgin Isl. 12 (4), p. 541; localidade típica: Hispaniola.

Polygonus leo ishmael Evans, 1952. Cat. Amer. Hesp. 2, p. 54; [holó]tipo macho, Haiti; BM (NH); syn. nov.

O síntipo de $P$. amyntas descrito da América e examinado no Museu de Copenhage representa a população das Antilhas (Antilhas Britânicas); é igual à figura de $P$. lividus, um exemplar com as manchas transparentes da asa anterior um pouco maiores, porém este caráter varia, a julgar pelos exemplares examinados das Antilhas Britânicas onde há exemplares iguais ao figurado por Hübner e outros, em maior número, iguais ao síntipo de amyntas; no entanto, estas manchas não chegam ao tamanho das de $P$. leo pallida. O síntipo macho de $P$. amyntas é aqui designado LECTÓTIPO, possuindo a seguinte etiqueta: / amynthas [sic]/ - ZMUC, e como não existem síntipos de $P$. lividus, designa-se aqui o mesmo exemplar como NEÓTIPO, sendo portanto, os dois nomes sinônimos objetivos. O lectótipo e o neótipo são designados para garantir a identificação da espécie.

Esta subespécie ocorre em Puerto Rico, Haiti, St. Tomas, Guana Isl., sendo P. l. ishmael um novo sinônimo.

\section{Polygonus leo arizonensis (Skinner, 1911)}

Erycides amyntas var. arizonensis Skinner, 1911. Trans. Amer. Ent. Soc. 37: 209, pl. 10 (d, v); exemplares, 3-IX-[sem ano], Florence, Arizona, [USA], C.R. Biedermann leg.

Acolastus amyntas arizonensis; Barnes \& McDunnough, 1917. Check List Lep. Bor.-Amer., p. 17.

Polygonus leo arizonensis; Kendall \& Freeman, 1963. Butt. Skipp. Texas., p. 3.

Muito semelhante aos exemplares do México a América do Sul, no entanto, os desenhos na face ventral da asa posterior são mais contrastados. EVANS (1952) a menciona na sinonímia de Polygones leo leo, mas já KENDALL \& FREEMAN (1963) a mencionam como subespécie de $P$. leo. Só conhecida do Arizona (USA).

\section{Polygonus leo hagar Evans, 1951}

Polygonus leo hagar Evans, 1952. Cat. Amer. Hesp. 2, p. 54; [holó]tipo macho, Jamaica; BM (NH).

Esta subespécie só ocorre na Jamaica.

\section{Polygonus leo histrio Röber, 1925}

Polygonus (Acolastus) histrio Röber, 1925. Ent. Mitt., Berlin, 14: 161; 1 macho, provavelmente Panamá. Polygonus leo histrio; Ferris, 1989. Mem. Lep. Soc. 3: 5, 67.

A procedência é certamente um erro, como o próprio autor já supunha. $\mathrm{O}$ holótipo macho (SMT) mostra claramente representar a população da Flórida e de Cuba. As manchas transparentes da asa anterior são grandes como em $P$. leo pallida e os desenhos da face ventral da asa posterior são apagados, como em $P$. leo hagar, nesta as manchas transparentes da asa anterior são reduzidas como em $P$. leo leo. Evans (1951) a menciona como um sinônimo de Polygonus leo leo.

\section{Polygonus leo pallida Röber, 1925, ssp. rev., stat. nov.}

Polygonus amyntas pallida Röber, 1925. Ent. Mitt., Berlin, 14: 161; Peru.

O LECTÓTIPO do Peru, designado por MIELKE (1989) - SMT, representa toda a população continental que ocorre desde o México até a Bolívia, Argentina e Uruguai. Evans (1952) a menciona como um sinônimo de P. leo leo. 


\section{Polygonus savigny (Latreille, [1824]), stat. nov. \\ Polygonus savigny savigny (Latreille, [1824]), stat. nov.}

Hesperia savigny Latreille, [1824], in Latreille \& Godart. Enc. Méth. 9, p. 716, 741; Antilhas.- Viette, 1956. Lambillionea 56: 90; [sín]tipo.

Polygonus manueli manueli Bell \& W. Ph. Comstock, 1948. Amer. Mus. Novit. 1379: 4, fig. 1 (gen. masc.); holótipo macho, Nova Bremen [atualmente Dalbérgia], [Santa Catarina], Brasil; AMNH; syn. nov.

Polygonus mimeticus J. Zikán \& W. Zikán, 1968. Pesq. agropec. bras. 3: 62; nom. nud. (ICZN, Art. 12.1. - sem descrição).

O exame do síntipo de $H$. savigny, encontrado por VIETTE (1956) - MNHM, e aqui designado LECTÓTIPO, possuindo as seguintes etiquetas: / Type/ Ancienne Collection Muséum de Paris/ Hesperia savigny Latr. Encycl. Méthod. vol. 9, 1824, p. 741 (P. Viette XI-1956) /, e do holótipo de P. manueli mostraram a sinonímia. Polygonus mimeticus, mencionado por ZIKÁN (1968), cujo exemplar identificado assim está no IOC, é um nome inválido. Evans (1952) menciona H. savignyi como subespécie de $P$. leo. O lectótipo é designado para garantir a identificação da espécie.

\section{Polygonus savigny punctus Bell \& W. Ph. Comstock, 1948, comb. nov.}

Polygonus manueli punctus Bell \& W. Ph. Comstock, 1948. Amer. Mus. Novit. 1379; 7; holótipo macho, St. Vincent, British West Indies; AMNH.

Polygonus manueli señdo um sinônimo de Polygonus savignyi, P. manueli punctus passa a ser uma subespécie desta.

\section{Polythrix octomaculata (Sepp, [1844])}

Hesperia octomaculata Sepp, [1844]. Surin. Vlind. 2, p. 123, pl. 58 (larva, pupa, d, v); Suriname; biologia, planta hosp.

Goniuris [sic] decussata Ménétriés, 1855. Enum. Corp. Anim. Mus. Petr., Lep. 1, p. 61, pl. 5, fig. 2, v); Haiti; ZISP; syn. nov.

O exame de um síntipo de $G$. decussata, depositado no ZISP e aqui designado LECTÓTIPO, mostrou ser um sinônimo de $P$. octomaculata. A procedência Haiti do lectótipo de $H$. decussata deve ser um engano, pois nunca mais foi lá coletado. O lectótipo é designado para garantir a identificação da espécie.

\section{Pyrgini (Bumeister, [31-XII]-1878) Orfila, 1949}

\section{Aethilla haber (Mabille, 1891), sp. rev.}

Eurypterus haber Mabille, 1891. Ann. Soc. ent. Belg. 35, C.R., p. 79; macho, provavelmente dos Andes do Peru.-Mabille \& Vuillot, 1895. Novit. Lep. 12, p. 135, 136, pl. 19, fig. 1 (dorsal, ventral).

A figura de MABILLE \& VuILLOT (1895) mostra muito bem não ser sinônimo de Aethilla echina echina Hewitson, 1870, como o diz EvANS (1953), razão de sua revalidação. As manchas irregulares e mais pálidas da face dorsal das asas diagnosticam a espécie. É uma espécie rara que ocorre nas florestas do nordeste e sudoeste do Brasil: Pernambuco (Goiana), Bahia (Palmeiras, Lençois), Minas Gerais (Marliéria, Viçosa), Espírito Santo (Santa Teresa, Conceição da Barra, Linhares), Estado do Rio de Janeiro (Imbariê, Petrópolis, Tinguá, Guapimirim). 


\section{Anastrus chaqua Evans, 1953, stat. nov.}

Anastrus obscurus chaqua Evans, 1953. Cat. Amer. Hesp. 3, p. 186, pl. 47 (gen. masc.); [holó]tipo macho, VII-1910, Chaquimayo, S. Peru, 3000ft, H. \& C. Watkins leg.; BM (NH).

A subespécie descrita por EvANS (1953), além de ser simpátrica com Anastrus obscurus obscurus Hübner, [1824] (G. Lamas in litt.), possui a genitália masculina diferente desta, como mostra EVANS (1953), razão de se atribuir o status de espécie.

\section{Clito Evans, 1953}

Clito Evans, 1953. Cat. Amer. Hesp. 3, p. 152; espécie tipo: Hydraenomia aberrans Draudt, 1924; designada originalmente como [Papilio] clito Fabricius, 1787, espécie tipo mal identificada e aqui substituida com base no ICZN (Art. 70.3.2.).

O holótipo de $H$. aberrans foi examinado - SMF.

\section{Clito aberrans (Draudt, 1924), sp. rev.}

Hydraenomia aberrans Draudt, 1924, in Seitz. Gross-Schmett. Erde 5, p. 1049, pl. 178b (d); 1 macho [holótipo], Teffé, [Amazonas, Brasil]; coleção Seitz.

Clito clito; Evans, 1953. Cat. Amer. Hesp. 3, p. 153, pl. 44 (gen. masc.); syn.: aberrans.

Papilio clito Fabricius, segundo Evans (1953) o sinônimo sênior de $H$. aberrans, é uma espécie de Milanion Godman \& Salvin, 1895, razão da revalidação desta. Veja adiante em Milanion clito (Fabricius, 1787).

\section{Heliopyrgus domicella margarita (Bell, 1937), comb. nov.}

Pyrgus domicella var. margarita Bell, 1937. Amer. Mus. Novit. 914: 17; holótipo macho, Margarita

Island, Venezuela; AMNH.

Heliopetes domicella margarita; Evans, 1944. Entomol. 77: 179.

Pyrgus domicella margarita; Austin \& Warren, 2001. Dugesiana 8: 4.

AUSTIN \& WARREN (2001) revalidaram o gênero, sem no entanto confirmar que esta subespécie deve ser também transferida para Heliopyrgus, então feito aqui.

\section{Milanion clito (Fabricius, 1787), comb. nov.}

Papilio clito Fabricius, 1787. Mant. Ins. 2, p. 91; Caiena, [Guiana Francesa]; coleção v. Rohr.

O exame de um síntipo macho de $P$. clito, aqui designado LECTÓTIPO, possuindo a seguinte etiqueta: /Clito/ - ZMUC, mostrou ser uma espécie de Milanion Godman \& Salvin, 1895. Evans (1953) a menciona como uma espécie de Clito Evans, 1955. Não foi possível associá-la com qualquer espécie do gênero com base na obra de Evans (1953), no entanto, $P$. clito se assemelha muito com M. hemestinus; Evans, 1953 (nec Mabille \& Boullet, 1917). O lectótipo é designado para garantir a identificação da espécie.

\section{Milanion leucaspis (Mabille, 1878)}

Pythonides leucaspis Mabille, 1878. Pet. Nouv. Ent. 2: 230; Caiena, [Guiana Francesa] e Brasil; coleção Mabille.

Milanion pilumnus var. hemestinus Mabille \& Boullet, 1917. Bull. Soc. ent. France, p. 57; 2 machos, Amazonas superior, Peru; coleção Boullet no Museu de Paris; syn. nov.

Os exames de um síntipo fêmea de $P$. leucaspis, aqui designado LECTÓTIPO, possuindo as seguintes etiquetas: / Type H. 690/ Bresil, Leucaspis Mab. type/ 
R. Oberthür Coll. Brit. Mus. 1931-136/ - BM (NH), e de um síntipo macho de $M$. pilumnus var. hemestinus, aqui designado LECTÓTIPO, possuindo as seguintes etiquetas: / Type/ Hillap, Pérou 1905 O. Staudinger, Coll. Boullet Museum Paris/ M. Pilumnus var. Hemestinus Mab. et. Boull./ Milanion pilumnus var. hemestinus Mab. Boull. Bull. Soc. ent. Fr., 1917: p. 57/ - MNHP, mostraram a sinonímia. Há ainda um outro síntipo macho de $P$. leucaspis, aqui designado PARALECTÓTIPO, com as seguintes etiquetas:/ Origin./ Sao Paulo, Brasil, Mart./ Pyth. leucaspis Mb./ Pyth. Leucaspis Mab./ Leucaspis Mab./ - ZMHU. Evans (1953) menciona M. hemestinus como uma espécie distinta de leucaspis, provavelmente então uma espécie a ser descrita ou um sinônimo de $P$. clito Fabricius, 1787. Os lectótipos são designados para garantir a identificação da espécie.

\section{Mylon maimon (Fabricius, 1775), sp. rev., comb. nov.}

Papilio maimon Fabricius, 1775. Syst. Ent., p. 534; Asia.- Butler, [1870]. Cat. diurn. Lep. Fabricius, p. 162; como sinônimo de Papilio rosimon.

Papilio menippus Fabricius, 1776. Gen. Ins., p. 272; Suriname; coleção Dr. Schultz; syn. nov.

O exame de um síntipo de $P$. maimon, aqui designado LECTÓTIPO, possuindo a seguinte etiqueta: / maimon/ - ZMUC, mostrou ser um sinônimo sênior de $P$. menippus, razão da revalidação. Até o presente era considerado um sinônimo de Castalius rosimon (Fabricius, 1775), um Lycaenidae asiático (BUTLER [1870], Evans 1953: 225). A procedência Ásia é obviamente um lapso. Não foram encontrados síntipos de $P$. menippus na mesma coleção. O lectótipo é designado para garantir a identificação da espécie.

\section{Ouleus fridericus fridericus (Geyer, 1832)}

Achlyodes fridericus Geyer, 1832. Zutr. Samml. exot. Schmett. 4, p. 9, figs 611, 612 (d, v); Suriname, Grimm leg.

Tagiades chacona Plötz, 1886. Stett. ent. Ztg. 47: 112; Panama; syn. nov.

O exame de um síntipo de $T$. chacona, aqui designado LECTÓTIPO, possuindo as seguintes etiquetas: / Original/ S.-America/ Tagiades chacona Plötz/ Nisoniades chacona Pl. Panama/ ơ Ebrietas chacona Pl. type (sec. Mab. prope livius Mab.) Am. m./ Lectotypus Tagiades chacona Plötz, 1886, Zool. Staatssammlg. München, O. Mielke det. 1979/ - ZSBS, mostrou a sinonímia. EvANS (1953) menciona $T$. chacona como um sinônimo de Gorgythion begga plautia (Möschler, 1877). O lectótipo é designado para garantir a identificação da espécie.

\section{Ouleus juxta juxta (Bell, 1934)}

Pythonides juxta Bell, 1934. Amer. Mus. Novit. 745: 2, fig. 4 (gen. masc.); holótipo macho, San Antonio, Peru, Klug leg.; American Museum of Natural History.

Ouleus matria matria Evans, 1953. Cat. Amer. Hesp. 3, p. 104, pl. 39 (gen. masc.); [holó]tipo macho, VII-1932, Iquitos, upper Amazonas, [Peru], G. Klug leg.; BM (NH); syn. nov.

Pythonides juxta; Evans, 1953. Cat. Amer. Hesp. 3, p. 124.

Ouleus juxta juxta; Lamas, 1994, in Foster et al. RAP Working Paper 6: 174.

Os exames dos holótipos dos dois taxa mostraram a sinonímia nunca explicada. Evans (1953) menciona juxta como uma espécie de Pythonides Hübner, [1819], não identificada no BM (NH). 


\section{Potamanaxas paralus (Godman \& Salvin, 1895), stat. rev.}

Potamanax paralus Godman \& Salvin, 1895. Biol. Centr.-Amer., Lep. Rhop. 2, p. 392; Cosnipata Valley, Peru, H. Whiteley leg.

Potomanaxas [sic] thestia paralus; Evans, 1953. Cat. Amer. Hesp. 3, p. 141.

Potamanaxas paralus era tida como uma subespécie de $P$. thestia (Hewitson, 1870) (EvANS 1953), no entanto, os dois taxons são virtualmente simpátricos em San Martin (cerca de Tarapoto) e Cuzco (cerca de San Pedro, Vale do Cosñipata), Peru, embora $P$. thestia parece ocorrer em altitudes um pouco maiores $(1250-1400 \mathrm{~m})$ que $P$. paralus $(850-1050 \mathrm{~m})$ (G. Lamas in litt.); razão da revalidação de seu status.

\section{Pythonides herennius herennius Geyer, [1838]}

Pythonides herennius Geyer, [1838], in Hübner. Samml. exot. Schmett. 3, pl. 33, figs 1, 2 (macho d, v), 3, 4 (fêmea d, v); Brasil.

Pythonides vicinus Mabille \& Boullet, 1917. Bull. Soc. ent. France (1916), p. 320; 1 fêmea [holótipo], [IV-1913, Morretes, Paraná - no rótulo do holótipo], Brasil, [P. Lombard leg. - no rótulo do tipo]; Museu de Paris; syn. nov.

O exame de holótipo de $P$. vicinus depositado no MNHP mostrou a sinonímia. Não foram encontrados síntipos de $P$. herennius no $\mathrm{ZMHU}$.

\section{Pythonides nides Mielke \& Casagrande, sp. nov. Figs $17-20$}

Pythonides vicinus; Evans, 1953. Cat. Amer. Hesp. 3, p. 122, pl. 41 (gen. masc.).

Espécie bem caracterizada por Evans (1953) sob o nome Pythonides vicinus Mabille \& Boullet, 1917; uma identificação errônea. O holótipo foi identificado no $\mathrm{BM}(\mathrm{NH})$, quando de visita à instituição em 1976 como $P$. vicinus.

Holótipo macho com as seguintes etiquetas: /Baixo Guandu E[spírito] S[anto, Brasil]. 26-IX-1970, Claudionor Elias leg./ Holótipo Pythonides nides Mielke \& Casagrande, 2002/ Pythonides vicinus Mab. \& Boull., 1917, BM. O. Mielke det. 1976/ DZ 5.602/. UFPC.

Alótipo fêmea com as seguintes etiquetas:/ Alotipo/ Conceição da Barra, Esp.[írito] Santo, Brasil, 5-V-1968, C. \&. C.T. Elias leg./ Alótipo Pythonides nides Mielke \& Casagrande, 2002/ DZ 5.603/. UFPC.

Parátipos. Dois machos 18-XI-1971, 18-III-1976, Itaguaçu, Espírito Santo, Brasil, C. Elias leg., DZ 5.604, 5.607; 2 machos 26-IX-1968, Conceição da Barra, Espírito Santo, Brasil, C. \& C.T. Elias leg., DZ 5.608, 5.609; 3 machos 25-IV-1970, 1 macho 26-X-1970, 1 fêmea 4-VI-1971 Baixo Guandu, Espírito Santo, Brasil, DZ 5.610-5.614; 1 macho 27-IX-1974, Linhares, Espírito Santo, Brasil, C. Elias leg., DZ. 5.606; 1 macho 6-IV-1970, Aimorés, Minas Gerais, C. Elias leg., DZ 5.605. UFPC.

Etimologia. Nome criado com as últimas letras do gênero Pythonides. 


\section{Quadrus jacobus (Plötz, 1884), comb. nov.}

Tagiades jacobus Plötz, 1884. Jahrb. nass. Ver. Nat., Wiesbaden, 37: 45; [holótipo] n 5.916, Rio [de Janeiro, Brasil]; Mus. Berol.

Eracon jacobus; Evans, 1953. Cat. Amer. Hesp. 3, p. 36.

Quadrus zolus Mielke, 1968. Jour. Lep. Soc. 22: 5, figs 5, 6 (macho d, v), 38-41 (gen. masc.), 42 (gen. fem.); holótipo macho, 21-II-1966, Jardim Zoológico, Brasília, Distrito Federal, Brasil, Mielke leg.; UFPC-OM; syn. nov.

Os exames do síntipo fêmea de $T$. jacobus, aqui designado LECTÓTIPO, possuindo as seguintes etiquetas: / Type/ Rio. v. Lgsdf/ 5916/ - ZMHU, e do holótipo de $Q$. zolus mostraram a sinonímia. Esta espécie nunca foi mencionada no gênero Quadrus Lindsey, 1925 e Evans (1953) a incluiu em Eracon Godman \& Salvin, 1894. O lectótipo é designado para garantir a identificação da espécie.

\section{Hesperiinae (Latreille, 1809) Doherty, 1886}

\section{Anthoptus epictetus (Fabricius, 1793)}

Hesperia epictetus Fabricius, 1793. Ent. Syst. 3, p. 330; Indiis; Dom. Jones (Jon. fig. pict. 6. tab.75. fig. 3.

Cobalus nigritulus Mabille, 1883. Ann. Soc. ent. Belg. 27, C.R., p. 62; Panama, Brasil; coleção Mabille; syn. nov.

Os exames do síntipo macho de $H$. epictetus, aqui designado LECTÓTIPO, possuindo a seguinte etiqueta: / epictetus/ - ZMUC, e do síntipo fêmea de $C$. nigritulus, aqui designado LECTÓTIPO, possuindo as seguintes etiquetas: /Origin./ B.C.A. Lep. Rhop. Mnestheus simplicissimus, H.-S./P. b. 87: 2/909/Cob. nigritulus Mab./ Coll. Staudinger/ Merida Hahnel/ - ZMHU, mostraram a sinonímia. A procedência não coincide com a mencionada na descrição original, no entanto, como este exemplar possui rótulos de "Origin." e "Cob. nigritulus", este com a letra de Mabille, deve ser mesmo um dos síntipos. EvANS (1955) menciona C. nigritulus na sinonímia de Nastra insignis, atualmente uma espécie de Anthoptus Bell, 1942. Os lectótipos são designados para garantir a identificação da espécie.

\section{Argon lota (Hewitson, 1877), comb. nov.}

Hesperia lota Hewitson, 1877. Ann. \& Mag. Nat. Hist. (4) 19: 81; sem dados; coleção Staudinger.

Pamphila cerymicoides Burmeister, 1878 (Berg. in litt.). Descr. phys. Rép. Arg. 5, p. 276; Atlas (1879), pl. 9, fig. 10 (d, v); Missiones de la Provincia de Corrientes, Argentina; syn. nov.

Carystus argus Möschler, 1879. Verh. zool.-bot. Ges. Wien 28 (1878): 212; 1 macho [holótipo], Colombia; syn. nov.

Carystoides lota; Evans, 1955. Cat. Amer. Hesp. 4, p. 249, pl. 71 (gen. masc.); syn.: alda.

Os exames de um síntipo fêmea de $H$. lota, aqui designado LECTÓTIPO, possuindo as seguintes etiquetas: / Typus/ Lota Hew./ 123:1/ Coll. Staudinger/ ZMHU, de um síntipo fêmea de $P$. cerymicoides, aqui designado LECTÓTIPO,

Figs 17-28. (17-20) Pythonides nides: (17-18) holótipo macho, faces dorsal e ventral; (19-20) alótipo fêmea, faces dorsal e ventral; (21-24) Carystoides ploetzi: (21-22) holótipo macho, faces dorsal e ventral; (23-24) alótipo fêmea, faces dorsal e ventral; (25-28) Zenis jebus beckeri: (25-26) holótipo macho, faces dorsal e ventral; (27-28) alótipo fêmea, faces dorsal e ventral. 

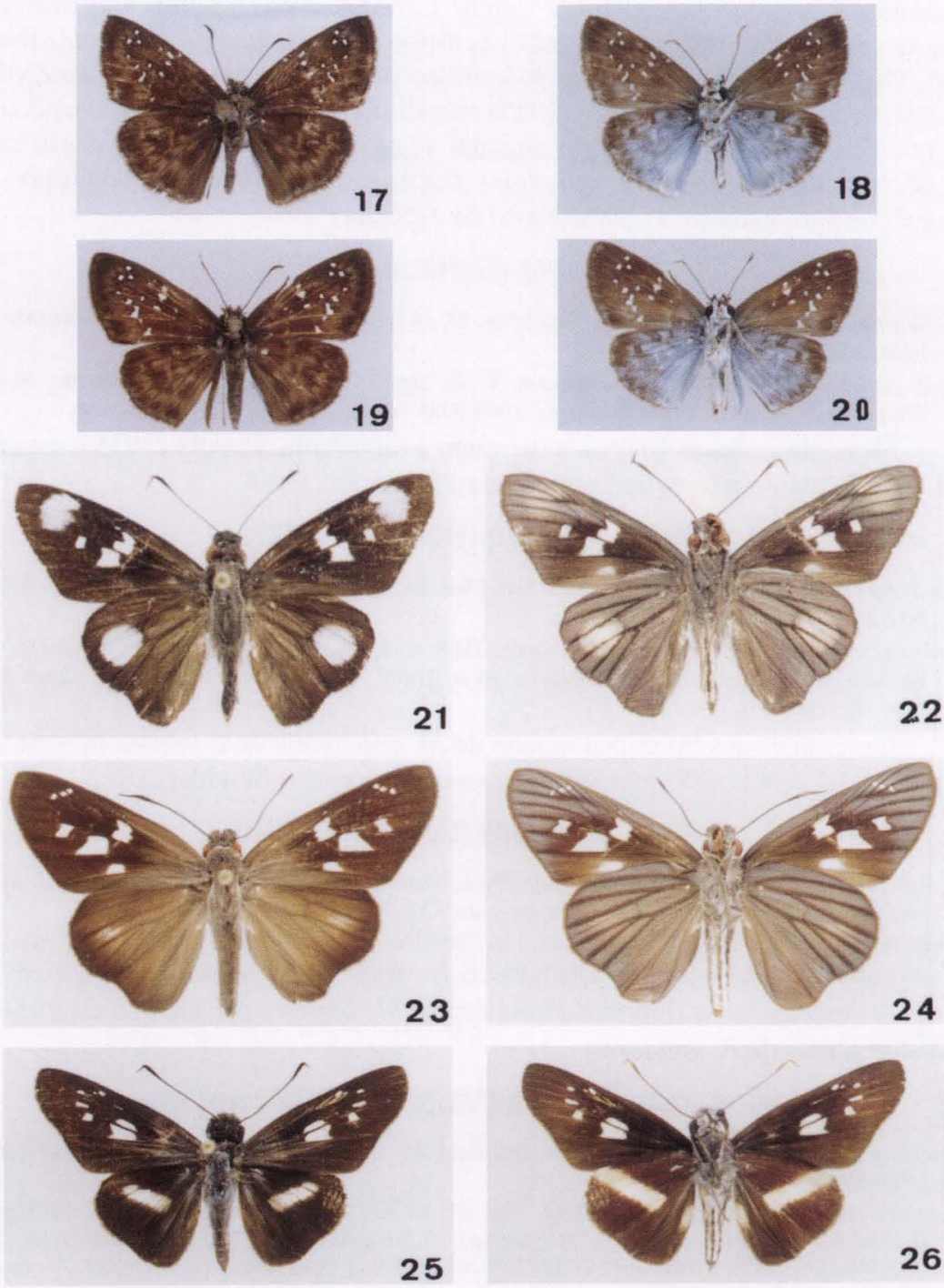

25
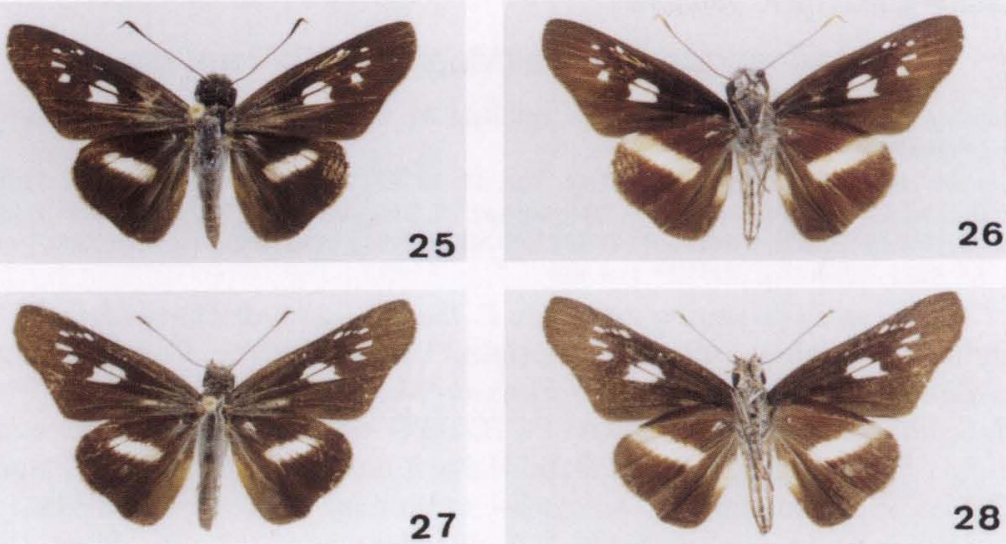

Revta bras. Zool. 19 (Supl. 1): 27 - 76, 2002 
possuindo as seguintes etiquetas: / Typus/ Cobalus argus Mschlr. Hayward det./ Misiones./ Col. Antigua./ Lectotypus/ Lectótipo de Pamphila cerymicoides Burm., 1878, Mielke det. 1970/ - MBR, e do holótipo de C. argus, depositado no ZMHU, mostraram a sinonímia. EVANS (1955) menciona $H$. lota como uma espécie de Carystoides Godman, 1901, e, por enganar-se nas datas, menciona C. argus como a espécie válida, com $P$. cerymicoides como seu sinônimo. Os lectótipos são designados para garantir a identificação da espécie.

\section{Arita arita (Schaus, 1902)}

Cobalus arita Schaus, 1902. Proc. U.S. Nat. Mus. 24: 441; [holó]tipo $\mathrm{n}^{\circ} 6.010$, Trinidad, British West Indies; USNM.

Tigasis akuris Bell, 1942. Bol. Ent. venezol. 1: 75, fig. 3 (gen. masc.); holótipo macho, X-1940, Akuriman, Venezuela; AMNH.- Evans, 1955. Cat. Amer. Hesp. 4, p. 174; syn. nov.

Os exames dos holótipos mostraram a sinonímia. EvANS (1955), seguindo Bell (1942), mantém a segunda em Tigasis Godman, 1900.

\section{Arita polistion (Schaus, 1902)}

Megistias polistion Schaus, 1902. Proc. U.S. Nat. Mus. 24: 450; [holó]tipo n ${ }^{\circ}$.041, Petropolis, [Estado do Rio de Janeoro], Brasil; USNM.

Lerodea remea Bell, 1941. Amer. Mus. Novit. 1125: 6, fig. 12 (gen. masc.); holótipo macho, New Bremen [atualmente Dalbérgia], Santa Catarina, Brasil; AMNH.- Evans, 1955. Cat. Amer. Hesp. 4, p. 396; syn. nov.

Os exames dos holótipos macho de $M$. polistion e de $L$. remea mostraram a sinonímia. Evans (1955) mantém L. remea em Lerodea Scudder, 1872.

\section{Arotis pandora (Lindsey, 1925)}

Pereneia pandora Lindsey, 1925. Denis. Univ. Bull., Jour. Sc. Lab. 21: 197, pl. 19, fig. 6 (gen. masc.); holótipo macho, 1-VII- 1920, El Campamiento, Col. Perene, Peru; CU.

Mnasitheus similis de Jong, 1983. Tijd. Ent. 126: 245, 256, figs 20 (venação), 21, 22 (gen. masc.), 59, 60 (macho d, v); holótipo macho, Suriname, E. H. Jonkers leg.; Rijksmus. Leiden; syn. nov.

A descrição e as figuras do holótipo de $M$. similis sugerem que esta seja um sinônimo junior de $P$. pandora.

\section{Atalopedes flaveola (Mabille, 1891), sp. rev.}

Pamphila flaveola Mabille, 1891. Ann. Soc. ent. Belg. 35, C.R., p. 184; macho, fêmea, Porto Cabello, [Venezuela].

Atalopedes clarkei Burns, 1989. Jour. Lep. Soc. 43: 12, 13, 18, 19, 21, 25, 27, 29, 30, 31, figs 3, 4 (macho d, v), 13, 14 (fêmea d, v), 20 (estigma), 26, 27 (gen. masc.), 36, 37 (gen. fem.), 42, 43 (v), 44 (biótopo); holótipo macho, 12-II-1985, El Morro, Margarita Island, Nueva Esparta, Venezuela, J.F. Gates Clarke leg.; USNM; syn. nov.

Os exames do síntipo macho de $P$. flaveola, aqui designado LECTÓTIPO, possuindo as seguintes etiquetas: / Origin./ Lectotypus/ Pto. Cabello, Hahnel/ P. flaveola Mab. $\sigma^{x} /$ Coll. Staudinger/ Flaveola Mab./ - ZMHU, do síntipo fêmea de $P$. flaveola, aqui designado PARALECTÓTIPO, possuindo as seguintes etiquetas: / Origin./ Paralectotypus/ Pto. Cabello Hahnel/ flaveola Mab. + / Coll. Staudinger/ - ZMHU, e do holótipo de A. clarkei mostraram a sinonímia. Evans (1955) menciona $P$. flaveola na sinonímia de Atalopedes campestris (Boisduval, 1852). O lectótipo é designado para garantir a identificação da espécie. 
coleção H. Ebert, DZ 5.111 (UFPC); 1 macho, VII-1996, 1 macho V-1997, Tingo Maria, Huánuco, Peru, M. Büche leg., OM 43.238, OM 48851 (UFPC-OM).

Etimologia. O nome específico é em homenagem ao autor de muitas espécies de Hesperiidae neotropicais, Carl Plötz.
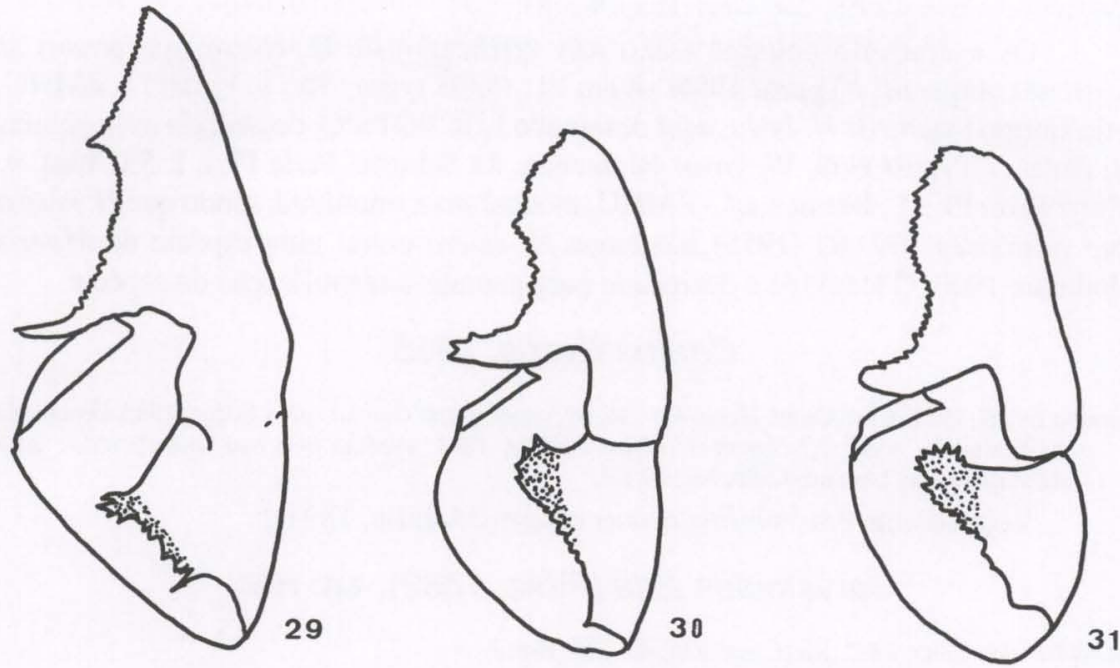

Figs 29-31. Vistas internas das valvas direitas. (29) Sarbia curitiba, UFPC 4.262; (30) Sarbia oneka, UFPC-OM 13.128; (31) Sarbia soza, UFPC 2.431.

\section{Chalcone briquenydan briquenydan (Weeks, 1901), sp. rev., comb. nov.}

Pamphila briquenydan Weeks, 1901. Proc. N. England Zool. Club 2: 87; 5-IV-1899, near La Paz, Bolívia.

Chalcone chalcone corta Evans, 1955. Cat. Amer. Hesp. 4, p. 371, pl. 81 (gen. masc.); holótipo macho, La Paz, Yungas, Bolívia, 1000 m; BM (NH); syn. nov.

Thoon briquenydan; Evans, 1955. Cat. Amer. Hesp. 4, p. 194.

Os exames do síntipo fêmea de $P$. briquenydan, aqui designado LECTÓTIPO, possuindo as seguintes etiquetas: / La Paz, Bolivia, APRIL 5, 1899, COLL. A. G. Weeks, JR./ M.C.Z. Type 16713/ Pamphila briquenydan Weeks Holotype/ MCZ, e do holótipo de C. c. corta mostraram a sinonímia. EvANS (1955) a menciona como uma espécie de Thoon Godman, 1900. O lectótipo é designado para garantir a identificação da espécie.

\section{Chalcone briquenydan chalcone (Schaus, 1902), comb. nov., stat. nov.}

Augiades chalcone Schaus, 1902. Proc. U.S. Nat. Mus. 24: 437; [holó]tipo macho, $n^{\circ} 6.000$, Petrópolis,

[Estado do Rio de Janeiro], Brasil; USNM.

Chalcone chalcone chalcone; Evans, 1955. Cat. Amer. Hesp. 4, p. 371, pl. 81 (gen. masc.); syn.: turbis.

O nome da espécie sendo Chalcone briquenydan, A. chalcone passa a ser uma de suas subespécies. EvANS (1955) a menciona como Chalcone chalcone chalcone. 


\section{Callimormus rivera (Plötz, 1882), comb. nov.}

Hesperia rivera Plötz, 1882. Stett. ent. Ztg. 43: 318; [holó]tipo n 5.305, Rio [de Janeiro, Brasil]; Mus. Berol.

Hesperia beda Plötz, 1886. Stett. ent. Ztg. 47: 90; Blumenau, [Santa Catarina, Brasil]; syn. nov. Moeris rivera; Evans, 1955. Cat. Amer. Hesp. 4, p. 33.

Os exames do holótipo (sexo não verificado) de $H$. rivera que possui as seguintes etiquetas: / Typus/ 5305/ rivera Pl., (5305 type) / Rio v. Lgdsf./ - ZMHU, e do síntipo macho de $H$. beda, aqui designado LECTÓTIPO, possuindo as seguintes etiquetas: / Typus/ Coll. Weymer/ Blumenau, 81 Schultz/ Beda Pl. i. 1. 531 best. v. Plötz/ Beda Pl. i. l., Blumenau/ - ZMHU, mostraram a sinonímia, sendo que $H$. rivera tem prioridade. EVANS (1955) menciona $H$. rivera como uma espécie de Moeris Godman, 1900. O lectótipo é designado para garantir a identificação da espécie.

\section{Cantha Evans, 1955}

Cantha Evans, 1955. Cat. Amer. Hesp. 4, p. 46, 69; espécie tipo Cantha calva Evans, 1955; designada originalmente como [Cyclopides] celeus Mabille, 1891, espécie tipo mal identificada e aqui substituida com base no ICZN, Art. 70.3.2.

Veja adiante em Vehilius celeus celeus (Mabille, 1891).

Carystoides alda (Plötz, 1882), sp. rev.

Hesperia alda Plötz, 1882. Stett. ent. Ztg. 43: 326; Brasil.

Evans (1955) menciona esta espécie como Carystoides lota, com H. alda como seu sinônimo, no entanto, aquela pertence ao gênero Argon Evans, 1955. Assim sendo, $H$. alda passa a ser o nome da espécie. Nenhum síntipo desta foi encontrado nos museus mencionados no início.

\section{Carystus ploetzi Mielke \& Casagrande, sp. nov. \\ Figs 21-24}

Carystus senex; Evans, 1955. Cat. Amer. Hesp. 4, p. 235, pl. pl. 70 (gen. masc.).

Tendo em vista que Carystus senex; Evans, 1955 é um lapso de identificação, pois Hesperia senex Plötz, 1882 é um sinônimo novo de Panoquina peraea (Hewitson, 1866) (veja adiante), aquele é aqui descrito como uma espécie nova. A descrição de EVANS (1955) caracteriza bem a espécie.

Holótipo macho com as seguintes etiquetas: /Holotipo/ X-1981, Rio Arapiuns, Pa[rá, Brasil], Kesselring leg./ OM 52.063/ Holótipo Carystus ploetzi Mielke \& Casagrande, 2002/ - UFPC-OM; Alótipo fêmea com as seguintes etiquetas/ Alotipo/ Iquitos, [Loreto] Peru/ OM 49.883/ Alótipo Carystus ploetzi Mielke \& Casagrande, 2002/ - UFPC-OM.

Parátipos. Um macho, Óbidos, Pará, Brasil, OM 8.741; 1 mach V-1960, Pará, Brasil, A. Miles Moss leg., ex coleção BM (NH), DZ 5.86 (UFPC); 1 macho, Pará, Brasil, A. Miles Moss leg., ex coleção BM (NH), DZ 5.076 (UFPC); 1 macho, 1-VI-1942, Rio Itacoahy, Benjamin Constant, Amazonas, Brasil, A. Parko leg., ex col. Gagarin, OM 11.301 (UFPC-OM); 1 fêmea, 29-IV-1972, Quellgebiet [área de nascente] des [do] Rio Juruá, Cruzeiro do Sul, Acre, 200 m, [coletor ilegível], ex 


\section{Chalcone briquenydan australis Mielke, 1980, comb. nov.}

Chalcone chalcone australis Mielke, 1980. Acta biol. paranaense 8-9: 150, figs 72-75 (macho, fêmea d, v); holótipo macho n ${ }^{1.595,18-I-1961, ~ P e l o t a s, ~ R i o ~ G r a n d e ~ d o ~ S u l, ~ B r a s i l, ~ B i e z a n k o ~ l e g . ; ~ U F P C . ~}$

O nome da espécie sendo Chalcone briquenydan, A. c. autralis passa a ser uma de suas subespécies.

\section{Chalcone tania (Schaus, 1902)}

Augiades tania Schaus, 1902. Proc. U.S. Nat. Mus. 24: 438; [holótipo] macho $\mathrm{n}^{\circ}$ 6.002, Petopolis,

[Estado do Rio de Janeiro], Brasil; USNM.

Augiades anita Schaus, 1902. Proc. U.S. Nat. Mus. 24: 438; [holótipo macho], $\mathrm{n}^{\circ}$ 6.001, Petropolis,

[Estado do Rio de Janeiro], Brasil; USNM; syn. nov.

Chalcone tania; Evans, 1955. Cat. Amer. Hesp. 4, p. 372, pl. 81 (gen. masc.).

Os exames dos holótipos de A. tania e A. anita mostraram a sinonímia; em A. anita a faixa discal da face ventral da asa posterior está bem desenvolvida, enquanto que em A. tania está somente indicada. EvANS (1955) sinonimiza A. anita com Metron fasciata (Möschler, 1877).

\section{Cobalopsis nero (Herrich-Schäffer, 1869)}

Cobalus nero Herrich-Schäffer, 1869. Corr.-Blatt zool.-min. Ver, Regensburg 23: 201; sem dados.

Cobalus zetus Bell, 1942. An. Esc. Nac. Cienc. Biol., Mexico, 2 (4): 465, fig. 8 (gen. masc.); holótipo $\mathrm{n}^{\circ} 3.502$, macho, dezembro, Guerrero, Mexico, R. Müller leg.; coleção Escola Nacional de Ciencias Biológicas, Mexico; syn. nov.

O exame do holótipo de $C$. zetus, depositado no $\mathrm{AMNH}$, mostrou ser um sinônimo junior de $C$. nero.

\section{Cobalopsis hazarma (Hewitson, 1877), sp. rev., comb. nov.}

Hesperia hazarma Hewitson, 1877. Ann. \& Mag. Nat. Hist. (4) 19: 84; sem dados; coleção Staudinger. Megistias sancoya Schaus, 1902. Proc. U.S. Nat. Mus. 24: 452; [holótipo] macho, ${ }^{\circ}$ 6.048, Petropolis,

[Estado do Rio de Janeiro], Brasil; USNM; syn. nov.

Cobalopsis sancoya; C. Mielke, 1995. Revta bras. Zool. 11: 764; syn.: gisparoides, olivacea, prospa.

Os exames do síntipo fêmea de $H$. hazarma, aqui designado LECTÓTIPO, possuindo as seguintes etiquetas: / Typus/ Hazarma/Hazarma Hew./Coll. Sommer/ Coll. Staudinger/ - ZMHU, e do holótipo de $M$. sancoya mostraram a sinonímia. EVANS $(1955,1956)$ menciona $H$. hazarma na sinonímia de Cymaenes tripuncata alumna (Butler, 1877) e M. sancoya como uma espécie de Cymaenes Scudder, 1872. C. MielKe (1995) já informou sobre outros sinônimos de $M$. sancoya. O lectótipo é designado para garantir a identificação da espécie.

\section{Cobalopsis miaba (Schaus, 1902)}

Megistias miaba Schaus, 1902. Proc. U.S. Nat. Mus. 24: 450; [holótipo], ${ }^{\circ}$ 6.043, sem dados; USNM. Megistias vegrandis Hayward, 1934. Rev. Soc. ent. arg. 6: 162, pls 11, fig. 6(d), 18, fig. 13 (gen. masc.); holótipo macho, Misiones, Argentina; coleção Breyer; syn. nov.

Cymaenes vegrandis; Evans, 1955. Cat. Amer. Hesp. 4, p. 137.

Os exames dos holótipos mostraram a sinonímia. EvaNs (1955) menciona M. vegrandis como uma espécie de Cymaenes Scudder, 1872. A coleção Breyer está no MLP. 


\section{Copaeodes jean favor Evans, 1955}

Copaeodes jean favor Evans, 1955. Cat. Amer. Hesp. 4, p. 309; [holó]tipo macho, Castro, Paraná, [Brasil], E. D. Jones leg.; BM (NH).

Ancyloxypha melanoneura orientalis Hayward, 1967. Acta zool. lill. 21: 17; holótipo fêmea, Misiones, Argentina; syn.: melanoneura; Hayward; IML; syn. nov.

Os exames dos holótipos de C. $j$. favor e A. $m$. orientalis mostraram a sinonímia.

\section{Corticea mendica schwarzi (Bell, 1941)}

Lerodea schwarzi Bell, 1941. Amer. Mus. Novit. 1125: 4, fig. 11 (gen. masc.); holótipo macho, near Cali, Western Cordillera, Colombia; AMNH.

Lento muska Evans, 1955. Cat. Amer. Hesp. 4, p. 59, pl. 57 (gen. masc.); [holó]tipo macho, 3-III-1944, Cali, Colombia, 5000 ft., C. B. Williams leg.; BM (NH); syn. nov.

Os exames dos holótipos de L. schwarzi e L. muska mostraram a sinonímia.

\section{Corticea rivula (Mabille, 1891), sp. rev., comb. nov.}

Pamphila rivula Mabille, 1891. Ann. Soc. ent. Belg. 35, C.R., p. 185; Teffé, [Amazonas, Brasil]. Mellana rivula rivula; Evans, 1955. Cat. Amer. Hesp. 4, p. 360. (sem gênero) rivula; Burns, 1994. Jour. Lep. Soc. 48: 301.

O exame do síntipo de $P$. rivula, aqui designado LECTÓTIPO, possuindo as seguintes etiquetas: / Origin./ Teffé Hhnl. [Hahnel]/ Rivula Mab./ Pamphila rivula Mab./ Coll. Staudinger/ - ZMHU, mostrou ser uma espécie de Corticea Evans, 1955, razão de sua revalidação. EVANS (1955) a menciona como uma espécie de Mellana Hayward, 1948 e BuRNS (1994) desconhece o gênero. O lectótipo é designado para garantir a identificação da espécie.

\section{Cymaenes perloides (Plötz, 1882)}

Hesperia perloides Plötz, 1882 (Prittwitz in litt.). Stett. ent. Ztg. 43: 318; Brasil.

Megistias vanilia Schaus, 1902. Proc. U.S. Nat. Mus. 24: 451; [holó]tipo ${ }^{\circ}$ 6.045, Petropolis, [Estado do Rio de Janeiro], Brasil; USNM; syn. nov.

O exame do holótipo de $M$. vanilia mostrou ser um sinônimo de $H$. perloides.

\section{Cymaenes tripunctata tripunctata (Latreille, [1824])}

Hesperia tripunctata Latreille, [1824], in: Latreille \& Godart. Enc. Méth. 9, p. 752; Brasil; coleção Latreille.

Eutychide astiga Schaus, 1902. Proc. U.S. Nat. Mus. 24: 441; macho, Castro, Parana; Petropolis, [Estado do Rio de Janeiro], Brasil; [holó]tipo ${ }^{\circ}{ }^{\circ} 6.011$; USNM; syn. nov.

Os exames do síntipo de $H$. tripunctata, aqui designado LECTÓTIPO, possuindo as seguintes etiquetas:/ Type/ tripunctata/ Ex Musaeo Dr. Boisduval/ R. Oberthür Coll. Brit. Mus. 1931-136/ - BM (NH), e do holótipo de E. astiga de Castro, Paraná, Brasil, mostraram a sinonímia. O lectótipo é designado para garantir a identificação da espécie. 


\section{Cynea anthracinus holomelas (Mabille, 1891), comb. nov., stat. nov.}

Pamphila holomelas Mabille, 1891. Ann. Soc. ent. Belg. 35, C.R., p. 169; macho, Pebas, [Peru].

Rhinthon luctatius Schaus, 1913. Proc. zool. Soc. London 24: 361, pl. 54, fig. 9 (d, v); macho, Guapiles,

Costa Rica e Santa Rosa, [Veracruz], Mexico; BM (NH); syn. nov.

Cynea anthracinus luctatius; Evans, 1955. Cat. Amer. Hesp. 4, p. 275.

Euphyes holomelas; Evans, 1956. Cat. Amer. Hesp. 4, Add, p. 3.

Os exames do síntipo macho de $P$. holomelas, aqui designado LECTÓTIPO, possuindo as seguintes etiquetas: / Origin./ P. holomelas Mab./ Pamphila Holomelas Mab./ Pebas Hhl./ Coll. Staudinger/ Holomelas Mab./ - ZMHU, e do síntipo macho de $R$. luctatius de Guapiles, Costa Rica, aqui designado LECTÓTIPO - USNM, mos- traram a sinonímia. EVANS (1956) menciona $P$. holomelas como espécie de Euphyes Scudder, 1872. Os lectótipos são designados para garantir a identificação da espécie.

\section{Cynea bistrigula (Herrich-Schäffer, 1869)}

Cobalus bistrigula Herrich-Schäffer, 1869. Corr.-Blatt zool.-min. Ver. Regensburg 23: 203; sem dados.

Rhinthon bomax Schaus, 1902. Proc. U.S. Nat. Mus. 24: 442; [holó]tipo macho ${ }^{\circ}$ 6.015, Petropolis, [Estado do Rio de Janeiro], Brasil; USNM; syn. nov.

O exame do holótipo de $R$. bomax mostrou ser um sinônimo de $C$. bistrigula.

\section{Cynea robba nippa Evans, 1955}

Cynea robba nippa Evans, 1955. Cat. Amer. Hesp. 4, p. 278; [holó]tipo macho, Chapada [dos Guimarães], Mato Grosso, [Brasil], H.H. Smith leg.; BM (NH).

Cynea conta Mielke, 1968. Jour. Lep. Soc. 22: 17, figs 29, 30 (macho d, v), 92-95 (gen. masc.), 96 (estigma), holótipo macho, 25-II-1966, Fercal, Ribeirão da Contagem, Brasília, DF, Brasil, O. Mielke leg.; UFPC-OM; syn. nov.

Os exames dos holótipos mostraram a sinonímia.

\section{Damas horridus (Bell, 1940), comb. nov.}

Metiscus horridus Bell, 1940. Amer. Mus. Novit. 1094: 7, fig. 7 (gen. masc.); holótipo macho, Iquitos, Pelu; coleção Bassler no AMNH.

Enosis horridus; Evans, 1955. Cat. Amer. Hesp. 4, p. 215.

O exame do tipo mostrou ser uma espécie de Damas Godman, 1901. Evans (1955) a menciona no gênero Enosis Mabille, 1889.

\section{Enosis schausi Mielke \& Casagrande, nom. nov.}

Hesperia misera Schaus, 1902. Proc. U.S. Nat. Mus. 24: 456; [holó]tipo macho, $\mathrm{n}^{\circ}$ 6.061, Petropolis, [Estado do Rio de Janeiro], Brasil; USNM; praeocc. (Lucas, 1856).

Enosis misera; Evans, 1955. Cat. Amer. Hesp. 4, p. 217, pl. 68 (gen. masc.).

A espécie de Schaus é um homônimo de Hesperia misera Lucas, 1857, uma subespécie de Wallengrenia otho (J. E. Smith, 1787), razão do nome novo. 


\section{Enosis uza uza (Hewitson, 1877), sp. rev., comb. nov.}

Hesperia uza Hewitson, 1877. Ann. \& Mag. Nat. Hist. (4) 19: 82; sem dados; coleção Staudinger. Pamphila agassus Mabille, 1891. Ann. Soc. ent. Belg 35, C.R., p. 182; macho, Massauary [Amazonas,

Brasil]; syn. nov.

Os exames do síntipo macho de $H$. uza, aqui designado LECTÓTIPO, possuindo as seguintes etiquetas: / Typus/ uza/ Uza Hew./ Cobalus violaceus M./ Coll. H.-Sch./ Coll. Staudinger/ Coll. Staudinger [algo ilegível]/ - ZMHU, e do síntipo macho de $P$. agassus, aqui designado LECTÓTIPO, possuindo as seguintes etiquetas: / Origin./ Massauary, Hahn./ C. agassus Mab./ P. Agassus Mab./ P. agassus Mab./ Coll. Staudinger/ - ZMHU, mostraram a sinonímia. EvANS (1955) menciona $H$. uza como sinônimo de Vettius tertianus (Herrich-Schäffer, 1869). Os lectótipos são designados para garantir a identificação da espécie.

\section{Enosis uza pruinosa (Plotz, 1882), comb. nov.}

Hesperia pruinosa Plötz, 1882. Stett. ent. Ztg. 43: 320; América do Sul

Enosis agassus pruinosa; Evans, 1955. Cat. Amer. Hesp. 4, p. 214.

Em conseqüência da sinonímia anterior, $H$. pruinosa é uma subespécie de Enosis uza, razão da nova combinação. Evans (1955) a menciona como subespécie de Enosis agassus (Mabille, 1891).

\section{Euphyes cornelius cornelius (Latreille, [1824])}

Hesperia cornelius Latreille, [1824], in: Latreille \& Godart. Enc. Méth. 9, p. 722, 764; macho, Cuba. Amblyscirtes insulae-pinorum [sic] Holland, 1916. Ann. Carnegie Mus. 10: 508, pl. 31, fig. 7 (macho v - tipo), 8 (fêmea v - tipo); tipo macho 19-VII-1912 e tipo fêmea 10-VI-1910, Nueva Gerona, Isla de Pines, Cuba, Link leg.; syn. nov.

Amblyscirtes folia insulae-pinorum [sic]; Evans, 1955. Cat. Amer. Hesp. 4, p. 387.

O exame do síntipo macho de $A$. insulaepinorum, aqui designado LECTÓTIPO, possuindo as seguintes etiquetas: / insulae-pinorum Type/ July 19 1912/ Nueva Gerona, Isle of Pines G. Link, Coll/ Amblyscirtes insulae-pinorum Holland o Type, Ann. C. M. Vol. X, Pl. XXXI, fig. 7./ - CMP, mostrou ser um sinônimo junior de $H$. cornelius. EVANS (1955) menciona $A$. insulae-pinorum [sic] como uma subespécie de Amblyscirtes folia Godman, 1900. O lectótipo é designado para garantir a identificação da espécie.

\section{Eutocus vetulus vetulus (Mabille, 1883), sp. rev., comb. nov.}

Cobalus vetulus Mabille, 1883. Ann. Soc. ent. Belg. 27, C.R., p. 62; Brasil; coleção Mabille; praeocc. (Mabille, 1878).

Eutocus matildae vinda Evans, 1955. Cat. Amer. Hesp. 4, p. 97; [holó]tipo macho, V-VII-1884, Cavallo Cocha, Amazonas, Peru, M. de Mathan leg; BM (NH); syn. nov.

Vehilius vetulus vetulus; Evans, 1955. Cat. Amer. Hesp. 4, p. 141, pl. 62 (gen. masc.).

Vehilius vetustus Mielke, 1968. Rev. Bras. Biol. 28: 452; Brasil; nom.nov. pro Cobalus vetulus Mabille, 1883, praeocc.: Pamphila vetula Mabille, 1878 ; syn. nov.

MIELKE (1968), considerando o Artigo 31.2. do ICZN, considerou $C$. vetulus Mabille, 1883 um homônimo de Pamphila vetula Mabille, 1878, ambas então consideradas por EVANS (1955) como pertencentes à Vehilius Scudder, 1872, e renomeu a primeira. 
Os exames do síntipo fêmea de C. vetulus, aqui designado LECTÓTIPO, possuindo as seguintes etiquetas: /Origin./ Chiriqui [Panamá], Ribbe/ Coll. Staudinger/ Vetulus Mab. (Mab.) / Vetulus Mab./ - ZMHU, e do holótipo de E. m. vinda mostraram a sinonímia. Evans (1955) menciona C. vetulus em Vehilius Godman, 1900. A procedência Brasil do lectótipo de C. vetulus deve ser um erro, aliás já detectado por EVANS (1955), pois a menciona entre aspas. O lectótipo é designado para garantir a identificação da espécie.

Prevalece o nome $C$. vetulus, de acordo com o Artigo 59.4. do ICZN, espécie então revalidada.

\section{Eutocus vetulus matildae (Hayward, 1941), comb. nov.}

Lerodea matildae Hayward, 1941. Rev. Mus. La Plata, n. s., Zool 2: 294, fig. (gen. masc.; holótipo macho, Misiones, Argentina; coleção Hayward.

Eutocus matildae matildae; Evans, 1955. Cat. Amer. Hesp. 4, p. 97, pl. 59 (gen. masc.).

Sendo $C$. vetulus revalidado, L. matildae passa a ser uma subespécie desta. EVANS (1955) a menciona como uma espécie.

\section{Eutychide rastaca (Schaus, 1902), sp. rev.}

Cobalus rastaca Schaus, 1902. Proc. U.S. Nat. Mus. 24: 440; [holó]tipo fêmea, ${ }^{\circ}$ 6.009, Petropolis, [Estado do Rio de Janeiro], Brasil; USNM.

Eutychide angus Evans, 1955. Cat. Amer. Hesp. 4, p. 200; [holó]tipo fêmea, Petrópolis, [Estado do Rio de Janeiro, Brasil]; BM (NH); syn. nov.

Os exames dos holótipos mostraram que $E$. angus é um sinônimo junior. Evans (1955) menciona C. rastaca como sinônimo de Argon argus, um sinônimo junior de $A$. cerymicoides.

\section{Gallio carasta (Schaus, 1902), comb. nov.}

Vehilius carasta Schaus, 1902. Proc. U.S. Nat. Mus. 24: 448; [holótipo] macho, n 6.037, Petrópolis, [Estado do Rio de Janeiro], Brasil; USNM.

Stomyles gallio Mabille, 1904, in Wytsman. Gen. Ins. 17, p. 132; 1 exemplar [holótipo], Brasil; syn. nov.

Os exames dos holótipos mostraram que $S$. gallio, macho - BM (NH), é um sinônimo junior de $V$. carasta. Evans (1955) menciona $V$. carasta como uma espécie de Vehilius Godman, 1900.

\section{Halotus angellus (Plötz, 1886)}

Hesperia angellus Plötz, 1886. Stett. ent. Ztg. 47: 94; Chiriqui, [Panama], Ribbe leg. [Cauca, [Colombia] - no rótulo do tipo].

Eutychide candallariae Strand, 1921. Arch. Natg. 86A (7): 166; 1 macho [holótipo], IV-1909, Candallaria, Costa Rica; DEI; syn. nov.

Eutychide candallariae; Evans, 1955. Cat. Amer. Hesp. 4, p. 200.

Os exames do síntipo macho de $H$. angellus, aqui designado LECTÓTIPO, possuindo as seguintes etiquetas: /Original/ S.-America Caucathal/ Hesperia Angellus Plötz/ ơ Halotus angellus Pl. Cauca type/ Lectotypus Hesperia angellus Plötz, 1886. Zool. Staatssammlg. München, O. Mielke det. 1979/-ZSBS, e do holótipo 
de $E$. candallariae mostraram a sinonímia. O lectótipo de $H$. angellus não possui abdome. Evans (1955) menciona E. candallariae como uma espécie de Eutychide Godman, 1900. O lectótipo é designado para garantir a identificação da espécie.

\section{Jongiana nom. nov.}

Surina de Jong, 1983. Tijd. Ent. 126: 248, 266; tipo: Surina unica de Jong, 1983; praeocc. (Walker, 1869 [Lepidoptera]).

O nome Surina estando preocupado, propõem-se o nome Jongiana, em homenagem ao Dr. Rienk de Jong, autor de Surina.

\section{Jongiana unica (de Jong, 1983), comb. nov.}

Surina unica de Jong, 1983. Tijd. Ent. 126: 248, 266, figs 45 (venação), 6-48 (gen. masc.), 68, 69 (macho d, v); holótipo macho, Surinam, Tengberg leg.; Rijskmus. Leiden.

O nome do gênero tendo mudado, a espécie é combinada com este nome novo.

\section{Lerodea eryhrostictus (Prittwitz, 1868)}

Pirgus [sic] erythrostictus Prittwitz, 1868. Stett. ent. Ztg. 29: 186, fig. 1 (d, v, antena, venação); 1 macho [holótipo], Corcovado, [Rio de Janeiro, Estado do Rio de Janeiro, Brasil]; coleção Prittwitz.

Lerodea tesera Schaus, 1902. Proc. U.S. Nat. Mus. 24: 448; [holótipo] macho, ${ }^{\circ} 6.035$, Rio de Janeiro, Brasil; USNM; syn. nov.

Vidius tesera; Evans, 1955. Cat. Amer. Hesp. 4, p. 123, pl. 61 (gen. masc.)

Os exames dos holótipos de P. erythrostictus e L. tesera mostraram a sinonímia. Evans (1955) menciona L. tesera como uma espécie de Vidius Evans, 1955.

\section{Ludens ludens (Mabille, 1891)}

Fig. 32

Cobalus ludens Mabille, 1891. Ann. Soc. ent. Belg., C. R., p. 83; Chiriqui, [Panama]; coleção Staudinger.

Ilustra-se a valva direita da genitália masculina para comparar com L. petrovna .

Ludens petrovna (Schaus, 1902), sp. rev.

Fig. 33

Mnestheus petrovna Schaus, 1902. Proc. U.S. Nat. Mus. 24: 457; [holótipo] macho, nº 6.064, Petrópolis, [Estado do Rio de Janeiro], Brasil; USNM.

Mnestheus petrovna, mencionada por Evans (1955) como sinônima de $L$. ludens (Mabille, 1891), é uma espécie distinta. São espécies muito semelhantes, no entanto, as genitálias masculinas as separam bem; enquanto que em L. ludens a ponta da parte ventro-distal da valva possui a curvatura uniforme, em $L$. petrovna ela possui uma expansão nítida (Fig. 33), além da ponta ser também mais bem esclerotinizada.

Ludens ludens é conhecida do Panamá e provavelmente também da Guiana, Venezuela e norte do Brasil (Amazonas), como mencionado por EvANS (1955). L. petrovna ocorre no Brasil, desde o sul do Pará (Paragominas), Bahia e Minas Gerais até o litoral de Santa Catarina, em áreas de floresta. 

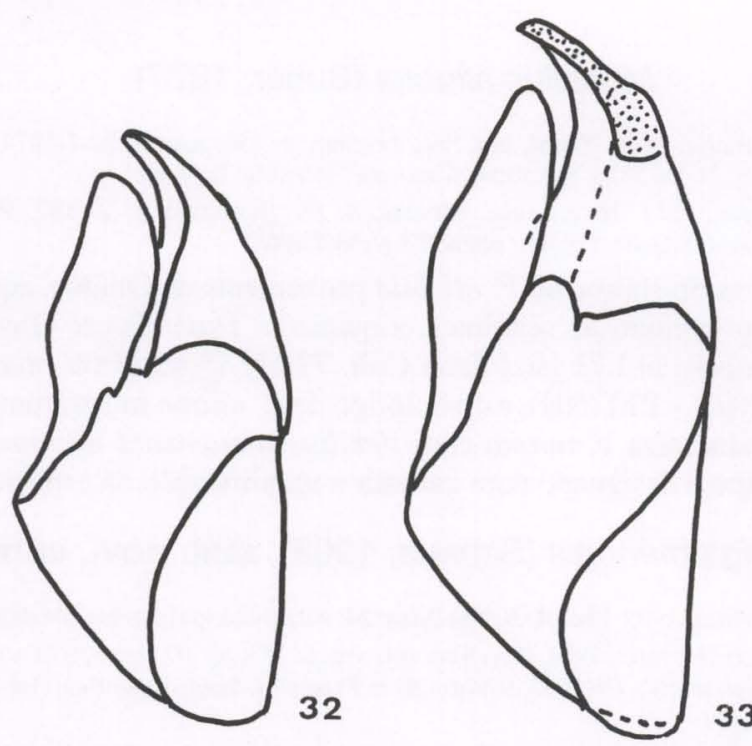

Figs 32-33. Vistas internas das valvas direitas. (32) Ludens ludens, UFPC-OM 30.227; (33) Ludens petrovna, UFPC-OM 13.312.

\section{Metron zimra (Hewitson, I-1877)}

Hesperia zimra Hewitson, I-1877. Trans. ent. Soc. London, p. 77; Brasil; coleção Hewitson.- Kirby, 1879. Cat. Coll. Diurn. Lep. Hewitson, p. 225.

Pamphila fasciata Möschler, ?-1877. Verh. zool.-bot. Ges. Wien 26: 335, pl. 4, fig. 19 (d); 1 fêmea [holótipo], interior do Suriname; coleção Möschler; syn. nov.

Metron fasciata; Evans, 1955. Cat. Amer. Hesp. 4, p. 377, pl. 8 (gen. masc.); syn.: zimra.

Metron zimra; Lamas, 1994, in Foster et al. RAP Working Paper 6: 177.

Hesperia zimra tem prioridade sobre P. fasciata, publicada após I-1877, razão da revalidação. EvANS (1955) menciona $H$. zimra como sinônimo de $P$. fasciata razão da revalidação não mencionada por LAMAS (1994).

\section{Mnasicles hicetaon Godman, 1901}

Mnasicles hicetaon Godman, 1901, in Godman \& Salvin. Biol. Centr.-Amer., Lep. Rhop. 2, p. 603; 3, pl. 103, fig. 27 (gen. masc.); 2 machos, Ciudad in Durango, Mexico, Forrer leg.; 1 macho, Vera Cruz, [Mexico], F. D. Godman leg.

Perimeles stollmeyeri Bell, 1932. Jour. N. Y. Ent. Soc. 39: 524, pl. 40, fig. 3 (gen. masc); holótipo macho, abril, Pt. of Spain (Botanical Gardens), Trinidad, B.W.I.; coleção Bell [AMNH]; syn. nov. Moeris stollmeyeri; Evans, 1955. Cat. Amer. Hesp. 4, p. 148.

Os exames do síntipo macho de Mnasicles hicetaon, aqui designado LECTÓTIPO, possuindo as seguintes etiquetas: / Type/ Type H. T./ $\sigma^{*} /$ Vera Cruz, Mexico, F.D.G./ 832/ Godman-Salvin Coll. 1913.-2./ Sp. figured/ B.C.A. Lep. Rhop. Mnasicles hicetaon, Godm./ - BM(NH) e do holótipo de P. stollmeyeri, mostraram a sinonímia. Evans (1955) menciona $P$. stollmeyeri como uma espécie de Moeris Godman, 1900. 


\section{Mnasilus allubita (Butler, 1877)}

Pamphila allubita Butler, 1877. Trans. ent. Soc. London, p. 151; macho, 24-1-1874, Obidos, [Pará, Brasil], macho, 21-IX-1874, Rio Sapó, Amazonas, [Brasil], Trail leg.

Vehilius norma Dyar, 1917. Insec. Insc. Menstr. 5: 65; [holó]tipo n 21.187, Plantation Kitty, Georgetown, Brit. Guiana; USNM; planta hosp.; syn. nov.

Os exames do síntipo de $P$. allubita proveniente de Óbidos, aqui designado LECTÓTIPO, possuindo as seguintes etiquetas: / Type/ Type/ Obydos 24/I/74/ Obydos, Amazonas, 24.I.71 [sic] Trail Coll. 77.65/ 77.65 Trail/ allubita But./ P. allubita Butl. Type/ - BM (NH), e do holótipo de $H$. norma mostraram a sinonímia. EVANS (1955) sinomiza V. norma com Vehilius stictomenes stictomenes (Butler, 1877). O lectótipo é designado para garantir a identificação da espécie.

\section{Moeris striga menopis (Schaus, 1902), stat. nov., comb. nov.}

Euphyes menopis Schaus, 1902. Proc. U.S. Nat. Mus. 24: 446; [holótipo] macho, ${ }^{\circ}{ }^{\circ} 6.030$, Peru; USNM. Phlebodes silvicultrix Hayward, 1934. Rev. Soc. ent. arg. 6: 153, pls 10, figs 5, 6 (d, v), 18, fig. 5 (gen. masc.); holótipo macho, IV-1932, Rosario de la Fronteira, Salta, Argentina, Breyer leg.; coleção Breyer; syn. nov.

Os exames dos holótipos de E. menopis e $P$. silvicultrix (MLP) mostraram a sinonímia. Evans (1955) sinonimiza E. menopis com Pompeius dares (Plötz, 1883). É a primeira vez citada em Moeris Godman, 1900, razão da nova combinação.

\section{Molo calcarea calcarea (Schaus, 1902), comb. nov.}

Padraona calcarea Schaus, 1902. Proc. U.S. Nat. Mus. 24: 454; tipos macho, fêmea, $\mathrm{n}^{\circ} 6.056$, Petropolis, [Estado do Rio de Janeiro], Brasil; USNM.

Molo menta menta Evans, 1955. Cat. Amer. Hesp. 4, p. 78, pl. 58 (gen. masc.); [holó]tipo macho, Corcovado, Rio [de Janeiro, Estado do Rio de Janeiro, Brasil]; BM (NH); syn. nov.

Anthoptus calcarea calcarea; Evans, 1955. Cat. Amer. Hesp. 4, p. 62, pl. 57 (gen. masc.).

Os exames do síntipo macho de $P$. calcarea, aqui designado LECTÓTIPO e do holótipo de Molo menta menta mostraram a sinonímia. EVANS (1955) menciona P. calcarea como uma espécie de Anthoptus Bell, 1942. O lectótipo é designado para garantir a identificação da espécie.

\section{Molo calcarea ponda Evans. 1955, comb. nov.}

Molo menta ponda Evans. 1955. Cat. Amer. Hesp. 4, p. 78; [holó]tipo macho, IX-1903, Cundinamarca, Cananche, Colombia, M. de Mathan leg.; BM (NH).

O nome da espécie sendo Molo calcarea, a subespécie descrita por EVANS passa a ser combinada com este nome.

\section{Molo visendus (Bell, 1942), comb. nov.}

Anthoptus visendus Bell, 1942. Amer. Mus. Novit. 1205: 7, fig. 12 (gen. masc.); holótipo macho, Equador; AMNH.

Anthoptus visendus; Evans, 1955. Cat. Amer. Hesp. 4, p. 62, pl. 57 (gen. masc.).

Molo petra Evans, 1955. Cat. Amer. Hesp. 4, p. 75, sem fig.; [holó]tipo macho, Bogotá, [Colombia]; $\mathrm{BM}(\mathrm{NH})$; syn. nov.

Os exames dos holótipos de $A$. visendus e $M$. petra mostraram a sinonímia. Evans (1955) menciona A. visendus como uma espécie de Anthoptus Bell, 1942. 


\section{Monca telata telata (Herrich-Schäffer, 1869)}

Cobalus telata Herrich-Schäffer, 1869. Corr.-Blatt zool.-min. Ver. Regensburg 23: 201; sem dados. Cyclopides metius Mabille, 1891. Ann. Soc. ent. Belg. 35, C.R., p. 74; macho [recte fêmea], Porto Cabello, [Venezuela]; syn. nov.

Cantha metius; Evans, 1955. Cat. Amer. Hesp. 4, p. 71.

O exame do síntipo de $C$. metius, aqui designado LECTÓTIPO, com as seguintes etiquetas: / Origin./ Coll. Staudinger/ Pto Cabello, Hahnel/ Cycl. Mettius Mab./ Cyclop. mettius Mb 336/Mettius Mab./ - ZMHU, mostrou a sinonímia. EvANS (1955) menciona $C$. metius no gênero Cantha Evans, 1955. A grafia do nome nas estiquetas é com dois " $t t$ ". O lectótipo é designado para garantir a identificação da espécie.

\section{Monca telata crispinus (Plötz, 1882), comb. nov., stat. nov.}

Hesperia crispinus V-Plötz, 1882. Stett. ent. Ztg. 43: 318; [holótipo] nº 5.306, México; Museu Berol. Hesperia tyrtaeus Plötz, XI-1882. Stett. ent. Ztg. 44: 51; Laguayra, [Venezuela]; syn. nov. Moeris crispinus; Evans, 1955. Cat. Amer. Hesp. 4, p. 148.

Os exames do holótipo macho de $H$. crispinus, possuindo as seguintes etiquetas: / Typus/ 5306/ Mexico Deppe/ crispinus Pl., 5306, type/ - ZMHU, e do síntipo macho de H. tyrtaeus, aqui designado LECTÓTIPO, possuindo as seguintes etiquetas: / 1424/ H. tyrtaeus Pl. La Guayra/ GEN. PREP. Mielke 1984/ Monca telata tyrtaeus (Plötz, 1883), O Mielke det. 1984/ - EMAU, mostraram a sinonímia. H. crispinus tem prioridade por ter sido publicado antes. EVANS (1955) menciona H. crispinus como uma espécie de Moeris Godman, 1900. O lectótipo é designado para garantir a identificação da espécie.

\section{Morys compta compta (Butler, 1877)}

Pamphila morys Butler, 1877. Trans. ent. Soc. London, p. 152; macho, fêmea, 26-II-1874, Oca, Rio Trombetas, Amazonas, [Pará, Brazil], Trail leg., 16-III-1874, Matatebem, opposite Itaituba, Amazonas, [Pará, Brazil], Trail leg., 15-IV-1874, Vila Bella, Amazonas, [Pará, Brazil], Trail leg. Hesperia leucopogon Plötz, 1882 (Becker in litt.). Stett. ent. Ztg. 43: 319; Laguayra, [Venezuela]; syn. nov.

Os exames do síntipo macho de $P$. morys, aqui designado LECTÓTIPO, possuindo as seguintes etiquetas: / Type H. 2238/77.65 Trail/ Type $P$. compta Butl./ Matatibem opp. Itaituba 16.III.74 Amazonas 77.65/ Matatibem opp. Itaituba 16/3/ 74./ P. compta Butl. type/ - BM (NH), e do síntipo macho de H. leucopogon, aqui designado LECTÓTIPO, possuindo as seguintes etiquetas: / 1421/ H. leucopogon Pl. La Guayra/ Morys compta compta (Butler, 1877) O. Mielke det. 1984/ GEN. PREP. MIELKE 1984/ - EMAU, mostraram a sinonímia. EVANS (1955) menciona H. leucopogon como sinônimo de Cynea irma (Möschler, 1879). Os lectótipos são designados para garantir a identificação da espécie.

\section{Mucia yva (Plötz, 1886)}

Hesperia yva Plötz, 1886. Stett. ent. Ztg. 47: 94; sem dados, coleçâo Möschler. Mucia yva; Evans, 1955. Cat. Amer. Hesp. 4, p. 284.

Espécie mencionada por EVANS (1955) como ocorrendo em Blumenau, Santa Catarina, Brasil, é uma espécie asiática, provavelmente um sinônimo junior de Suastus gremius (Fabricius, 1798), syn. nov. O tipo de $H$. yva foi examinado no ZMHU. 


\section{Nastra chao (Mabille, 1898)}

Pamphila chao Mabille, 1898. Ann. Soc. ent. France 66: 215; Bolívia; coleções Staudinger e Mabille. Nastra chao; Evans, 1955. Cat. Amer. Hesp. 4, p. 126, pl. 61 (gen. masc.).

Cymaenes geijskesi Jong, 1983. Tijd. Ent. 126: 244, 255, fig. 56 (macho d), 14-17 (gen. masc.); holótipo macho, 27-30-VIII- 1964, Paramaribo-Zanderij, Suriname, savanne, D. C. Geijskes leg.; Rijksmus. Leiden; syn. nov.

O exame de um dos síntipos de $P$. chao, aqui designado LECTÓTIPO, possuindo as seguintes etiquetas: / Origin./ P. chao Mab./ Coll. Staudinger/ Tanamp.[aya], Bol.[ivia], Garlepp/ - ZMHU, e da descrição de $C$. geijskesi mostraram a sinonímia. EVANS (1955) menciona um outro [sín]tipo no BM (NH) que só possui as duas asas esquerdas. O lectótipo é designado para garantir a identificação da espécie.

\section{Nastra incomptus (Hayward, 1934), comb. nov.}

Lerodea incomptus Hayward, 1934. Rev. Soc. ent. arg. 6: 127, 199, pl. 16, fig. 15 (gen. masc.); holótipo macho, Punta Lara, Argentina, Hayward leg.; coleção Breyer.-Evans, 1955. Cat. Amer. Hesp. 4, p. 395 .

Lerodea unipunctata Hayward, 1934. Rev. Soc. ent. arg. 6: 126, 199, pl. 6, fig. 15 (d); holótipo fêmea, Patquia, Prov. La Rioja, Argentina, Hayward leg.; coleção Breyer.-Evans, 1955. Cat. Amer. Hesp. 4., p. 395; syn. nov.

Lerodea uniformis Hayward, 1939. An. Soc. cient. arg. 126: 442, fig. 13 (gen. masc.); holótipo macho, Misiones, Argentina; coleção Hayward.- Evans, 1955. Cat. Amer. Hesp. 4., p. 395; syn. nov.

Os exames dos holótipos de L. incomptus - MLP, L. unipuntata-MLP e de L. uniformis - IML mostraram a sinonímia da espécie de Nastra Evans, 1955. As figuras originais da genitália masculina a caracteriza bem. EVANS (1955) as menciona como espécies de Lerodea Scudder, 1872.

\section{Nastra julia (Freeman, 1945)}

Lerodea julia Freeman, 1945. Ent. News 56: 204, fig. 1 (gen. masc.); holótipo macho, 15-X-1944, Pharr, Texas, USA; coleção Freeman.

Lerodea hoffmanni Bell, 1947. Amer. Mus. Novit. 1354: 8, fig. 10 (gen. masc.); holótipo macho, VI-1918, Colima, Mexico, C. C. Hoffmann leg.; AMNH.-Evans, 1955. Cat. Amer. Hesp. 4., p. 396; syn. nov.

Os exames dos holótipos mostraram a sinonímia. O holótipo de L. julia foi transferido para o AMNH. EVANS (1955) a menciona em Lerodea Scudder, 1872.

\section{Neoxeniades braesia andricus (Mabille, 1895)}

Proteides andricus Mabille, 1895. Bull. Soc. ent. France, p. 58; macho, fêmea, Santa Catarina, Brasil. Neoxeniades braesia andricus; Evans, 1955. Cat. Amer. Hesp. 4, p. 455.

Rhinthon cubana australis Mielke, 1970. Atas Soc. Biol. Rio de Janeiro 13: 139, figs 3-6 [nec 1, 2] (macho, fêmea d, v), 7-10 (gen. masc.), 11 (gen. fem.); holótipo macho, 3-IX-1967, Joinville, Santa Catarina, Brasil, H. Miers leg.; Departamento de Zoologia, Universidade Federal do Paraná; syn. nov.

Os exames do síntipo macho de $P$. andricus, aqui designado LECTÓTIPO, possuindo as seguintes etiquetas: / Type H. 2360/ $\mathrm{S}^{\mathrm{a}}$ Cathar. [ina]/ Pr. andricus (ina ?) Mab./ R. Oberthür Coll. Brit. Mus. 1931-136/ - BM (NH), e do holótipo de $R$. $c$. australis mostraram a sinonímia. O lectótipo é designado para garantir a identificação da espécie. 


\section{Niconiades merenda (Mabille, 1878)}

Proteides merenda Mabille, 1878. Pet. Nouv. Ent. 2: 202; Brasil; coleção Mabille.

Hesperia ulrica Plötz, 1882. Stett. ent. Ztg. 44: 48; [holótipo] n 5.231, Rio [de Janeiro], Brasil; Mus. Berol.; syn. nov.

Cynea ulrica; Evans, 1955. Cat. Amer. Hesp. 4, p. 281.

Os exames do síntipo macho de $P$. merenda, aqui designado LECTÓTIPO, possuindo as seguintes etiquetas: / Type/ Proteides brino Cram/ P. merenda Mab. $\sigma^{x}$ [letra de Mabille]/ not at all like brino fig/ R. Oberthür Coll. Brit. Mus. 1931-136/ - BM (NH), e do holótipo fêmea de $H$. ulrica - ZMHU mostraram a sinonímia. Há um outro síntipo macho, sem cabeça e abdome, de $P$. merenda, aqui designado PARALECTÓTIPO, possuindo as seguintes etiquetas: / Origin./ Merenda Mab./ Pr. merenda Mab. ơ/ Brasília Nv. Frib. [= Nova Friburgo, Estado do Rio de Janeiro]/ Coll. Staudinger Kasten 671./ Coll. Staudinger/ Merenda Mab./ - ZMHU. EvANS (1955) menciona $H$. ulrica como uma espécie de Cynea Evans, 1955. O lectótipo é designado para garantir a identificação da espécie.

\section{Panoquina lucas lucas (Fabricius, 1793)}

Hesperia lucas Fabricius, 1793. Syst. Ent. 3 (1), p. 329; America meridionalis Insulis; Dom v. Rohr. Goniloba sylvicola Herrich-Schäffer, 1865. Corr.-Blatt zool.-min. Ver. Regensburg 19: 55; Cuba. Panoquina lucas; Robbins et al., 1996, in: Wilson \& Sandoval. Manu, p. 252; syn.: sylvicola.

Embora esta sinonímia já tenha sido publicada (RoBBINS et al. 1996), ela nunca foi justificada. Os exames do síntipo macho de $H$. lucas, aqui designado LECTÓTIPO, possuindo a seguinte etiqueta: / lucas/ - ZMUC e do síntipo fêmea de G. sylvicola, aqui designado LECTÓTIPO, possuindo as seguintes etiquetas: / Origin./ Coll. Staudinger/ Coll. H.-Sch./ Sylviola HS/ Sylvicola H.-Sch./ - ZMHU, mostraram a sinonímia.

\section{Panoquina peraea (Hewitson, 1866)}

Hesperia peraea Hewitson, 1866. Trans. ent. Soc. London (3) 2: 496; Rio de Janeiro, [Brasil]; coleção Hewitson.-Bridges, 1988. Cat. Hesp. 1, p. 32, 145; 2, p. 40; syn.: californica.

Hesperia senex Plötz, 1882. Stett. ent. Ztg. 43: 449; [holótipo] n 5.318, Rio [de Janeiro, Brasil]; Mus. Berol.; syn. nov.

Prenes californica Weeks, 1902. Proc. New England Zool. Club 3: 11; 1888, "the specimen" [holótipo], Lower California, Mexico, Abbot Frazar leg.

Panoquina peraea california [sic]; Warren, 2000, in Llorente; González \& Papavero. Biod., Tax., Biogeogr. Art. Mex. 2, p. 564.

Os exames do síntipo macho de $H$. peraea, aqui designado LECTÓTIPO, possuindo as seguintes etiquetas: / Type/ Type H. T./ peraea/ Rio Hewitson Coll. 79-69 Isoteinon peraea, Hew. Type./ - BM (NH), do síntipo fêmea de H. senex, aqui designado LECTÓTIPO, possuindo as seguintes etiquetas: /Typus/ senex $\mathrm{Pl}$. 5318 type/ 5319 [sic]/ Rio, v. Lgsdf./ - ZMHU e do holótipo ("the specimen") macho de $P$. californica - MCZ, mostraram a sinonímia. $P$. californica não foi mencionada por EVANS (1955) e H. senex foi incluida por EVANS (1955) em Carystus Hübner, [1819]. A sinonímia estabelecida por BRIDGES (1988) nunca tinha sido explicada. WARREN (2000) a menciona como uma subespécie de $P$. peraea. 
Os lectótipos são designados para garantir a identificação da espécie.

Hesperia senex; Evans, 1955 não possuindo sinônimo, é descrita como Carystus ploetzi, sp. nov. (veja páginas anteriores).

\section{Papias phainis Godman, 1900}

Papias phainis Godman, 1900, in Godman \& Salvin. Biol. Centr.-Amer., Lep. Rhop. 2, p. 561; 3, pl. 100, fig. 16 (gen. masc.); macho, fêmea, Atoyac, [Veracruz, Mexico], H.H. Smith leg., Misantla, [Veracruz, Mexico], F. D. Godman leg.; San Geronimo, Guatemala, Champion leg.; Caché, Costa Rica, Rogers leg.

Lerodea unicolor Hayward, 1938. Rev. Ent., Rio de Janeiro, 9:372, fig. 4 (gen. masc.); holótipo macho, Paraguay.- Evans, 1955. Cat. Amer. Hesp. 4, p. 395; syn. nov.

Lerodea modesta Hayward, 1939. Rev. Ent., Rio de Janeiro, 11: 869, fig. 8 (gen. masc.); holótipo macho, Sucua, Equador, 900 m, M. Brown leg.- Evans, 1955. Cat. Amer. Hesp. 4, p. 396; syn. nov.

Os exames do síntipo macho de $P$. phainis, aqui designado LECTÓTIPO, possuindo as seguintes etiquetas: / Type/ $\sigma^{\approx} /$ Misantla, Mexico. Mar. 88. F. D. G./ Godman-Salvin Coll. 1914.-5./ Sp. figured/ B.C.A. Lep. Rhop. Papias phainis, Godm./ 824/ - BM (NH), e dos holótipos de L. unicolor e L. modesta - IML, mostraram a sinonímia. O lectótipo aqui designado é o mesmo exemplar mencionado por EVANS (1955) como tipo. Este mesmo autor menciona $L$. unicolor e $L$. modesta como espécies de Lerodea Scudder, 1872. O lectótipo é designado para garantir a identificação da espécie.

\section{Papias subcostulata (Herrich-Schäffer, 1870)}

Cobalus subcostulata Herrich-Schäffer, 1870. Corr.-Blatt zool.-min. Ver. Regensburg 24: 159; Brasil. Hesperia infuscata Plötz, 1882 (Hopffer in litt.). Stett. ent. Ztg. 43: 315; Brasil [Surinam - no rótulo do síntipo]; syn. nov.

Pamphila integra Mabille, 1891. Ann. Soc. ent. Belg. 35, C.R., p. 169; macho, fêmea, Honduras, Colombia; coleções Staudinger e Mabille; syn. nov.

Papias subcostulata integra; Evans, 1955. Cat. Amer. Hesp. 4, p. 157.

Enosis angularis infuscata; Evans, 1955. Cat. Amer. Hesp. 4, p. 216, pl. 68 (gen. masc.).

Os exames do síntipo macho de $H$. infuscata, aqui designado LECTÓTIPO, possuindo as seguintes etiquetas:/ Origin./ B.C.A. Lep. Rhop., Papias infuscatus, Plotz/ 897/ Infuscata Plötz/ Coll. Möschl./ Surinam, Bgdl., [ilegível] 76/ Verh. z. b. Ges: Wien, 1882, p. 325. Plötz. Stett. ent. Ztg. 1882. p. 315. no: 8/ Coll. Staudinger/ - ZMHU, e do síntipo macho de $P$. integra proveniente de Honduras, aqui designado LECTÓTIPO, possuindo as seguintes etiquetas: / Origin./ Honduras, 88. Wittk./P. integra Mab. + /Coll. Staudinger/ 894/ B.C.A. Lep. Rhop. Papias infuscatus, Plotz/-ZMHU, mostraram a sinonímia. Não foram encontrados síntipos de $C$. subcostulata no ZMHU, onde está a coleção de Herrich-Schäffer. EvANS (1955) menciona $H$. infuscata como uma subespécie de Enosis angularis (Möschler, 1877) e P. integra como uma subespécie de Papias subcostulata. Os lectótipos são designados para garantir a identificação da espécie. 


\section{Paratrytone gala (Godman, 1900), sp. rev., comb. nov.}

Atrytone gala Godman, 1900, in Godman \& Salvin. Biol. Centr.-Amer., Lep. Rhop. 2, p. 495; 3, pl. 94, figs 35, 36 (macho d, v); 1 macho [holótipo], Las Vigas, [Veracruz], México, coleção Schaus.

O holótipo no USNM mostra ser uma espécie de Paratrytone Godman, 1900; razão da nova combinação. EVANS (1955) a menciona na sinonímia de Mellana monica (Plötz, 1886), este um sinônimo de Quasimellana nicomedes (Mabille, 1883).

\section{Pararytone raspa Evans, 1955}

Librita raspa Evans, 1955. Cat. Amer. Hesp. 4, p. 361; [holó]tipo fêmea, Zamora, Equador, 3500 ft., O.T. Baron leg.; BM (NH).

Paratrytone miahua Steinhauser, 1996. Bull. Allyn Mus. 141: 4, figs 5-8 (macho, fêmea d, v), 13 (gen. masc.), 14 (gen. fem.); holótipo macho, 27-VIII-1989, 8 mi S. of Miahuatlan, Oaxaca, México, 7200 ft., John Kemner leg.; AME; syn. nov.

Segundo informação do Dr. Andrew Warren, $P$. miahua é um sinônimo junior de L. raspa, sendo a procedência correta desta Guerrero, México.

\section{Parphorus fartuga (Schaus, 1902)}

Phlebodes fartuga Schaus, 1902. Proc. U.S. Nat. Mus. 24: 445; [holótipo] macho, $\mathrm{n}^{\circ} 6.024$, Nova Friburgo, [Estado do Rio de Janeiro], Brasil; USNM.

Parphorus nemorus Bell, 1941. Amer. Mus. Novit. 1145: 6, fig. 13 (gen. masc.); holótipo macho, Nova Bremen [atual Dalbérgia], Santa Catarina, Brasil; AMNH; syn. nov.

Tigasis altona Evans, 1955. Cat. Amer. Hesp. 4, p. 176, pl. 65 (gen. masc.); [holó]tipo macho, Alto da Serra, [Paranapiacaba], São Paulo, [Brasil], R. Spitz leg.; BM (NH); syn. nov.

Os exames dos holótipos das três espécies mostraram a sinonímia. EVANS (1955) menciona $P$. fartuga na sinonímia de Parphorus decora (Herrich-Schäffer, 1969).

\section{Peba verames (Schaus, 1902)}

Callimormus verames Schaus, 1902. Proc. U.S. Nat. Mus. 24: 456; [hol6] tipo n ${ }^{\circ} 6.063$, Peru; USNM. Peba striata Mielke, 1968. Jour. Lep. Soc. 22: 9, figs 13, 14 (macho d, v), 54 (estigma), 55-58 (gen. masc.), 59 (gen. fem.); holótipo macho, 27-II-1966, Paraopeba, Minas Gerais, Brasil, O. Mielke leg.; UFPC-OM; syn. nov.

Os exames dos holótipos mostraram a sinonímia.

\section{Penicula subviridis (Plötz, 1886), comb. nov.}

Hesperia subviridis Plötz, 1886. Stett. ent. Ztg. 47: 97; São Paulo, [Brasil], Ribbe leg.- Evans, 1955.

Cat. Amer. Hesp. 4, p. 473; transfere para a região oriental: Ceilão.

Caltoris philippina; Evans, 1957. Ann. \& Mag. Nat. Hist. (12) 9: 752; part. syn.: Hesperia subviridis.

O síntipo fêmea de $H$. subviridis, aqui designado LECTÓTIPO, possuindo as seguintes etiquetas: / Original/ Hesperia subviridis $\mathrm{Plötz} / \mathrm{Brasil}$ : S. Paulo/ 우 Carystus subviridis Pl. typ. Sao Paolo/ Lectotypus Hesperia subviridis Plötz, 1886 Zool. Staatssammlg. München, O. Mielke det. 1979/ Gen. prep. Mielke, 1979/ZSM + Genitalprp. No. Rh. 896/-ZSBS, é uma espécie de Penicula Evans, bastante escassa e que ocorre no Brasil, na floresta atlântica, entre os Estados de 
São Paulo e Santa Catarina, até a altitude de 700 m. Evans (1955) a menciona como sendo uma espécie do Ceilão (= Sri Lanka). O lectótipo é designado para garantir a identificação da espécie.

\section{Pheraeus unia (Butler, 1870)}

Phlebodes unia Butler, 1870. Trans. ent. Soc. London, p. 507; St. Domingo; coleção Kaden in coll. Druce.

Pheraeus manes Steinhauser, 1991. Bull. Allyn Mus. 132: 41, figs 54, 55 (macho d, v), 92 (gen. masc.); holótipo macho, 7-8-IV- 1973. Santa Teresa, Espírito Santo, Brasil, C. Callaghan leg.; AME, transferido para o UFPC; syn. nov.

Os exames do síntipo fêmea, com abdome de macho (espécie ?) colado, de P. unia, aqui designado LECTÓTIPO, possuindo as seguintes etiquetas: / Type/ Type H. T./ St Domingo/ P. Unia Butl. type/ ㅇ with $\sigma^{x}$ body of a different species/ Druce Coll. ex Kaden Coll./ Phlebodes unia Butl. Type./ Genus ? unia Butl. Godman-Salvin Coll. 1913.-2./ San Domingo, W. Indies. Druce Coll./ - BM (NH), e do holótipo de $P$. manes mostraram a sinonímia. O lectótipo é designado para garantir a identificação da espécie.

Esta espécie foi uma incógnita por muito tempo (SMITH et al., 1994).

\section{Phlebodes sameda (Herrich-Schäffer, 1869)}

Cobalus sameda Herrich-Schäffer, 1869. Corr.-Blatt zool.-min. Ver. Regensburg 23: 202; sem dados. Euroto schmithi Bell, 1940. Amer. Mus. Novit. 1064: 5, fig. 7 (gen. masc.); holótipo macho, Hansa Humboldt [atual Corupá], Santa Catarina, Brasil; AMNH; syn. nov.

Phlebodes schmithi; Evans, 1955. Cat. Amer. Hesp. 4, p. 271, pl. 72 (gen. masc.).

Phlebodes sameda; Evans, 1955. Cat. Amer. Hesp. 4, p. 272.

Os exames do síntipo fêmea de $C$. sameda, aqui designado LECTÓTIPO, possuindo as seguintes etiquetas: / Origin./ sameda m/ 946/ Sameda H.Sch./ fehlt bei Mabille/ Coll. Staudinger/ - ZMHU, e do holótipo de E. schmithi mostraram a sinonímia. Olectótipo só possui as duas asas direitas e o tórax. EVANS (1955) menciona as duas espécies. O lectótipo é designado para garantir a identificação da espécie.

\section{Poanes zachaeus (Plötz, l-1883), sp. rev.}

Hesperia zachaeus Plötz, I-1883. Stett. ent. Ztg. 44: 209; fêmea, Suriname.

Pamphila rolla Mabille, após 7-IV-1883. Ann. Soc. ent. Belg. 27, C.R., p. 70; América da Sul; coleção Mabille; syn. nov.

Pamphila lagon Mabille, 1891. Ann. Soc. ent. Belg. 35, C.R., p. 182; macho, Cooktown, [Australia]; syn. nov.

Poanes rolla; Evans, 1955. Cat. Amer. Hesp. 4, p. 348, pl. 78 (gen. masc.); syn.: zachaeus.

Poanes rolla sendo publicada após $H$. zachaeus, esta é revalidada. O exame do síntipo macho de $P$. lagon, aqui designado LECTÓTIPO, possuindo as seguintes etiquetas: / Origin./ Pamph. lagon Mab./ P. lagon Mab./ Cooktown Queesnl.[and Australia]/ - ZMHU, mostrou a sinonímia. A procedência Cooktown é um lapso. Não foram encontrados síntipos de $H$. zachaeus. EvANS (1955) menciona $P$. zachaeus como sinônimo de $P$. rolla e $P$. lagon na sinonímia de Pompeius pompeius (Latreille, [1824]). O lectótipo é designado para garantir a identificação da espécie. 


\section{Pompeius amblyspila (Mabille, 1898)}

Pamphila amblyspila Mabille, 1898. Ann. Soc. ent. France 66: 217; 1 macho [holótipo], Tanampaya, Bolívia; coleção Staudinger.

Pamphila crassinota Mabille, 1898. Ann. Soc. ent. France 66: 217; macho, Rio Tanampaya, Bolívia; coleção Staudinger; syn. nov.

Os exames do holótipo de $P$. amblyspila - ZMHU, e do síntipo de $P$. crassinota, aqui designado LECTÓTIPO, posuindo as seguintes etiquetas: / Origin./ Rio Tanampaya, Bolivia (La Paz), 1894, Garlepp/ Coll. Staudinger/ P. crassinota Mab./ Pamphila crassinota (Mab.) n. sp./ wohl nur Amblyspila var. (Stgr.) / ZMHU, mostraram a sinonímia. EVANS (1955) menciona $P$. crassinota na sinonímia de Pompeius dares (Plötz, 1883). O lectótipo é designado para garantir a identificação da espécie.

\section{Propapias sipariana (Kaye, 1925), sp. rev., comb. nov.}

Cymaenes sipariana Kaye, 1925. Trans. ent. Soc. London (1924), p. 418; 2-IV-1922, Siparia, Trinidad, Jackson leg.; coleção Kaye.

Rhinthon proximus Bell, 1934. Amer. Mus. Novit. 745: 6, fig. 5 (gen. masc.); holótipo macho, Putumayo River region, Peru, Klug leg.; AMNH; syn. nov.

Papias proximus; Evans, 1955. Cat. Amer. Hesp. 4, p. 158, pl. 64 (gen. masc.).

Synapte infusco Nicolay, 1980. Bull. Allyn Mus. 59: 5, fig. 5 (macho, fêmea d, v), 4 (gen. masc.); holótipo macho, 14-X-1974, Bayano, Panama Province, Panama, G. B. Small leg.; AME; syn. nov.

Os exames do síntipo fêmea de C. sipariana, aqui designado LECTÓTIPO, possuindo as seguintes etiquetas: / Type/ Cymaenes sipariana Kaye/ Thargella caura Plotz + / Siparia [ilegível] Trinidad, ab 21922 [ilegível]/ - AME, e dos holótipos de $R$. proximus e $S$. infusco mostraram a sinonímia, sendo $C$. sipariana o nome mais antigo, razão da revalidação. EvANS (1955) menciona $C$. sipariana na sinonímia de Thargella caura caura (Plötz, 1882) e $R$. proximus como uma espécie de Papias Godman \& Salvin, 1900. O lectótipo é designado para garantir a identificação da espécie.

\section{Psoralis coyana (Schaus, 1902), sp. rev., comb. nov.}

Lerema coyana Schaus, 1902. Proc. U.S. Nat. Mus. 24: 453; [holó]tipo macho, $\mathrm{n}^{\circ}$ 6.052, Petrópolis,

[Estado do Rio de Janeiro], Brasil; USNM.- Evans, 1955. Cat. Amer. Hesp. 4, p. 165.

Psoralis ravus Evans, 1955. Cat. Amer. Hesp. 4, p. 174, pl. 65 (gen. masc.); [holó]tipo macho, São

Paulo, Brasil, E. D. Jones leg.; BM (NH); syn. nov.

Os exames dos holótipos mostraram a sinonímia. EVANS (1955) L. coyana como uma espécie de Lerema Scudder, 1872.

\section{Quasimellana servilius (Möschler, 1883), comb. nov.}

Apaustus servilius Möschler, 1883. Verh. zool.-bot. Ges. Wien 32: 329; 1 macho [recte fêmea, holótipo], interior do Suriname; coleção Möschler.

Mellana myron verba Evans, 1955. Cat. Amer. Hesp. 4, p. 358, pl. 79 (gen. masc.); [holó]tipo macho, Balzapamba, Equador; BM (NH); syn. nov.

Mnestheus servilius; Evans, 1955. Cat. Amer. Hesp. 4, p. 106.

Quasimellana verba; Burns, 1994. Jour. Lep. Soc. 48: 296, 298, 317, figs 105, 106 (macho d, v). 
Os exames dos holótipos de A. servilius e M. m. verba mostraram a sinonímia. O holótipo de A. servilius está no ZMHU. EvaNs (1955) menciona A. servilius como uma espécie de Mnestheus Godman, 1901 e BURNS (1994) transfere M. m. verba para o gênero Quasimellana, então estabelecido.

\section{Quinta cannae (Herrich-Schäffer, 1869)}

Cobalus cannae Herrich-Schäffer, 1869. Corr.-Blatt zool.-min. Ver. Regensburg 23: 203; sem dados. Papilio atiopides Larrañaga, 1923. Escritos Don Dámaso Antonio Larrañaga 2, p. 419; Montevideo, Uruguai; syn. nov.

Papilio atiopides é um nome completamente esquecido (nom. oblitum), pois após a sua publicação nunca mais foi usado. A descrição é muito imprecisa, mas aparentemente é um sinônimo de $Q$. cannae. Os exemplares que serviram ao livro de Larrañaga devem estar perdidos e como na descrição original não há referência aos exemplares em que se baseou a descrição, designa-se aqui um NEÓTIPO. Este é o mesmo exemplar síntipo macho de Cobalus cannae, aqui designado LECTÓTIPO, possuindo as seguintes etiquetas: /Lectotypus/ Origin./ Coll. Staudinger/ cannae m./ Coll. H.-Sch./ B.C.A. Lep. Rhop., Cobalus cannae H.-S./ - ZMHU. Há mais dois paralectótipos, aqui designados, na mesma instituição. O lectótipo e o neótipo são designados para garantir a identificação da espécie.

\section{Rhinthon cubana osca (Plötz, 1882)}

Hesperia osca Plötz, 1882. Stett. ent. Ztg. 44: 48; [holótipo] n 5219, Caracas, [Venezuela]; Mus. Berol. Proteides chiriquensis Mabille, 1889. Le Nat. (2) 3 (53): 157, fig. 1 (macho d, v); 1 macho [holótipo], Chiriqui, [Panama]; coleção Staudinger.

Proteides chiriquensis Mabille, 1889. Le Nat. (2) 3 (62): 239; Chiriqui, [Panama]; coleção Staudinger; praeocc. (Mabille, 1889); syn. nov.

MABILLE (1889) descreveu a mesma espécie duas vezes, pois as descrições são semelhantes. A segunda descrição de $P$. chiriquensis nunca mais foi mencionada na bibliografia. Os dois holótipos estão no ZMHU.

\section{Saturnus reticulata (Plötz, 1883), sp. rev.}

\section{Saturnus reticulata reticulata (Plötz, 1883), sp. rev.}

Hesperia reticulata Plötz, I-1883 (Herrich-Schäffer in litt.). Stett. ent. Ztg. 44: 208; Laguayra, Venezuela e Chiriqui, [Panama].

Saturnus tiberius reticulata; Evans, 1955. Cat. Amer. Hesp. 4, p. 268.

O nome $H$. reticulata tem prioridade sobre $A$. tiberius, razão da revalidação. Evans (1955) menciona $H$. reticulata como uma subespécie de A. tiberius, por creditar a data de 1882 para esta. Veja em Saturnus reticulata tiberius, a seguir.

Pela mesma razão, as seguintes subespécies são todas novas combinações:

\section{Saturnus reticulata conspicuus (Bell, 1941), comb. nov.}

Phlebodes tiberius race conspicuus Bell, 1941. Jour. N.Y. Ent. Soc. 49: 196; holótipo macho, Massaranduba-Blumenau, Santa Catarina, Brasil; AMNH.

Saturnus tiberius conspicuus; Evans, 1955. Cat. Amer. Hesp. 4, p. 269.

Revta bras. Zool. 19 (Supl. 1): 27 - 76, 2002 


\section{Saturnus reticulata meton (Mabille, 1891)}

Phamphila [sic] meton Mabille, 1891. An. Soc. ent. Belg. 35, C.R., p. 174; macho, Teffé, [Amazonas, Brasil].

Saturnus tiberius meton; Evans, 1955. Cat. Amer. Hesp. 4, p. 268.

Saturnus reticulata meton; Lamas, 1994, in Foster et al. RAP Working Paper 6: 177.

\section{Saturnus reticulata obscurus (Bell, 1941), comb. nov.}

Phlebodes tiberius race obscurus Bell, 1941. Jour. N.Y. Ent. Soc. 49: 197; holótipo macho, 20-II-1936,

El Volcan, Chiriqui, Panama, 4000 pés, W. J. Gertsch leg.; AMNH.

Saturnus tiberius obscurus; Evans, 1955. Cat. Amer. Hesp. 4., p. 268.

\section{Saturnus reticulata suffuscus (Hayward, 1940), comb. nov.}

Phlebodes tiberius f. suffuscus Hayward, 1940. Rev. Ent., Rio de Janeiro, 11: 875, fig. 18 (gen. masc.);

Sucua, Equador, $900 \mathrm{~m}$, M. Brown leg.

Saturnus tiberius suffuscus; Evans, 1953. Cat. Amer. Hesp. 4, p. 268.

\section{Saturnus reticulata tiberius (Möschler, 1883)}

Apaustus tiberius Möschler, III- 1883. Verh. zool.-bot. Ges. Wien 32: 329; 1 macho [holótipo], Interior do Suriname; coleção Möschler; syn. nov.

Saturnus tiberius tiberius; Evans, 1955. Cat. Amer. Hesp. 4, p. 267, 268, pl. 72 (gen. masc.).

Saturnus reticulata tiberius Lamas; Robbins \& Harvey, 1996. Rev. peruana Ent. 39: 69.

\section{Styriodes dedecora (Plötz, 1882), comb. nov.}

Hesperia dedecora Plötz, 1882. Stett. ent. Ztg. 44: 38; Laguayra, [Venezuela].

Styrioides [sic] quaka Evans, 1955. Cat. Amer. Hesp. 4, p. 211, pl. 68 (gen. masc.); [holó]tipo macho, Bolívia; BM (NH); syn. nov.

Cobalopsis dedecora; Evans, 1955. Cat. Amer. Hesp. 4, p. 158.

Os exames do síntipo macho de $H$. dedecora, aqui designado LECTÓTIPO, possuindo as seguintes etiquetas: / 1420/ H. dedecora Pl. La Guayra/ GEN. PREP. MIELKE 1984/ Styrioides quaka Evans, 1955, O. Mielke det. 1984/ - EMAU, e do holótipo de $S$. quaka mostraram a sinonímia. EvANS (1955) menciona $H$. dedecora como uma espécie de Cobalopsis Godman, 1900. O lectótipo é designado para garantir a identificação da espécie.

\section{Styriodes quadrinotata (Mabille, 1889)}

Enosis quadrinotata Mabille, 1889. Bull. Soc. ent. France (6) 9: 10; 1 macho [holótipo], Chiriqui, [Panamá]; coleção Staudinger.

Enosis inframaculata Strand, 1921. Arch. Natg. 86 (A) (7): 168; 1 macho (?) [holótipo], Costa Rica; DEI; syn. nov.

Os exames dos holótipos, ambos machos, mostraram a sinonímia. O holótipo de E. quadrinotata está no ZMHU e o de E. inframaculata está sem abdome. EvANS (1955) menciona E. inframaculata como um sinônimo de Enosis immaculata immaculata (Hewitson, 1868).

\section{Thespieus macareus (Herrich-Schäffer, 1869)}

Goniloba macareus Herrich-Schäffer, 1869. Corr.-Blatt zool.-min. Ver. Regensburg 23: 192; sem dados.

Thespieus cacajo Dyar, 1913. Proc. U.S. Nat. Mus. 44: 280; cotipos 2 machos, 1 fêmea, $\mathrm{n}^{\circ}$ 14.489, 
VIII-1906, Naranjo, Guerrero, México, 3000 pés, Schaus leg., VIII-1906, Cuernavaca, [Morelos], Mexico, Schaus leg.; USNM; syn. nov.

Os exames do síntipo macho de $G$. macareus, aqui designado LECTÓTIPO, possuindo as seguintes etiquetas: / Origin./ macareus/ Coll. H.-Sch./ 854/ Coll. Staudinger/ B.C.A. Lep. Rhop. Thespieus macareus, H.-Sch./ P. b. 57:4/ Lectotypus/ - ZMHU, e do síntipo macho de $T$. cacajo, aqui designado LECTÓTIPO, possuindo as seguintes etiquetas: /Type $\mathrm{N}^{\circ} 14.489$ U.S. N. M./ Naranjo Guerrero Mex./ Aug. 06/ 3000 Ft./ Thespieus cacajo Dyar Type/ Collection W. Schaus/, mostraram a sinonímia. Um outro síntipo de G. macareus é designado PARALECTÓTIPO - ZMHU. EvANS (1955) menciona $T$. cacajo como um sinônimo de $T$. dalman (Latreille, [1824]). Os lectótipos são designados para garantir a identificação dos taxa.

\section{Thespieus tapayuna Zikán, 1938}

Thespicus [sic] tapayuna Zikán, 1938. Rev. Ent., Rio de Janeiro, 9: 330, pl. 4, figs 1-4 (macho, fêmea d, v); 1 macho, 4 fêmeas, março, Alto Itatiaia, [Itatiaia], Estado do Rio de Janeiro, 2.200 m, J. F. Zikán leg.

Thespieus tapayuna; Evans, 1955. Cat. Amer. Hesp. 4, p. 423, pl. 84 (gen. masc.).- Mielke, 1971. Rev. Brasil. Biol. 31: 269, figs 33-36 (macho, fêmea d, v), 105 (gen. fem.); lectótipo macho, 6-II-1930, Macieiras, Parque Nacional do Itatiaia, Itatiaia, Estado do Rio de Janeiro, Brasil, 1.960 m, Zikán leg., Instituto Oswaldo Cruz.

Thespieus paula Evans, 1955. Cat. Amer. Hesp. 4, p. 423, pl. 84 (gen. masc.); [holó]tipo macho, Paranapanema, São Paulo, Brasil; BM (NH); syn. nov.

Os exames do lectótipo e do holótipo mostraram a sinonímia. Voa nos campos de altitude da mata atlântica do sul e sudeste brasileiro: Estado do Rio de Janeiro (Nova Friburgo e Itatiaia - acima de 1.600 m) e Santa Catarina (Urubici acima de $1.700 \mathrm{~m}$ ), sendo bastante escassa. Na última localidade foi vista uma fêmea ovipositando em Chusque windischii L.G. Clark (Poceaea). A procedência Paranapanema deve ser um engano, pois, além de estar localizada no oeste de São Paulo, possui uma altitude abaixo de $500 \mathrm{~m}$. Evans (1955) menciona T. tapayuna como uma espécie da Colômbia.

\section{Turesis complanula (Herrich-Schäffer, 1869)}

Goniloba complanula Herrich-Schäffer, 1869. Corr.-Blatt zool.-min. Ver. Regensburg 23: 194; sem dados.

Molo stygia Evans, 1955. Cat. Amer. Hesp. 4, p. 78, pl. 58 (gen. masc.), [holó]tipo macho, V-1932, Iquitos, [Peru], Klug leg.; BM (NH); syn. nov.

O exame do holótipo de Molo stygius mostrou a sinonímia.

Esta espécie é conhecida na literatura como Turesis lucas (Fabricius, 1793), no entanto, o exame do síntipo de Hesperia lucas, mostrou ser o sinônimo sênior de Panoquina sylvicola (Herrich-Schäffer, 1865) (RoBBINS et al. 1996). Veja em Panoquina lucas (Fabricius, 1793). O nome mais velho para a espécie é então Turesis complanula (Herrich-Schäffer, 1869) (LAMAS 1994: 176), da qual não foram encontados síntipos no ZMHU, onde está grande parte da coleção HerrichSchäffer. O lectótipo é designado para garantir a identificação da espécie. 


\section{Turmada camposa (Plötz, 1886)}

Hesperia camposa Plötz, 1886. Stett. ent. Ztg. 47: 90; Brasil.

Pyrrhopyge maravilha Foetterle, 1902. Rev. Mus. Paulista 5: 637, pl. 16 [recte 18], fig. 1 (d, v); macho, fêmea, 1-2-II-1900, Itamaraty, [Petrópolis, Estado do Rio de Janeiro, Brasil], Foetterle \& Allan leg.; syn. nov.

Os exames do síntipo fêmea de $H$. camposa, aqui designado LECTÓTIPO, possuindo as seguintes etiquetas: / 우 ? camposa Pl. typ./ Hesperia camposa Plötz/ Lectotypus Hesperia camposa Plötz, 1886, Zool. Staatssammlung München, O. Mielke det. 1979/ - ZSBS, e do síntipo macho de $P$. maravilha, aqui designado LECTÓTIPO, possuindo as seguintes etiquetas:/ Petropolis, 2/II 1900/ Pyrr. Maravilha Fttle. $\sigma^{\pi}$ Petropolis Itamaraty 2/II 1900 Type - NHMV, mostraram a sinonímia. O exemplar fêmea de $P$. maravilha é aqui designado PARALECTÓTIPO - NHMW. Os lectótipos são designados para garantir a identificação da espécie.

\section{Vehilius celeus celeus (Mabille, 1891), comb. nov.}

Cyclopides celeus Mabille, 1891. Ann. Soc. ent. Belg. 35, C.R., p. 74; macho, Villa Bella, [Pará, Brazil]. Vehilius almoneus Schaus, 1902. Proc. U.S. Nat. Mus. 24: 448; [holó]tipo $\mathrm{n}^{\circ}$ 6.036, Peru; USNM.-Evans, 1955. Cat. Amer. Hesp. 4, p. 140, pl. 62 (gen. masc.); syn. nov.

Vehilius vetus oiticicai Mielke, 1973. Acta biol. paranaense 2: 34, figs 12-15 (macho, fêmea d, v), holótipo macho, 12-II-1963, Utinga, Belém, Pará, Brasil, Mielke \& Roppa leg.; MNRJ; syn. nov. Cantha celeus celeus; Evans, 1955. Cat. Amer. Hesp. 4, p. 69.

Os exames do síntipo macho de C. celeus, aqui designado LECTÓTIPO, possuindo as seguintes etiquetas: / Origin./ Celeus Mab./ cycl. Celeus Mb./ Villa Bella, Hhl./ - ZMHU, e dos holótipos de Vehilius almoneus e de Vehilius vetus oiticicai mostraram a sinonímia. EVANS (1955) menciona C. celeus em Cantha Evans, 1955, inclusive a designando como a espécie tipo do gênero, no entanto, como é um erro de reconhecimento da espécie, Cantha calva Evans, 1955, descrita por Evans (1955) como uma subespécie de C. celeus, é aqui designada como tipo do gênero - Art. 70.3.2. (ICZN). Cantha celeus; Evans, 1955 deve receber um nome novo, não feito aqui por falta de material desta espécie e o BM (NH) não enviar material emprestado devido à legislação brasileira em vigor. O lectótipo é designado para garantir a identificação da espécie.

\section{Vehilius celeus ochraceus Biezanko \& Mielke, 1973, comb. nov.}

Vehilius vetus ochraceus Biezanko \& Mielke, 1973. Acta biol. paranaense 2: 82, figs 48-51 (macho, fêmea d, v); holótipo macho, 23-IV-1958, Pelotas, Rio Grande do Sul, Brasil, C. Biezanko leg.; UFPC.

Tendo mudado o nome específico para Vehilius celeus, esta subespécie então é combinada com ela.

\section{Vehilius celeus vetus Mielke, 1969, comb. nov., stat. nov.}

Vehilius vetus Mielke, 1969. Rev. Bras. Biol. 29: 8, figs 11-14 macho, fêmea d, v), 38-41 (gen. masc.), 42 (gen. fem.); holótipo macho, 2-III-1967, Vila Velha, Ponta Grossa, Paraná, Brasil, Mielke \&

Tangerini leg.; UFPC.

Vehilius almoneus vetus; C. Mielke, 1995. Revta bras. Zool. 11: 763.

Tendo mudado o nome específico para Vehilius celeus, esta subespécie então é combinada com ela. 


\section{Vehilius inca (Scudder, 1872)}

Lerodea inca Scudder, 1872. Fourth Ann. Rep. Peab. Ac. Sc. (1871): 80; Peru, Henry Edwards leg. Vehilius chinta Schaus, 1902. Proc. U.S. Nat. Mus. 24: 449; [holó]tipo macho, $n^{\circ} 6.038$, Petropolis, [Estado do Rio de Janeiro], Brasil; USNM.- Evans, 1955. Cat. Amer. Hesp. 4, p. 142; syn. nov. Lerodea mocoreta Hayward, 1939. An. Soc. cient. arg. 127: 290, fig. 3 (gen. masc.); holótipo macho,

Corrientes, Argentina; coleção Hayward.- Evans, 1955. Cat. Amer. Hesp. 4, p. 396.; syn. nov.

Os exames do síntipo macho de $L$. inca, aqui designado LECTÓTIPO, possuindo as seguintes etiquetas: / Type 15311/329/ Peru/ Ler. Inca Sc. type/ MCZ, e dos holótipos de $V$. chinta e L. mocoreta - IML, mostraram a sinonímia. EVANS (1955) menciona $V$, chinta como uma espécie de Cymaenes Scudder, 1872 e L. mocoreta é mantida em Lerodea Scudder, 1872. O lectótipo é designado para garantir a identificação da espécie.

\section{Virga silvanus (Hayward, 1947), sp. rev.}

Mnestheus silvanus Hayward, 1947. Acta zool. lill. 4: 127, fig. 6 (gen. masc.); holótipo macho, Brasil; coleção Hayward.- Hayward, 1964. Acta zool. lill. 19: 326.

Virga phola Evans, 1955. Cat. Amer. Hesp. 4, p. 100, pl. 59 (gen. masc.); [holó]tipo macho, XII-1929, Mato Grosso, [Brasil], R. Spitz leg.; BM (NH); syn. nov.

Virga eliasi Mielke, 1968. Rev. Brasil. Biol. 29: 7, figs 7-10 (macho, fêmea d, v.), 31-34 (gen. masc.), 35 (estigma), 36, 37 (gen. fem.); holótipo macho, 1-8-IV-1967, Santa Teresa, Espírito Santo, Brasil, T. Elias leg.; UFPC; syn. nov.

Os exames dos holótipos das três espécies mostraram a sinonímia. EvANS (1955) menciona M. silvanus como sinônimo de Virga virginius (Möschler, 1882 - recte 1883 ).

\section{Wallengrenia otho clavus (Erichson, [1849])}

Hesperia clavus Erichson, [1849], in: Schomburgk. Reisen Brit. Guiana 3, p. 603; Brit. Guiana.

Pamphila helva Möschler, 1877. Verh. zool.-bot. Ges. Wien 26: 336, pl. 4, fig. 20 (d); macho, fêmea, Interior do Suriname; coleção Möschler; syn. nov.

Os exames do síntipo macho de $H$. clavus, aqui designado LECTÓTIPO, possuindo as seguintes etiquetas: / Typus/ 5527/ 155:4/ clavus Erichs. Guiana brit. Schomb./ - ZMHU, e do síntipo fêmea de $P$. helva, aqui designado LECTÓTIPO, possuindo as seguintes etiquetas: / Origin./ Type, Verhdlg. d. zool. bot.: Gesellschaft. Wien XXVI.t. IV.f. 20. p. 336/Surinam Bgdl., L. 75./Coll. Staudinger/Coll. Möschl./ 303/ B.C.A. Lep. Rhop., Atrytone helva, Möschl./ - ZMHU, mostraram a sinonímia. Os lectótipos são designados para garantir a identificação da espécie.

\section{Wallengrenia premnas (Wallengren, 1860)}

Hesperia premnas Wallengren, 1860. Wien. ent. Monatschr. 4 (2): 38; macho, janeiro, Buenos Aires, [Argentina]; Mus. Holm.

Atrytone chingachgook Weeks, 1909. Ent. News 20: 264; Suapure, Venezuela; syn. nov.

Conga chingachchook [sic]; Evans, 1955. Cat. Amer. Hesp. 4, p. 296.

Os exames do síntipo macho de $H$. premnas, aqui designado LECTÓTIPO, possuindo as seguintes etiquetas: / Thymelicus Hüb./ Hesp. premnas Wallengr./ Buen. Ayr.I - NRS, e do síntipo fêmea de A. chingachgook, aqui designado LECTÓTIPO, possuindo as seguintes etiquetas: / 751./ 7/ Suapure Venezuela/ not in B. M./ A. G. Weeks Collection/ M. C. Z. Type 16730/ 1/23/00/ A. chingachgook 
A.G. Weeks. Jr Suapure/ - MCZ, mostraram a sinonímia. EvANS (1955) menciona A. chingachgook (por erro como chingachchook) uma espécie de Conga Evans, 1955. Os lectótipos são designados para garantir a identificação da espécie.

\section{Zariaspes mythecus Godman, 1900}

Zariaspes mythecus Godman, 1900, in Godman \& Salvin. Biol. Centr.-Amer., Lep. Rhop. 2, p. 486; 3, pl. 93, figs 32, 33 (macho d, v), 34 (gen. masc.), 35, 36 (fêmea d, v); 8 machos, 4 fêmeas, Acapulco, Dos Arroyos, R. Papagaio, Acaguizotla, all in Guerrero, Mexico, baixa altitude, H.H. Smith leg.; coleção Godman \& Salvin.

Copaeodes chromis Skinner, 1919. Ent. News 30: 100; 1 macho (?), Colima, Mexico; Academy of Natural Sciences of Philadelphia; syn. nov.

Pseudocopaeodes eunus chromis; Evans, 1955. Cat. Amer. Hesp. 4, p. 316.

O exame de um síntipo macho de Zariaspes mythecus, aqui designado LECTÓTIPO, possuindo as seguintes etiquetas: / Type/ Type H. T./ $\sigma^{*} /$ Acapulco, Guerrero. Sept. H.H. Smith./ Godman-Salvin Coll. 1913.-2./ B.C.A. Lep. Rhop. Zariaspes mythecus, Godm./ Sp. figured./ BM (NH) e do holótipo de C. chromis CMP, mostraram a sinonímia. EVANS (1955) menciona C. chromis como uma subespécie de Pseudocopaeodes eunus (W. H. Edwards, 1881). O lectótipo é designado para garantir a identificação da espécie.

\section{Zenis jebus beckeri ssp. nov.}

Figs 25-28

Zenis jebus melaleuca; Evans, 1955. Cat. Amer. Hesp. 4, p. 411, pl. 83 (gen. masc.).

Tendo em vista que Zenis jebus melaleuca; Evans, 1955 é um lapso de identificação, pois Hesperia melaleuca Plötz, 1882 é um sinônimo novo de Zenis minos (Latreille, [1824]) (veja a seguir), aquele é aqui descrito como uma subespécie nova. A descrição de EVANS (1955) caracteriza bem a subespécie.

Holótipo macho com as seguintes etiquetas: / Holotipo/ Linhares, ES [Espírito Santo, Brasil] 1-8-IX-1973, C. Elias leg./ Holótipo Zenis jebus beckeri Mielke \& Casagrande, 2002/ DZ 5.095/ - UFPC; alótipo fêmea com as seguintes etiquetas: / Alotipo/ Linhares, Espírito Santo, Brasil, VII-1981, C. Elias leg./ Alótipo Zenis jebus beckeri Mielke \& Casagrande, 2002/ DZ 5.103/ - UFPC. Parátipos: 1 macho, 2 fêmeas II-1970, 1 macho I-1971, Maracay, Aragua, Venezuela, 500 m, Romero leg., OM 49.811, 17.924, 49.795, 49.987; 1 macho, I-1971, Car[retera] Choroni, Aragua, Venezuela, 800 m, Romero leg., OM 49.875; 1 macho XII-1977, Rancho Grande, Aragua, Venezuela, 800 m, Romero leg., OM 49.955; 1 macho, 7-X-1946, 1 fêmea 30-VIII-1946, Samariapa, TFA, Venezuela, 120 m, Lichy leg., OM 39.942, OM 39.977; 1 fêmea 5-IX-1978, Yanahurco, Napo, Equador, Lafebre leg., OM 49.915; 1 macho, 7-VII-1972, Riozinho, Pimenta Bueno, Rondônia, Brasil, 200 m, Mielke \& Brown leg., DZ 5.092; 1 fêmea 17-31-VIII-1987, Ouro Preto d'Oeste, Rondônia, Brasil, C. Elias leg., DZ 5.100; 1 macho, 9-VIII-1988, Ariquemes, Rondônia, Brasil, Miers leg., OM 18.703; 1 macho 5-20-VII-1990, Fazenda Paraná, Brasnorte, Mato Grosso, Brasil, 400 m, C. Mielke \& Miers leg., OM 26.186; 1 macho 13-I01978, Alto Rio Arinos, Fazenda São João, Diamantino, Mato Grosso, Brasil, Mielke \& Furtado leg., OM 49.787; 1 macho 26-VIII-1974, Alto Rio 
Paraguai, Barra dos Bugres, Mato Grosso, 150, Furtado leg., DZ 5.109; 1 fêmea 21-VIII-1974, Imperatriz, Maranhão, Brasil, Exc. Dept. Zool. leg., DZ 5.108; 1 macho 26-VII-1976, Goiás Velho, Goiás, Brasil, Gifford leg., DZ 5.116; 1 macho 29-V-1969, Santa Rita do Araguaia, Goiás, Brasil, K. Brown leg., OM 49.675; 1 macho 11-IX-1984, Planaltina, Distrito Federal, Brasil, 1000 m, V. O. Becker leg., OM 51.264; 1 macho, 20-VI-1968, Mucuri, Bahia, Brasil, Elias leg., DZ 5.021; 1 fêmea 18-III-1970, 1 macho 7-XI-1971, 2 machos 7-XI-1972 Itaguaçu, Espírito Santo, Brasil, C. Elias leg., DZ 5.071, DZ 5.079, DZ 5.087; DZ 5.063; 1 fêmea VII-1980, Linhares, Espírito Santo, Brasil, C. Elias leg., DZ 5.029; 1 fêmea 3-VII-1967, Santa Teresa, Espírito Santo, Brasil, C. \& C.T. Elias leg., DZ 5.037; 1 macho 4-V-1970, 1 fêmea 20-VIII-1970, 1 macho 23-XI-1971, 4-XII-1971, 1 macho 26-III-1973, Baixo Guandu, Espírito Santo, Brasil, C. \& C.T. Elias leg., DZ 5.045, DZ 5.053, DZ 5.061, DZ 5.084, DZ 5.069; 2 machos 26-IX1970, 2 machos 10-X-1970, Baixo Guandu, Espírito Santo, Brasil, C. Elias leg., DZ 5.077, DZ 5.085, DZ 5.093, DZ 5.101; 1 macho, 2 fêmeas 3-4-XI-1973, 1 fêmea 1-IV-1973, Alto Rio Paraná, Fazenda Nova Estrela, Pereira Barreto, São Paulo, Brasil, H. Ebert leg., DZ 5.117, DZ 5.023, DZ 5.031, DZ 5.031; UFPC.

Etimologia. O nome é uma homenagem ao Dr. Vitor O. Becker, eminente especialista em microlepidópteros neotropicais.

\section{Zenis minos (Latreille, [1824])}

Hesperia minos Latreille, [1824], in: Latreille \& Godart. Enc. Méth. 9, p. 720, 756; Brasil.

Hesperia melaleuca Plötz, 1882 (Weymer in litt.). Stett. ent. Ztg. 43: 443; Rio [de Janeiro, Brasil]; syn. nov.

Zenis jebus melaleuca; Evans, 1955. Cat. Amer. Hesp. 4, p. 411, pl. 83 (gen. masc.).

$\mathrm{O}$ exame do síntipo fêmea de $H$. minos, aqui designado LECTÓTIPO, possuindo as seguintes etiquetas: / Type/ H. minos Lat. Bresil/ R. Oberthür Coll. Brit. Mus. 1931-136/ Ex musaeo P. Mabille 1923/ Somm [?]/ - BM (NH) e do síntipo macho de $H$. melaleuca, aqui designado LECTÓTIPO, possuindo as seguintes etiquetas: / Typus/Coll. Weymer/Melaleuca Weymr., 83 Plötz, Plötz [?]/ Hesp. n. sp: 72 Staud./ ? Claudianus Latr., [/] Berl. Museum/Melaleuca mihi, Amer. Mer./ - ZMHU, mostraram a sinonímia. O lectótipo de H. minos não possui abdome e o de $H$. melaleuca está sem cabeça, abdome e asa anterior direita. Evans (1955) menciona H. melaleuca como uma subespécie de Zenis jebus (Plötz, 1882), que por não ter sinônimo junior é descrita como nova linhas atrás. Os lectótipos são designados para garantir a identificação da espécie.

AGRADECIMENTOS. Deixamos aqui os nossos mais sinceros agradecimentos a todos os curadores das coleções mencionadas no início; ao Dr. Gerardo Lamas, Museu de Historia Natural, Lima, Peru, por ter olhado as franjas das asas posteriores do síntipo de Erycides spurius e chegado à conclusão que estavam coladas, resolvendo então a sinonímia aqui proposta e pelas informação a respeito de Chioides cinereus, Chioides concinnus e Potamanaxas paralus; ao Dr. Andrew Warren pela informação da sinonímia de Paratrytone raspa; ao Dr. Gert Hatschbach do Museu Botânico de Curitiba, Paraná, pela identificação da planta hospedeira de Thespieus tapayuna e ao Dr. Albino Morimasa Sakakibara pela ajuda na interpretação do código de nomenclatura zoológica. 


\section{REFERÊNCIAS BIBLIOGRÁFICAS}

Austin, G.T. \& O.H.H. Mielke. 1998. Hesperiidae of Rondônia, Brazil: Aguna Williams (Pyrginae), with a partial revision and descriptions of new species from Panama, Ecuador, and Brazil. Revta bras. Zool., Curitiba, 14 (4): 889-965.

Austin, G.T. \& A.D. WARREN. 2001. Taxonomix notes on some Neotropical skippers (Lepidoptera: Hesperiidae): Pyrgus, Heliopyrgus, and Heliopetes (Pyrginae). Dugesiana, Guadelajara, 8: 1-13.

BARnES, Wm. \& J. McDunnough 1917. Check List of the Lepidoptera of Boreal America. Decatur, Illinois, Herald Press, IX+392p.

BelL, E.L. 1932. Description of new Hesperiidae from Trinidad, B.W.I., and South America (Lepidoptera-Rhopalocera). Jour. N.Y. Ent. Soc. 39: 523-531.

. 1934. New Hesperiidae from Trinidad and Peru (Lepidoptera: Rhopalocera). Amer. Mus. Novit. 745: 1-6.

. 1937. New genera and species of Neotropical Hesperiidae with notes on some others (Lepidoptera; Rhopalocera). Amer. Mus. Novit. 914: 1-17.

-1940. A new genus and some new species of Neotropical Hesperiidae (Lepidoptera: Rhopalocera). Amer. Mus. Novit. 1094: 1-5.

- 1941. Two new subspecies of Phlebodes tiberius Moeschler. Jour. N.Y. Ent. Soc. 49: 193-197.

- 1941. New species of Neotropical Hesperiidae (Lepidoptera: Rhopalocera). Amer. Mus. Novit. 1125: 1-10.

. 1942. New genera and new species of Neotropical Hesperiidae (Lepidoptera: Rhopalocera). Amer. Mus. Novit. 1205: 1-9.

. 1942. New species of Venezuelan Hesperiidae (Lepidoptera-Rhopalocera). Bol. Ent. venezol., Caracas, 1: 73-77.

. 1942. New records and species of Hesperiidae from Mexico (Lepidoptera: Hesperiidae). An. Esc. Nac. Ciênc. Biol., Mexico, 2 (4): 455-468.

-1947. A new genus and some new species and subspecies of Neotropical Hesperiidae (Lepidoptera, Rhopalocera). Amer. Mus. Novit. 1354: 1-12.

BeLl, E. \& W. Рн. Сомsтоск. 1948. A new genus and some new species and subspecies of American Hesperiidae (Lepidoptera, Rhopalocera). Amer. Mus. Novit. 1739: 1-23.

Bridges, C.A. 1988. Catalogue of Hesperiidae (Lepidoptera: Rhopalocera). Urbana, Charles A. Bridges. VIIp., Part I Alphabetic List of Names, 205p.; Part II Index to Genera, 676p.; Part II Index to Authors, 78p.; Part IV Bibliography, 54p.; Part V Index to Journals and Serials, 20p.; Part VI Index to bibliography by year, 7p.; Appendix I Synonymic List of Family-Group Names, 1p.; Appendix II Synonymic List of Genus-Group Names, 8p.; Annotations on the Catalogue of Hesperiidae 1, 1p.; Annotations on the Catalogue of Hesperiidae 2, 1p.; Annotations on the Catalogue of Hesperiidae 3, 4p.; Annotations on the Catalogue of Hesperiidae 4, 2p.; Annotations on the Catalogue of Hesperiidae 5, 6p.

BurmeIster, H.C.C. 1878-1880. Description physique de la République Argentine d'après des observations personelles et étrangeres. 5. Lepidoptères. Primière partie. Contenant les diurnes, crépusculaires et bombycoïdes. Buenos Aires, P.E. Coni; Paris, F. Savy; Halle, E. Anton., VI+526p. (1878); Atlas, IV+64p. (1879-1880).

BURNS, J.M. 1989. Phylogeny and zoogeography of the bigger and better genus Atalopedes (Hesperiidae). Jour. Lep. Soc., Los Angeles, 43: 11-32.

1994. Genitalia at the generic level: Atrytone restricted, Anatrytone ressurected, new genus Quasimellana - and Yes! We have no Mellanas (Hesperiidae). Jour. Lep. Soc., Los Angeles, 48: 273-337.

BUtLER, A.G. [1870]. Catalogue of diurnal Lepidoptera described by Fabricius in the collection of the British Museum. London, British Museum, V+303p.

1870. Descriptions of some new diurnal Lepidoptera, chiefly Hesperiidae. Trans. ent. Soc. London, p. 485-520. 
1877. On the Lepidoptera of the Amazons collected by James W. H. Trail, Esq., during the years 1873 to 1875 . Trans. ent. Soc. London, p. 105-156.

Comstock, W. PH. 1944. Insects of Puerto Rico and Virgin Islands. Scientific Survey of Porto Rico and the Virgin Islands 12 (4): 419-622.

CRAMER, P. 1779-1780. De uitlandische Kapellen voorkomende in de drie Waereld-Deelen Asia, Africa en America. Papillons exotiques des trois parties du monde l'Asie, l'Afrique et l'Amerique 4, p. 1-176. Amsteldam, S.J. Baalde; Utrecht, Barthelemy Wild.

DE JoNG, R. 1983. Annotated list of the Hesperiidae (Lepidoptera) of Surinam, with descriptions of new taxa. Tijd. Ent., Leiden, 126: 233-268.

DraudT, M. 1921-1924. B. Grypopcera, p. 836-1011, pls 160-191; in A. SEITZ. Die Gross-Schmetterlinge der Erde. Stuttgart, Alfred Kernen. 5, 1141p.

DYAR, H.G. 1917. Miscelaneous new American Lepidoptera. Insec. Insc. Menstr., Cambridge, 5: 65-69. ERICHSON, W.F. [1849]. Insekten, p. 553-617, In: R. SCHOMBURGK. Reisen in Britisch-Guiana in den Jahren 1840-1844. Im Auftrag Sr. Mäjestat des Königs von Preussen. Versuch einer Fauna und Flora von Britisch-Guiana. Nach Vorlagen von Johannes Müller, Ehrenberg, Erichson, Klotzsch, Troschel, Cabanis und anderen. Leipzig, J. J. Weber, 3, p. I-VIII, 531-1262.

Evans, W.H. 1944. An analysis of the genus Heliopetes Billberg (Lepidoptera-Hesperiidae) with genitalia drawings. Entomol., London, 77: 179-185.

1937. A Catalogue of the African Hesperiidae indicating the classification and nomenclature adopted in the British Museum. XII+212p. London, British Museum (Natural History).

- 1951. A Catalogue of the American Hesperiidae indicating the classifiction and nomenclature adopted in the British Museum (Natural History). Part I. Introduction and Group A Pyrrhopyginae. London, British Museum (Natural History). X+92p.

. 1952. A Catalogue of the American Hesperiidae indicating the classifiction and nomenclature adopted in the British Museum (Natural History). Part II. Pyrginae. Section I. London, British Museum (Natural History), V+178p.

- 1953. A Catalogue of the American Hesperiidae indicating the classifiction and nomenclature adopted in the British Museum (Natural History). Part III. Pyrginae. Section II. London, British Museum (Natural History), V+246.

1955, 1956. A Catalogue of the American Hesperiidae indicating the classifiction and nomenclature adopted in the British Museum (Natural History). Part IV. Hesperiinae and Megathyminae. London, British Museum (Natural History), V+499, pls 54-88 (1955). Addenda et corrigenda (1956), sep., p. 1-4.

. 1957. Revisional notes on the Hesperiidae of Europe, Asia and Australia. Ann. \& Mag. Nat. Hist., London, (12) 9: 749-752.

FABRICIUS, J. СH. 1775. Systema entomologiae, sistens insectorum classes, ordines, genera, species, adiectis synonymis, locis, descriptionibus observationibus. Flensburgi et Lipsiae, Korte. $[\mathrm{IV}]+[\mathrm{XII}]+[\mathrm{XVI}]+832 \mathrm{p}$.

-1776. Genera insectorum eorumque characteres naturalis secundum numerum, figuram, situm et proportionem omnium partum oris adjecta mantissa specierum nuper detectarum. Chilonii, Bartsch, XIV+310p.

1787. Mantissa insectorum sistens species nuper detectas adiectis synonymis, observationibus, descriptionibus, emendationibus. Hafniae, Christian Gottlieb Proft. 2, [I]+382p.

-1793. Entomologia systematica emendata et aucta. Secundum classes, ordines, genera, species adjectis synonymis, locis, observationibus, descriptionibus. Hafniae, Christian Gottlieb Proft, Fil. et Soc. 3, IV+ 487p.

FERRIS, C. 1989. Supplement to: A Catalogue/ Checklist of the Butterflies of America North of Mexico. Mem. Lep. Soc. 3, VII+103p.

Foetterle, J.G. 1902. Descripção de lepidopteros novos do Brasil. Rev. Mus. Paulista, São Paulo, 5: 618-652.

FreEman, H.A. 1945. A new species of Lerodea from Texas (Lepidoptera: Hesperiidae). Ent. News,

Revta bras. Zool. 19 (Supl. 1): 27 - 76, 2002 
Philadelphia, 56: 203-205.

GeYer, C.E.A. [1832-1833], In: J. HÜBNER. Zuträge zur Sammlung exotischer Schmettlinge [sic], Augsburg, J. Hübner, 4, p. 1-48.

- [1827-1838], In: J. HÜBnER. Sammlung exotischer Schmetterlinge, Augsburg, J. Hübner, 3,53 pls.

GMELIN, P.F. 1790. Caroli a Linné. Systema naturae per regna tria naturae, secundum classes, ordines, genera, species, cum characteribus, differentiis, synonymis, locis. Editio decima tercia, aucta, reformata. Lipsiae, Georg Emanuel Beer. 1 (5), p. [2]+2225-3020.

Godman, F.D. \& O. Salvin, 1895. On a new speciers of Hesperiidae of the genus Amenis, Watson. Ann. \& Mag. Nat. Hist., London, (6) 15: 372-373.

_.1887-1901. Biologoia Centrali-Americana. Insecta. Lepidoptera-Rhopalocera. London, Dulau \& Co., Bernard Quaritch. 2, 1-782p.

HaYward, K.J. 1934. Lepidópteros argentinos. Familia Hesperidae. IV. Subfamilia Phampilinae [sic].

V. Resúmen, Clave, Apéndice e Indice. Rev. Soc. ent. arg., Buenos Aires, 6: 97-233.

. 1938. A new genus and several new species of Neotropical Hesperidae. Rev. Ent., Rio de Janeiro, 9: 370-374.

- 1939. New species of Neotropical Hesperiidae (Lep.). Rev. Ent., Rio de Janeiro, 10: 517-525.

1939. Hesperioidea argentina VIII. An. Soc. cient. arg., Buenos Aires, 126: 429-459.

1939. Hesperioidea argentina IX. An. Soc. cient. arg., Buenos Aires, 127: 285-293.

. 1940. New species of Neotropical Hesperiidae from Ecuador (Lep.). Rev. Ent., Rio de

Janeiro, 11: 861-877.

- 1941. Hesperiidarum Argentinae Catalogus. Rev. Mus. La Plata, n. s., Zool. 2: 227-340.

. 1947. Nuevas especies de hespéridos sudamericanos (Lep. Rhop.). Acta zool. lill., Tucumán,

4: $121-128$

1964. Lista de los tipos de Insecta (exceptuando Diptera) conservados en el Instituto Miguel

Lillo. Acta zool. lill., Tucumán, 19: 297-334.

1967. Ancyloxypha melanoneura orientalis subsp. n. Acta zool. lill., Tucumán, 21: 17-18.

HeppNer, J.B. \& G. LAMAS. 1982. Acronyms for World Museum Collections of Insects, with a Emphasis on Neotropical Lepidoptera. Bull. Ent. Soc. Amer. 28 (3): 305-315.

HERRICH-SCHÄFFER, G.A.W. 1867-1871. Prodromus systematis lepidopterorum. Versuch einer systematischen Anordnung der Schmetterlinge. Corr.-Blatt zool.-min. Ver Regensburg 21 (9): 100-106, (10): 124-128, (11): 138-144, (12): 161-172; 22 (8/9): 119-138, (11): 172-176; 23 (4): 56-64, (5):67-77, (9): 130-141, (11): 163-172, (12): 184-204; 24 (9/10): 154-160; 25 (6/7): 103-104.

HewITson, W.C. 1866. Descriptions of new Hesperiidae. Trans. ent. Soc. London, p. 479-501.

1877. Descriptions of twenty-five new species of Hesperiidae. Ann. \& Mag. Nat. Hist., London, (4) 19: 76-85.

Holland, W.J. 1916. The Lepidoptera of the Isle of Pines, being a list of the species collected on the island by Mr. J.L. Graf and Mr. G.A. Link, Sr., in 1910 and 1912-1913. Ann. Carnegie Mus., Pittsburgh, 10: 487-518.

HÜBNER, J. 1816-1819. Verzeichniss bekannter Schmettlinge [sic]. Augsburg, Jacob Hübner. [1], p. 1-16 (1816), (2-8), p. 17-128 [1819].

- 1825. Sammlung exotischer Schmetterlinge. Augsburg, Jacob Hübner. 2, pl. [144].

KAYE, W.J. 1925. New species and sub-species of Trinida Rhopalocera and Heterocera. Trans. ent. Soc. London (1924), p. 413-428.

Kendall, R.O. \& H.A. Freeman. 1963. The butterflies and skippers of Texas - a tentative list. Privatly printed through the Welder Wildlife Foundation for distribution to members of the Lepidopterists' Society, most especially the 1963 National Meeting at San Antonio Texas, 6p.

KIRBY, W.F. 1879. Catalogue of the Collection of Diurnal Lepidoptera formed by the late William Chapman Hewitson of Oatlands, Walton-on-Thames; and bequested by him to the British Museum. London, John Van Voorst, IV+246p.

LAMAS, G. 1994. Butterflies of the Explorer's Inn Reserve, p. 62-63, 162-177. In: Foster, R.B., J.L. 
CARR \& A.B. ForSYTH (Eds). The Tambopata-Candamo Reserved Zone of Southeastern Perú: A Biological assessment. RAP Working Papers, Conservation International, 6: [II]+1-184.

Lamas, G.; R.K. Robbins \& D. HaRvey. 1996. Mariposas del alto Rio Napo, Loreto, Perú (Lepidoptera: Papilionoidea y Hesperioidea). Rev. peruana Ent. 39: 63-74.

Lamas, G.; J. Grados \& G. Valencia. 1999. Mariposas de Machu Picchu, Cuzco, Peru: Un inventario preliminar (Lepidoptera: Rjhopalocera). Rev. peruana Ent. 41: 1-8

LARRAÑAGA, D.A. 1923-1930. Escritos de Don Dámaso Antonio Larrañaga. Los publica el Instituto Histórico y Geográfico del Uruguay. 2, p. 1-512 (1923); Atlas (Parte II. Zoologia, Paleontologia y Mapas), p. 1-6+2, pls 1-131 (1930). Edición Nacional, Montevideo, Imprenta Nacional.

Latreille, P.A. \& J.B. Godart. 1819-[1824]. Encyclopédie Méthodique. Histoire naturelle. Entomologie, ou histoire naturelle des crustacés, des arachnides et des insectes. Paris, veuve Agasse. 9 (1), p. I-II, 3-328 (1819), (2), p. 329-828. [1824]

LindSEY, A.W. 1925. The Cornell University Entomological Expedition to South America of 1919-1920. Scientific results. N ${ }^{\circ}$ II. Hesperioidea. Denis. Univ. Bull., Jour. Sc. Lab., Granville, 21: 71-113. Mabille, P. 1877. [Diagnoses de nouvelles espèces d'hespérides]. Ann. Soc. ent. France (5) 7, Bull. ent., p. 39-40.

.1878. Diagnoses de lépidoptères nouveaux du groupe des hespérides. Pet. Nouv. Ent., Paris, 2: 201-202.

1878. Descriptions de lépidoptères nouveaux de la famille des hespérides. Pet. Nouv. Ent., Paris, 2: 229-230, 233-234, 237-238.

. 1878. Diagnoses de Lépidoptères (Hespérides) nouveaux. Le. Nat., Paris, 10: 77, 78, 98, 99 , 108, 109, 146-148, 169-171, 180, 181, 221, 242, 254, 255, 265, 266, 275.

. 1880. [A note]. Ann. Soc. ent. France (5) 10, Bull. ent., p. 46.

1883. Description d'hespéries. Ann. Soc. ent. Belg. 27, C.R., p. 51-78.

1888. Diagnodes de lépidoptères (Hespérides) nouveaux. Le Nat., Paris, (2) 2: 77-78, 98-99, 108-109, 146-147, 169-171, 180-181, 221, 242, 254-255, 265-266, 2754.

. 1889. [Note sur un genre nouveaux de lépidoptères]. Bull. Soc. ent. France (6) 9: 9-10.

. 1891. Description d'hespérides nouvelles. Ann. Soc. ent. Belg. 35, C.R., p. 59-88, 106-121, 168-187.

1895. Description de quelques hespérides nouvelles. Bull. Soc. ent. France, p. 55-59.

1898. Description de lépidoptères nouveaux. Ann. Soc. ent. France 66: 182-231.

1903-1904. Lepidoptera Rhopalocera Fam. Hesperidae, In: P. WyTSMAN. Genera Insectorum, V. Verteneuil \& L. Desmet, Bruxelles, 17, p. 1-78 (1903), 79-210, 4 pls (1904).

Mabille, P. \& P. Vuillot. 1890-1895. Novitates lepidopterologicae. Paris, Paulo Vuillot, 1, p. 1-8; 2, p. $9-15 ; 3$, p. $17-23 ; 4$, p. $25-33 ; 5$, p. $35-40 ; 6$, p. $41-48 ; 7$, p. $49-58 ; 8$, p. $59-62 ; 9$, p. $63-89 ; 10$, p. 91-104; 11, p. 107-134; 12, p. 135-161.

Mabille, P. \& E. Boullet. 1917. Description d'hespérides nouveaux (Lep.). Bull Soc. ent. France, p. 54-60.

- 1917. Description d'hespérides nouveaux (Lep. Hesperiinae, Sect. B). Bull Soc. ent. France, 1916, p. 320-325.

MÉNÉTRIÉs, E. 1855-1857. Enumeratio corporum animalium Musei Imperialis Academiae Scientiarum Petropolitanae. Classis insectorum. Ordo lepidopterorum. Petropoli, Eggers et Soc., Lipsiae, Leop. Voss. 1, XV+97+[2], pls 1-6 (1855), 2, VI+67-112+[2]+99-144+[2]p., pls 7-14 (1857).

MielKe, C.G.C. 1995. Papilionoidea e Hesperioidea (Lepidoptera) de Curitiba e seus arredores, Paraná, Brasil, com notas taxonômicas sobre Hesperiidae. Revta bras. Zool., Curitiba, 11: 759-776.

MiELKE, O.H.H. 1968. Lepidoptera of the Central Brazil plateau. II. New genera, species and subspecies of Hesperiidae. Jour. Lep. Soc., Los Angeles, 22: 1-20.

-1968. Lepidoptera do Planalto Central Brasileiro. V: Novas espécies de Hesperiidae e anotações sôbre outras espécies conhecidas. Rev. Brasil. Biol., Rio de Janeiro, 28: 447-455.

-1969. Novos Hesperiinae brasileiros (Lepidoptera: Hesperiinae). Rev. Brasil. Biol., Rio de 
Janeiro, 29: 1-12.

- 1970. Dois novos Hesperiinae brasileiros (Lepidoptera: Hesperiidae). Atas Soc. Biol. Rio de Janeiro 13: 139-142.

- 1973. Contribuição ao estrudo faunístico dos Hesperiidae americanos. III. Espécies coletadas em duas excursões ao Pará e Amapá, Brasil (Lepidoptera). Acta biol. paranaense, Curitiba, 2: $17-40$.

- 1989. Sobre os tipos de Hesperiidae descritos por Röber (Lepidoptera). Revta Brasil. Zool., Curitiba, 6: 131-146.

-1980. Contribuição ao estudo faunístico dos Hesperiidae americanos. VI. Nota suplementar às espécies de Hesperiinae do Rio Grande do Sul, Brasil (Lepidoptera). Acta biol. paranaense, Curitiba, 8-9: 127-172.

MösChLER, H.B. 1877. Beiträge zur Schmetterlings-Fauna von Surinam. Verh. zool.-bot. Ges. Wien 26: 293-352.

- 1879. Neue exotische Hesperiiden. Verh. zool.-bot. Ges. Wien 28: 203-230.

- 1883. Beiträge zur Schmetterlings-Fauna von Surinam. V. (Supplement). Verh. zool.-bot. Ges. Wien 32: 303-362.

Nicolay, S.S. 1980. Descriptions of new Hesperiidae from Panama and Ecuador (Pyrginae and Hesperiinae). Bull. Allyn Mus., Sarasota, 59: 1-17.

PLöTz, C. 1879. Die Hesperiinen-Gattung Erycides Hübn. und ihre Arten. Stett. ent. Ztg. 40: 406-411, 474.

- 1882. Die Hesperiinen-Gattung Hesperia Aut. und ihre Arten. Stett. ent. Ztg. 43: 314-344; 436-456; 44: 26-64.

- 1883. Die Hesperiinen-Gattung Hesperia Auct. und ihre Arten. Stett. ent. Ztg. 44: 195-233.

. 1884. Die Hesperiinen-Gruppe der Achlyoden. Jahrb. nass. Ver. Nat., Wiesbaden. 37: 1-55.

. 1886. Nachtrag und Berichtigungen zu den Hesperiinen. Stett. ent. Ztg. 47: 83-117.

PriTTwITZ, O.F.W.L. von. 1867-1871. Lepidopterologisches. Stett. ent. Ztg. 28: 257-277 (1867); 29: 185-200, 244-248 (1868); 32: 237-252 (1871).

ReakiRT, T. 1867. Descriptions of some new specires os diurnal Lepidoptera, Series II. Proc. Ac. Nat. Sc. Philadelphia 18: 331-342.

Robbins, R.K.; G. Lamas; O.H.H. Mielke; D.J. Harvey \& M.M. Casagrande. 1996. Taxonomic composition and ecological structure of the species-rich butterfly community at Pakitza, Parque Nacional del Manu, Perú, p. 217-252, In: D.E. Wilson \& A. Sandoval (Ed.). Manu. The biodiversity of Southeastern Peru. La biodiversidad del Sureste del Perú. Washington, DC, Smithsonian Institution, 679p.

RöвER, J.K.M. 1925. Neue südamerikanische Falter (Lep.). Ent. Mitt., Berlin, 14: 85-100, 156-162.

Schaus, W. 1902. Descriptions of new American Butterflies. Proc. U.S. Nat. Mus. 24: 383-460.

. 1913. New species of Rhopalocera from Costa Rica. Proc. zool. Soc. London 24: 339-367.

SCUDDER, S.H. 1872. A systematic revision of some of the American butterflies, with brief notes on those known to occur in Essex County, Massachusetts. Fourth Ann. Rep. Peab. Ac. Sc. (1871), p. 24-83. SEPP, J. 1843-1848. Surinaamsche Vlinders. Naar het leven geteekend. Papillions de Surinam. Dessinés d'après nature. Amsterdam, Jan Christian Sepp en Zoon. 2, p. I-IV, 109-152, 169-224.

Skinner, H. 1911. The larger boreal American Hesperiidae, including Eudamus, Erycides, Pyrrhopyge and Megathymus. Trans. Amer. Ent. Soc. 37: 169-209.

- 1919. Description of a new species of Hesperidae (Lepidoptera). Ent. News, Philadelphia, 30: 100 .

SMith, D.S.; L.D. Miller \& J.Y. Miller. 1994. The butterflies of the West Indies and South Florida. Oxford, New York, Tokyo, Oxford University Press, 264p.

Steinhauser, S.R. 1991. Taxonomic notes and descritions of new taxa in the Neotropical Hesperiidae.

Part II. Heteropterinae and Hesperiinae. Bull. Allyn Mus., Sarasota, 132: 1-79. 1996. Three new Paratrytone species from Mexico (Hesperiidae: Lepidoptera). Bull. Allyn Museum, Sarasota, 141: 1-11. 
STRAND, E. 1921. Systematisch-Faunistische Beiträge zur Kenntnis exotischer Heterocera und Grypocera auf Grund von Material des Deutschen Entomologischen Museums. Arch. Natg., Berlin, 86A (7): 113-172.

VIETTE, P. 1956. Note sur quelques types de Latreille. Lambillionea, Bruxelas, 56: 88-92.

WaLLENGREN, H.D.J. 1860. Lepidopterologische Mittheilungen. Wien. ent. Monatschr. 4 (2): 33-46.

WaAren, A.D. 2000. Hesperioidea (Lepidoptera), p. 535-580, In: J. Llorente; E. GonZÁlez \& N. PAPAVERo (Eds). Biodiversidad, Taxonomia y Biogeografia de Artropodos de Mexico: Hacia una sintesis de su conocimiento 2. Mexico, Conabio-UNAM, 676p.

Weeks Jr., A.G. 1901. Descriptions of seven new butterflies from Bolivia. Proc. N. England Zool. Club, Cambridge, 2: 85-90.

. 1902. Some undescribed butterflies from Colombia and from lower California. Proc. N. England Zool. Club, Cambridge, 3: 9-13.

. 1909. New South American butterflies. Ent. News, Philadelphia, 20: 263-264.

ZiKán, J.F. 1938. Novos lepidopteros da família Hesperidae. Rev. Ent., Rio de Janeiro, 9: 321-336.

ZIKÁN, J.F. \& W. ZIKÁN. 1968. Inseto-fauna do Itatiaia e da Mantiqueira. III. Lepidoptera. Pesq. agropec. bras., Brasília, 3: 45-109.

Recebido em 11.IX.2001; aceito em 25.III.2002. 